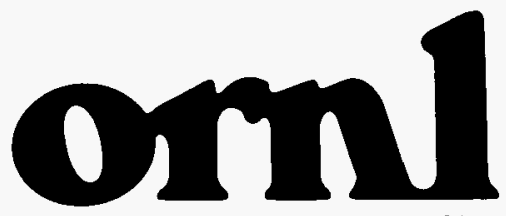

OAK RIDGE NATIONAL LABORATORY

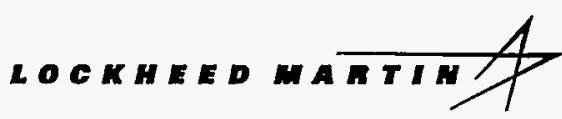

\section{RECEIVED}

JUL 211997

OSTI

G. H. Forbes

P. V. Egidi

\title{
CONFIRMATORY RADIOLOGICAL SURVEY OF THE GRAND JUNCTION PROJECTS OFFICE REMEDIAL ACTION PROJECT EXTERIOR PORTIONS, 1989-1995
}




\section{DISCLAIMER}

This report was prepared as an account of work sponsored by an agency of the United States Government. Neither the United States Government nor any agency thereof, nor any of their employees, makes any warranty, express or implied, or assumes any legal liability or responsibility for the accuracy, completeness, or usefulness of any information, apparatus, product, or process disclosed, or represents that its use would not infringe privately owned rights. Reference herein to any specific commercial product, process, or service by trade name, trademark, manufacturer, or otherwise does not necessarily constitute or imply its endorsement, recommendation, or favoring by the United States Government or any agency thereof. The views and opinions of authors expressed herein do not necessarily state or reflect those of the United States Government or any agency thereof. 


\section{DISCLAIMER}

Portions of this document may be illegible electronic image products. Images are produced from the best available original document. 
ORNL/TM-13356

\title{
CONFIRMATORY RADIOLOGICAL SURVEY OF THE GRAND JUNCTION PROJECTS OFFICE REMEDIAL ACTION PROJECT EXTERIOR PORTIONS, 1989-1995
}

\author{
G. H. Forbes \\ P. V. Egidi
}

Report Issued - April 1997

Prepared for the

U.S. Department of Energy

Office of Environmental Restoration

Southwestern Area Programs Division

Off-Site Remediation Branch

Washington, D.C.

\author{
Prepared by the \\ OAK RIDGE NATIONAL LABORATORY \\ Environmental Technology Section \\ Grand Junction, Colorado \\ managed by \\ LOCKHEED MARTIN ENERGY RESEARCH CORPORATION \\ for the \\ U.S. DEPARTMENT OF ENERGY \\ under contract DE-AC05-960R22464
}





\section{TABLE OF CONTENTS}

TABLES $\ldots \ldots \ldots \ldots \ldots \ldots \ldots \ldots \ldots \ldots \ldots \ldots \ldots \ldots \ldots \ldots \ldots$

FIGURES $\ldots \ldots \ldots \ldots \ldots \ldots \ldots \ldots \ldots \ldots \ldots \ldots \ldots \ldots \ldots \ldots$

ABBREVIATIONS, ACRONYMS, AND INITIALISMS . . . . . . . . . . . vii

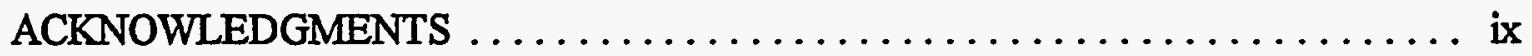

EXECUTIVE SUMMARY $\ldots \ldots \ldots \ldots \ldots \ldots \ldots \ldots \ldots \ldots \ldots \ldots \ldots \ldots$

1.0 INTRODUCTION $\ldots \ldots \ldots \ldots \ldots \ldots \ldots \ldots \ldots \ldots \ldots \ldots \ldots \ldots \ldots \ldots$

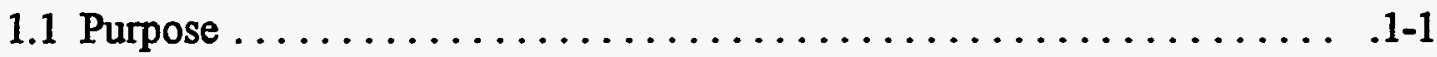

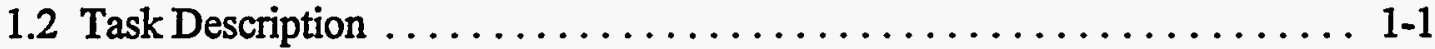

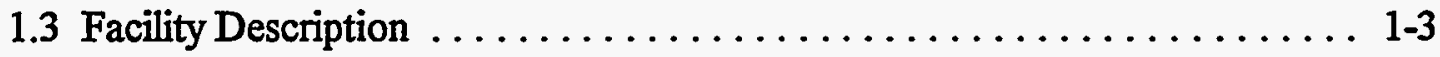

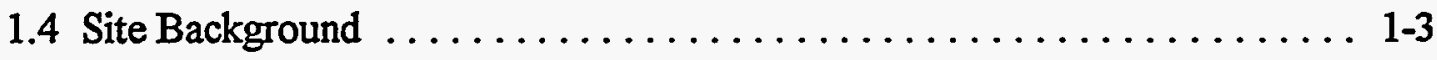

1.5 Overview of the Facility Contamination $\ldots \ldots \ldots \ldots \ldots \ldots \ldots \ldots \ldots$

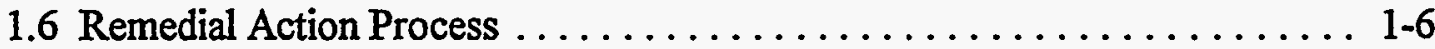

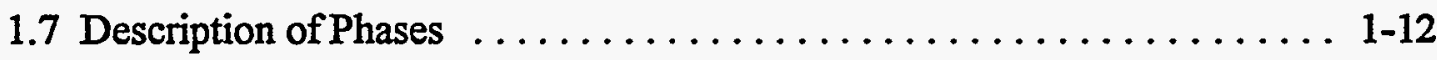

1.8 Approach to Verification $\ldots \ldots \ldots \ldots \ldots \ldots \ldots \ldots \ldots \ldots \ldots \ldots \ldots \ldots$

2.0 DOCUMENT REVIEW . . . . . . . . . . . . . . . . . . 2-1

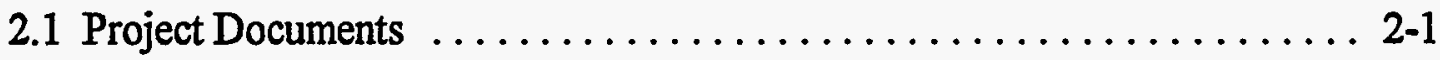

2.2 PCB Area Analytical Review . . . . . . . . . . . . . . . 2-2

2.3 Treasure Island Landfill Document Review . . . . . . . . . . . . . 2-3

2.4 The Remedial Action Contractor (RAC) Completion Report . . . . . . . . 2-5

2.5 Administrative Record and Certification Docket ............ 2-5

3.0 RESULTS AND DISCUSSIONS $\ldots \ldots \ldots \ldots \ldots \ldots \ldots \ldots \ldots \ldots \ldots \ldots \ldots \ldots$

3.1 Background Radiation Measurements ................. 3-1

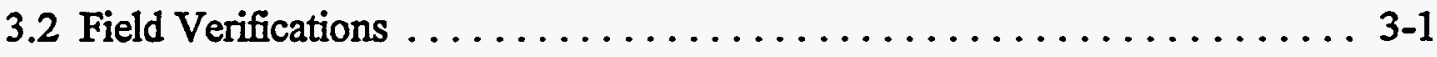

3.3 Gamma Scans and Delta Measurements . . . . . . . . . . . . . . 3-2

3.4 Measurements and Surface Activity Levels . . . . . . . . . . . . . 3-2

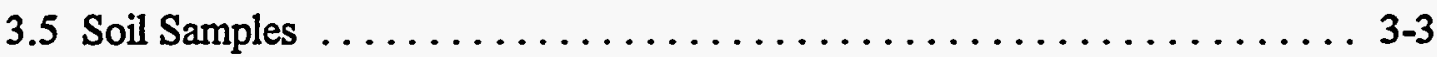

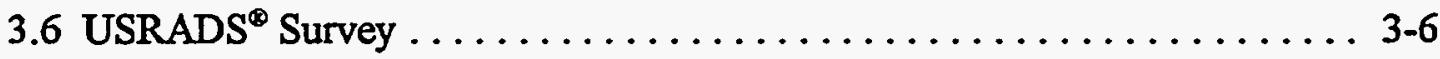

3.7 Other Measurements and Samples . . . . . . . . . . . . . 3-9

3.8 Radon Flux . . . . . . . . . . . . . . . . . . . . . 3-12

3.9 Large-Area Verification Protocol .................. 3-13 
4.0 DISCUSSIONS AND CONCLUSIONS $\ldots \ldots \ldots \ldots \ldots \ldots \ldots \ldots \ldots$ 4-1

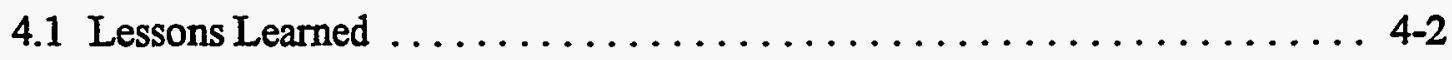

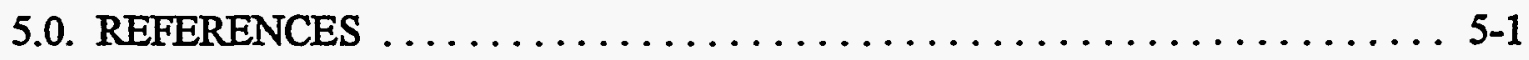

APPENDIX A STATEMENT OF VERIFICATION FOR THE OUTDOOR AREAS AT THE GRAND JUNCTION PROJECTS OFFICE REMEDIAL ACTION PROJECT, GRAND JUNCTION, COLORADO

APPENDIX B ELIPGRID-PC

APPENDIX C

GAMMA EXPOSURE RATE RANGES AND DELTA-GAMMA MEASUREMENT LOCATIONS

APPENDIX D APPENDIXE APPENDIXF SURFACE ACTIVITY MEASUREMENTS AND LOCATIONS SOIL SAMPLE RESULTS

COMPARISON OF RAC AND IVC SPLIT SAMPLE ANALYSES APPENDIX G REVIEW OF RAC'S JUSTIFICATION FOR CERTIFICATION OF LAV AREAS 


\section{FIGURES}

1.1 Grand Junction Projects Office

1.2 Location of uranium and vanadium refinery, 1943 to 1946 , and

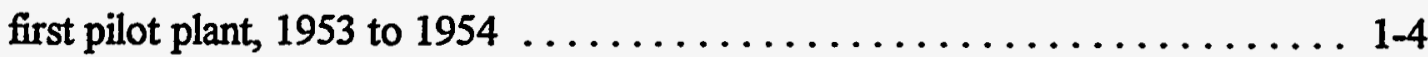

1.3 Location of second pilot plant, 1955 to $1958 \ldots \ldots \ldots \ldots \ldots \ldots \ldots \ldots$

1.4 Aerial view of facility showing drum storage areas, circa $1970 \ldots \ldots \ldots \ldots 1-7$

1.5 Time line of major projects and operations conducted at GJPO $\ldots \ldots \ldots \ldots 1-8$

1.6 Areas assessed as contaminated and original phase designators . . . . . . . . . 1-9

1.7 Areas remediated by the remedial action contractor (RAC) and final

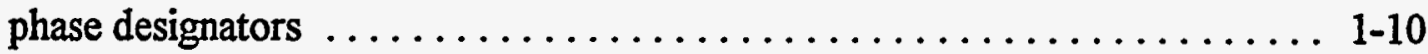

3.1 Track map of GJPO USRADS gamma exposure rate survey $\ldots \ldots \ldots \ldots \ldots$ 3-7

3.2 IVC IV investigative trenches and chemical sampling locations . . . . . . . 3-11

3.3 IVC IV soil sample locations on LAV segments $\ldots \ldots \ldots \ldots \ldots \ldots \ldots$ 3-14

\section{TABLES}

3.1 Summary of gamma exposure rate ranges $\ldots \ldots \ldots \ldots \ldots \ldots \ldots \ldots \ldots .2$

3.2 Summary of soil sample analyses $\ldots \ldots \ldots \ldots \ldots \ldots \ldots \ldots \ldots \ldots \ldots \ldots \ldots$ 


\section{ABBREVIATIONS, ACRONYMS, AND INITIALISMS}

AEC

ALARA

CDH\&E

COE

$\mathrm{cu}$

$\mathrm{D} \& \mathrm{D}$

DOE

$\mathrm{DOE} / \mathrm{RL}$

EM

ERDA

ETS

FS

$\mathrm{ft}$

FUSRAP

FY

GC

GJ

GJPO

GJPORAP

GM

HOG

HQ

in.

IV

IVC

kcpm

LAV

LTSM

$\mathrm{m}$

MED

$\mu \mathrm{R} / \mathrm{h}$

NEAWA

NURE

OCS
Atomic Energy Commission

as low as reasonably achievable

Colorado Department of Health and Environment

Corps of Engineers

cubic

Decontamination and Decommissioning

U.S. Department of Energy

U.S. Department of Energy, Richland Operations

Environmental Restoration and Waste Management

Energy Research and Development Administration

Environmental Technology Section

feasibility study

feet

Formerly Utilized Sites Remedial Action Program

fiscal year

gas chromatograph

Grand Junction (Colorado)

Grand Junction Projects Office

Grand Junction Projects Office Remedial Action Project

Geiger-Mueller

highest outdoor gamma

headquarters

inch(es)

independent verification

independent verification contractor

thousand counts per minute

large-area verification

Long-Term Surveillance and Monitoring Program

meter(s)

Manhattan Engineer District

microroentgen per hour

net estimated area-weighted average

National Uranium Resource Evaluation

Opposed Crystal System 
ORNL

OSHA

$\mathrm{pCi} / \mathrm{g}$

PCBs

PIC

PID

ppm

RAC

RCRA

$\mathrm{RI} / \mathrm{FS}$

ROD

SFMP

SVOC

TCLP

TMC

TPH

UMTRAP

UNC

USRADS $^{\circledast}$

USV

VOCs

yd
Oak Ridge National Laboratory

Occupational Safety and Health Act

picocuries per gram

polychlorinated biphenyls

pressurized ionization chamber

photoionization detector

parts per million

remedial action contractor

Resource Conservation and Recovery Act

remedial investigation/feasibility study

record of decision

Surplus Facilities Management Program

semivolatile organic compounds

toxicity characteristic leaching procedure

Technical Measurements Center

total petroleum hydrocarbons

Uranium Mill Tailings Remedial Action Project

United Nuclear Corporation

Ultrasonic Ranging and Data System

United States Vanadium

volatile organic compounds

yard 


\section{ACKNOWLEDGMENTS}

This project was sponsored by the U. S. Department of Energy under contract DE-AC05-960R22464 with Lockheed Martin Energy Research Corporation. The authors wish to acknowledge the following Oak Ridge National Laboratory/Grand Junction, Colorado staff: S. M. Smith, C. A. Muhr, A. R. Jones, and M. K. Jensen for providing valuable technical support; D. K. Halford, F. G. Gardner and M. T. Muck, for technical input and review; K. A. Hebbard and P. D. Roundtree for word processing of the report; and C. A. Little, for Environmental Technology Section management. The authors would also like to thank K. J. Brown in the Oak Ridge, Tennessee, office for technical editing. 



\section{EXECUTIVE SUMMARY}

The purpose of this independent assessment was to provide the U.S. Department of Energy (DOE) with an independent verification (IV) that the soil at the Grand Junction Projects Office (GJPO) complies with applicable DOE guidelines. Oak Ridge National Laboratory/ Environmental Technology Section (ORNL/ETS) which is also located at the GJPO, was assigned by DOE as the Independent Verification Contractor (IVC). The assessment included reviews of the decontamination and decommissioning plan, annual environmental monitoring reports, data in the pre- and post-remedial action reports, reassessment reports and IV surveys. Procedures and field methods used during the remediation were reviewed, commented on, and amended as needed. The IV surveys included beta-gamma and gamma radiation scans, soil sampling and analyses.

Based on the data presented in the post-remedial action report and the results of the IV surveys, the remediation of the outdoor portions of the GJPO has achieved the objectives. Residual deposits of uranium contamination may exist under asphalt because the original characterization was not designed to identify uranium and subsequent investigations were limited. The IVC recommends that this be addressed with the additional remediation. The IVC is working with the remedial action contractor (RAC) to assure that final documentation will be sufficient for certification. The IVC will address additional remediation of buildings, associated utilities, and groundwater in separate reports. Therefore, this is considered a partial verification.

Lessons learned by the IVC during this project that would enhance the success of a future D\&D project include the following:

1. The IVC should be assigned at the beginning of the project, in order to provide input to planning documents in the draft stage and help identify any potential problems.

2. A timely transfer of funds is critical to maintaining the continuity of $I V$ tasks.

3. If the project requirements change, possible impacts to the project schedule and budget need to be identified and addressed quickly.

4. A remedial action and verification plan should be considered during the engineering and planning portions of the project.

5. An understanding of the requirements for storage and archival of samples is needed at the beginning of the project.

6. To accurately reflect site conditions, proper instrumentation needs to be selected based on contaminants of concern and detection sensitivity.

7. Coordination and communication between the RAC and IVC are essential to project success. 


\subsection{INTRODUCTION}

\subsection{Purpose}

This report documents an independent verification (IV) that remediation of contaminated soil at the U.S. Department of Energy (DOE) Grand Junction Projects Office (GJPO) (Fig. 1.1) has effectively reduced contamination to levels within the DOE applicable guidelines. In accordance with the Verification and Certification Protocol for the Formerly Utilized Sites Remedial Action Program (FUSRAP) and Decontamination and Decommissioning Program (U.S. DOE 1990a), the independent verification contractor (IVC) has validated:

- the accuracy and completeness of field measurements,

- the credibility of followed procedures, and

- the accuracy and adequacy of the supporting documentation describing these remediation results.

This IV report of the outdoor areas is considered a partial report. The IVC will address in separate reports additional remediation of buildings and associated utilities, and cleanup of groundwater under the facility. These reports will become part of the final certification docket transmitted to the DOE Public Document Room in Washington, D.C. by the headquarters (HQ) program office.

\subsection{Task Description}

As part of its quality assurance program, DOE requires independent (third party) verification of the effectiveness of remedial actions conducted within FUSRAP and the Surplus Facilities Management Program (SFMP). Oak Ridge National Laboratory (ORNL)/Grand Junction (GJ) Environmental Technology Section (ETS) is the IVC for Grand Junction Projects Office Remedial Action Project (GJPORAP) for the DOE Environmental Restoration and Waste Management (EM) Decontamination and Decommissioning Program (D\&D). The objectives of the IVC covered in this partial report follow.

1. Verify the remediation of the GJPO facility through independent measurements, sampling, and analyses.

2. Review the remedial action plans, procedures, and other documents establishing cleanup limits.

3. Analyze representative samples of the site and produce a final verification report that becomes part of the final certification document. 


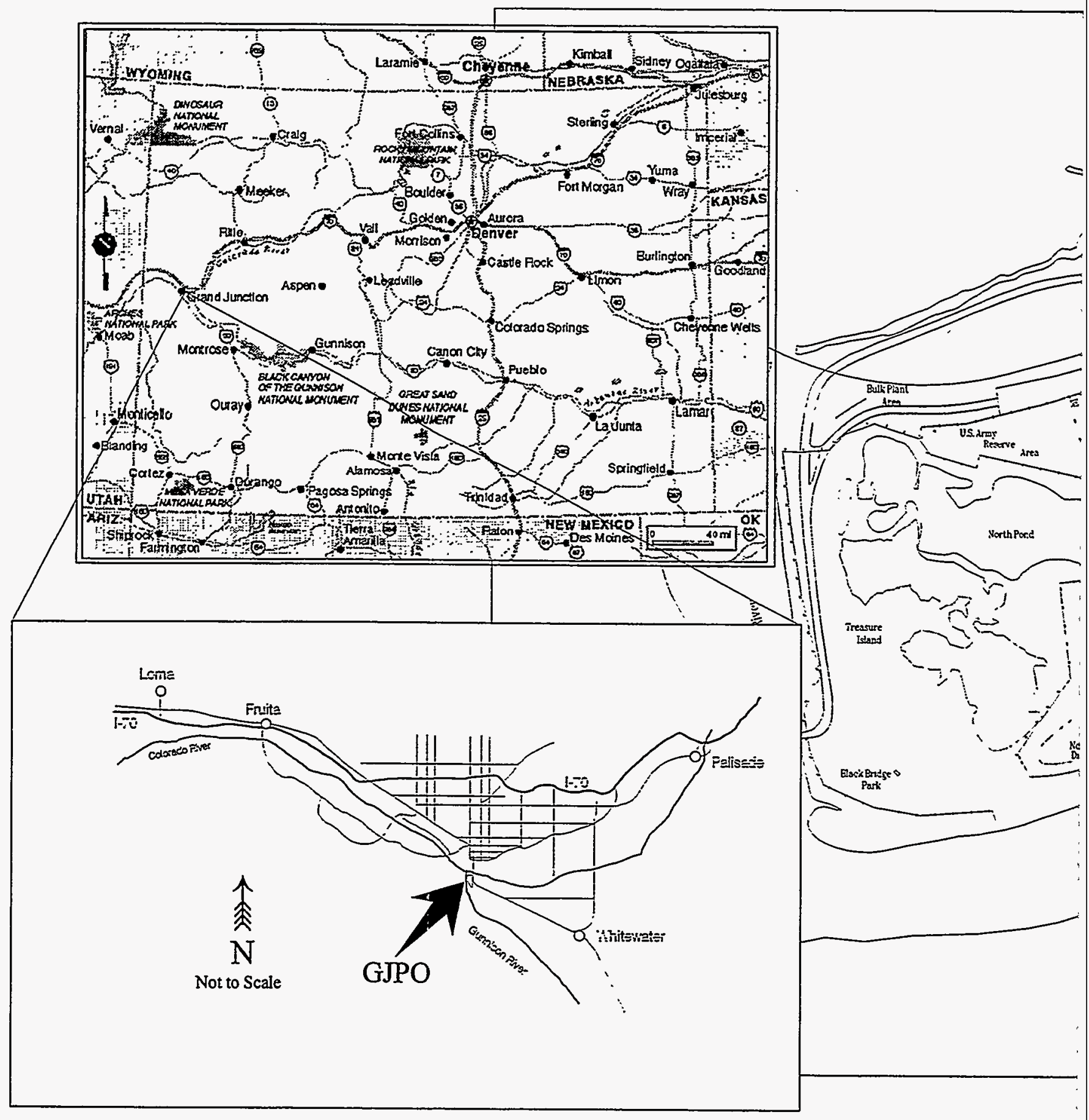

Fig. 1.1. Grand Junction Projects Office. 


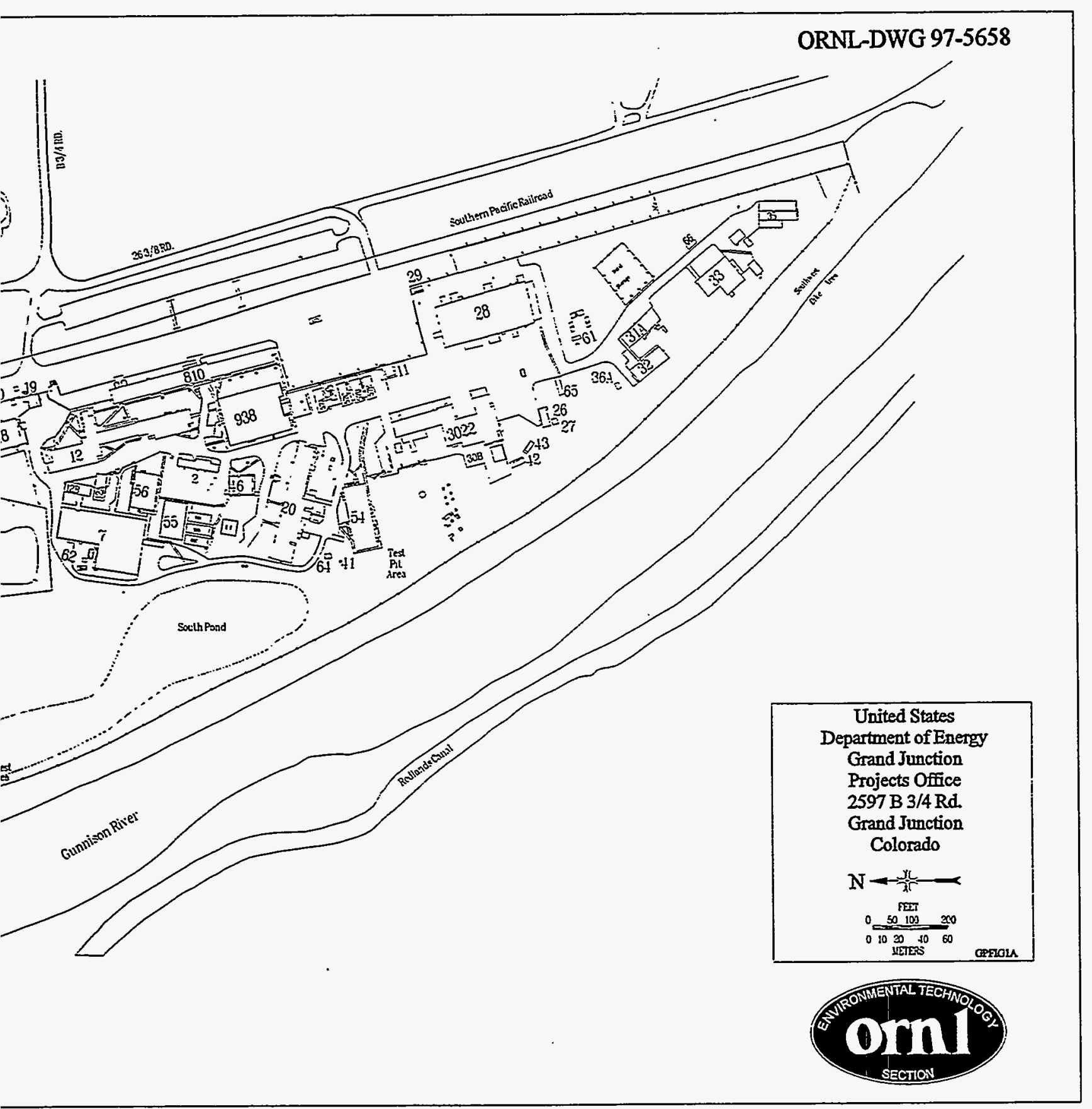


4. Select and archive a representative number of soil samples.

5. Prepare a statement of verification for the remediation of the outdoor areas of GJPO (Appendix A).

\subsection{Facility Description}

The GJPO facility is located in Mesa County, Colorado, immediately south and west of the Grand Junction city limits (Fig. 1.1). The facility encompasses 25 hectares (61.7 acres) in Sections 26 and 27, Township 1 South, Range 2 West, Ute Principal Meridian, at an elevation of approximately $1390 \mathrm{~m}$ ( $4560 \mathrm{ft}$ ). GJPO lies in the floodplain of the Gunnison River and is bordered by the river on the west and north. An earthen dike is located to the west between the facility and the river. The facility is approximately $0.9 \mathrm{~km}(0.6$ miles $)$ from populated areas of Grand Junction. One subdivision is located $0.16 \mathrm{~km}(0.1$ mile) across the river from the GJPO. A description of the geology of the site can be found in the remedial investigation/feasibility study (RI/FS) report (UNC 1989a).

There are approximately 30 buildings at the facility. The two bodies of water located at the facility are the North and South Ponds which encompass approximately $13,500 \mathrm{~m}^{2}$ and $15,200 \mathrm{~m}^{2}$ respectively. The area west of the North Pond was a former landfill, and since remediation, has become a wetlands area.

\subsection{Site Background}

In 1943 United States Vanadium (USV), under the name of Union Mine Development Corporation, established an office and built a uranium/vanadium refinery for the Army Corps of Engineers (COE) at the site of the current GJPO, as part of the Manhattan Engineer District (MED) (Fig. 1.2). The refinery was operated from 1943 to 1946 and was located approximately where Buildings 55 and 56 now stand. Numerous support facilities were associated with the refinery (Fig. 1.2). The COE transferred property title to the Atomic Energy Commission (AEC) when it was formed in 1947.

The AEC established the Colorado Raw Materials Office at the site, where personnel purchased and sampled uranium concentrate and ore until 1970. The AEC also constructed pilot plants in the 1950s to improve methods of uranium extraction. The first pilot plant was west of Building 1 and was more recently known as Building 6 (Fig. 1.2). Operations were conducted there from 1953 to 1954. The second, larger pilot plant, Building 31, was built in 1954, and was operated until 1958 (Fig. 1.3). Other buildings associated with the second pilot plant were Buildings 33, 34, and 35 . In addition, the AEC conducted the assay, stockpiling, and brokerage of vanadium and uranium ores and concentrates from 1948 to 


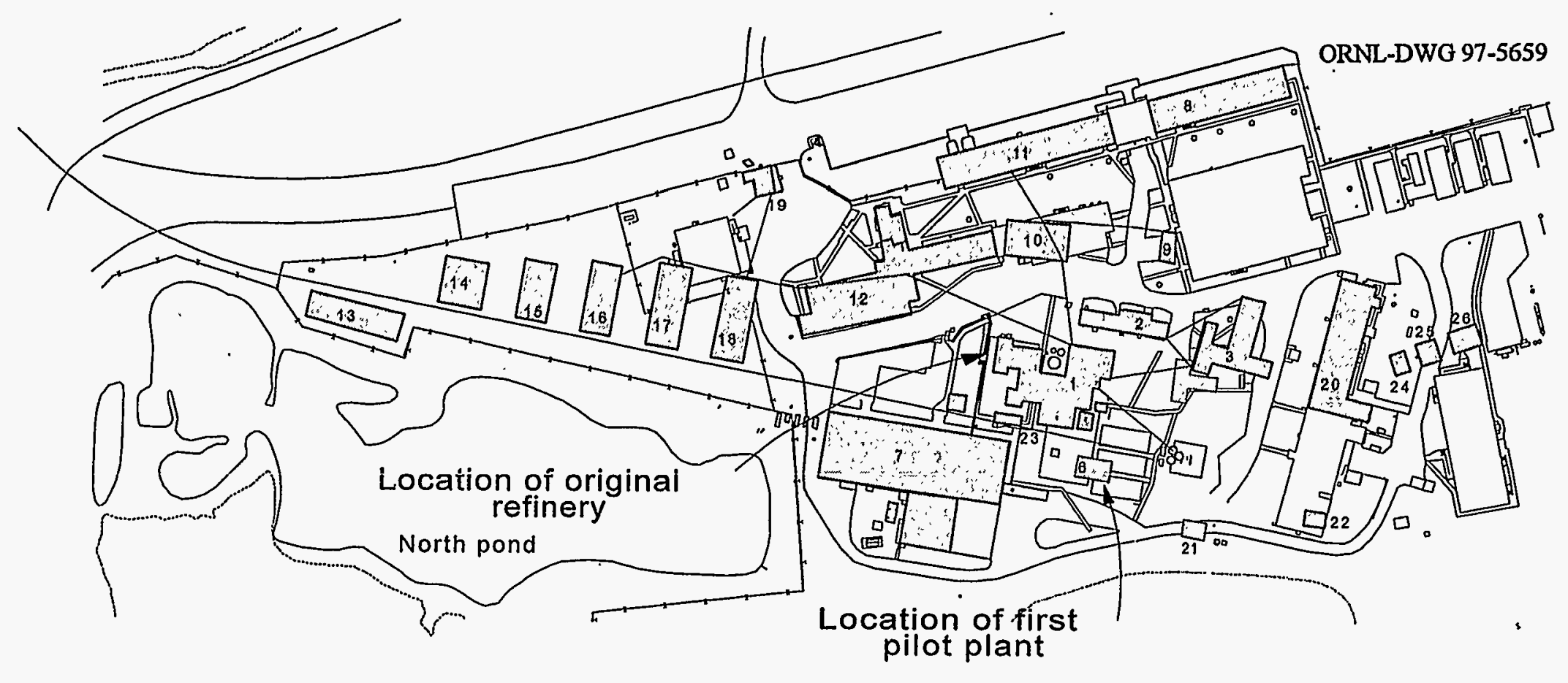

\begin{tabular}{|c|c|}
\hline \multicolumn{2}{|c|}{ Former facilities used before 1954 . } \\
\hline $\begin{array}{l}\text { 1. Boller House, Main Refinery } \\
\text { 2. Change House and Warehouse } \\
\text { 3. Research Laboratory } \\
\text { 6. First Pllot Plant } \\
\text { 7. Sample Plant } \\
\text { 8. Offles (Walker Lybarger) } \\
\text { 9. Paint Shop } \\
\text { 10. Garage } \\
\text { 11. Offleg (AS\&R, USGS) } \\
\text { 12. Office (Administration) } \\
\text { 13. Warehouse (Camp Supplles) } \\
\text { 14. Warehouse (Furniture) }\end{array}$ & $\begin{array}{l}\text { 15. Warehouse (Materials) } \\
\text { 16. Carpenter Shop } \\
\text { 17. Warehouse (USGS) } \\
\text { 18. Receiving Building } \\
\text { 19. Guard Shack } \\
\text { 20. Analytical Laboratory } \\
\text { 21. Supply Bullding (AS\&R) } \\
\text { 22. Warehouse (Paint) } \\
\text { 23. Warehouse (Materlals) } \\
\text { 24. Core Storage (USGS) } \\
\text { 25. Core Storage (USGS) } \\
\text { 28. Core Storage }\end{array}$ \\
\hline
\end{tabular}

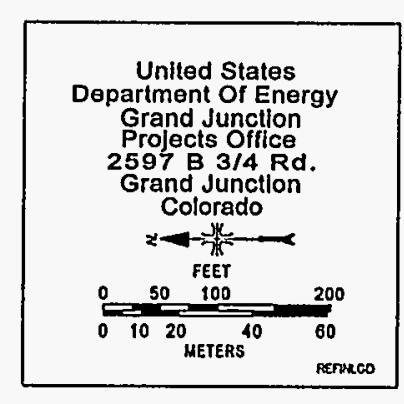

Fig. 1.2. Location of uranium and vanadium refinery, 1943 to 1946, and first pilot plant, 1953 to 1954. 


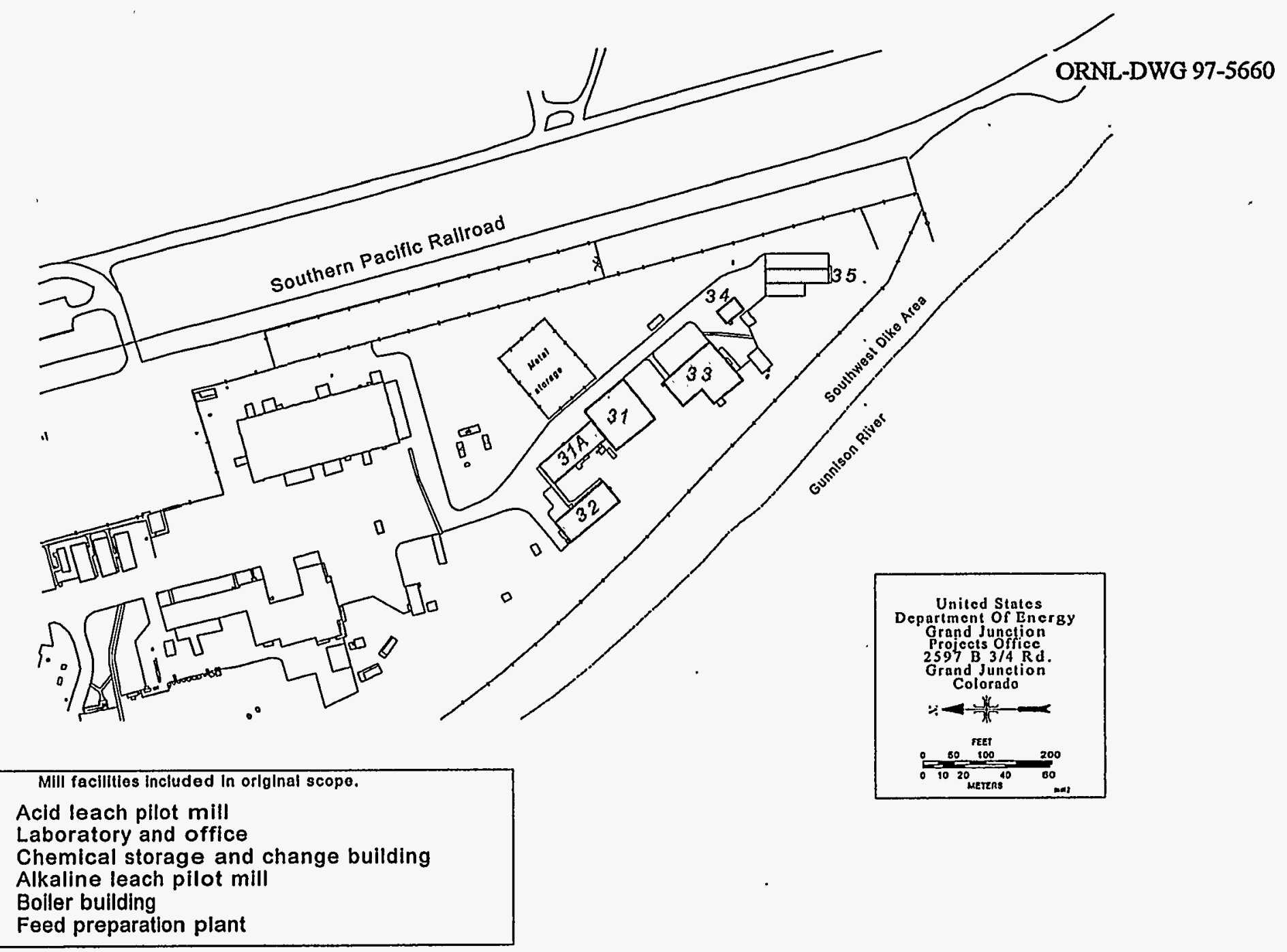

Fig. 1.3. Location of second pilot plant, 1955 to 1958. 
1975, with associated drum-handling activities. Most of the drum-handling activities were conducted in Buildings 7 (Fig. 1.2) and 35 (Fig. 1.3). Buildings 31, 33, 34, and much of the outdoor areas of the compound were used to store drums (Fig. 1.4).

Title passed from the AEC to its successor organizations: the Energy Research and Development Administration (ERDA) in 1975, and to DOE in 1977 (UNC 1990). Since 1975, the facility has supported various DOE programs, such as the National Uranium Resource Evaluation (NURE) Program, the Uranium Mill Tailings Remedial Action Project (UMTRAP), SFMP, the Long-Term Surveillance and Monitoring Program (LTSM), and the Technical Measurements Center (TMC). The DOE accepted the GJPO facility into SFMP in 1984 when site investigations formally began. In 1988, the DOE transferred the facility from SFMP to the DOE D\&D program. A historical review is available in the RI/FS report (UNC 1989a). Laboratory activities have been ongoing at the GJPO in support of these programs since 1943. Figure 1.5 is a time line representation of the major projects and operations conducted at the GJPO.

\subsection{Overview of the Facility Contanination}

Most of the contaminated materials at the GJPO facility are from pilot plant milling research operations, which involved testing and processing uranium ores at the site. The materials consist of uranium mill tailings, contaminated soil, ore, process-related slimes and equipment, heavy metals, and polychlorinated biphenyls (PCBs). In addition, laboratory debris and trash were disposed of on-site. Landfill operations began in the mid1950s and continued through the 1970s, in an area known as Treasure Island in the northwest portion of the facility (Fig. 1.1). Here, trash, construction debris, maintenance wastes, and incinerator ashes were discarded in topographically low areas and trenches of varying sizes. Apparently, much of the debris was burned in the excavations before backfilling. The original estimates of the volume of contaminated materials at the GJPO was approximately $61,600 \mathrm{~m}^{2}\left(81,000 \mathrm{yd}^{3}\right)$. Approximately 7 hectares (18 acres) of the 25hectare (61.7 acres) site were assessed to be contaminated (Fig. 1.6) (UNC 1989a). Investigations conducted between 1989 and 1993 resulted in an increase to the volume and area originally deemed as contaminated (Fig. 1.6) (UNC 1989a and 1990). As a result, approximately $230,000 \mathrm{~m}^{3}\left(300,000 \mathrm{yd}^{3}\right)$ of contaminated material have been removed and approximately 12 hectares (29.8 acres) of surface area have been remediated (Fig. 1.7).

\subsection{Remedial Action Process}

The original remedial design and scope of work for GJPORAP was based primarily on the data contained in Radiologic Characterization of the Department of Energy Grand Junction Projects Office Facility (Henwood and Ridolfi 1986). This included remediation 
部

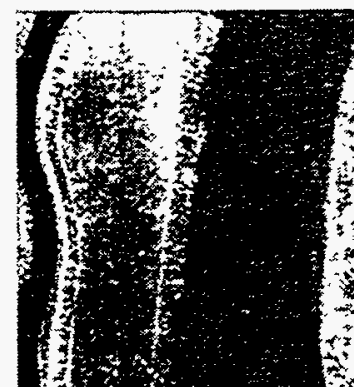

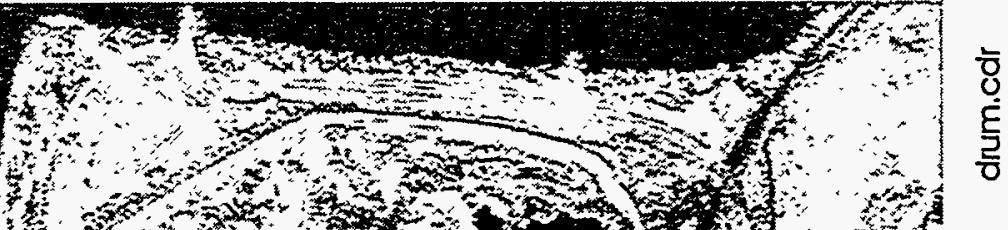

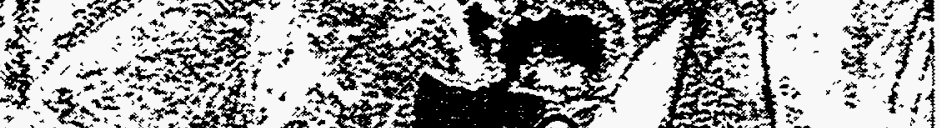

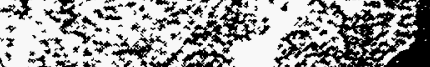

tots

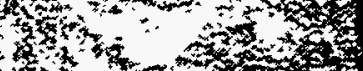

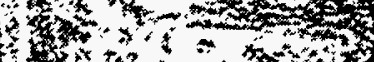

$6 x^{2},-3$

7

3

就

$\because \therefore x^{\prime}$

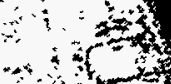

等,

(10)

(3)

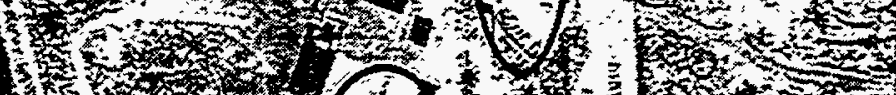

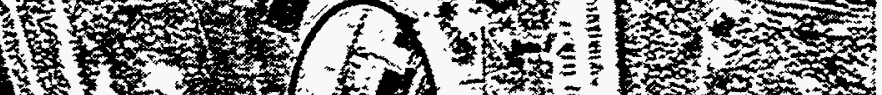

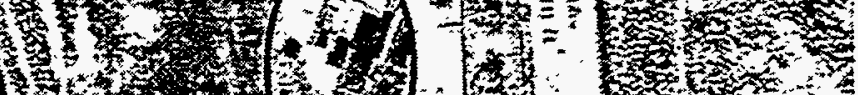

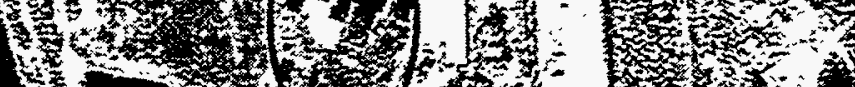

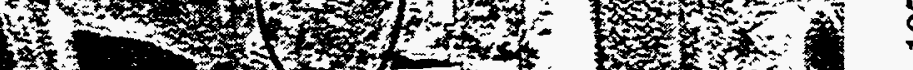

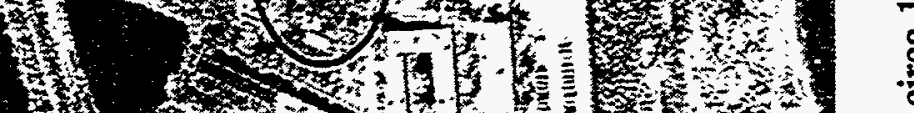

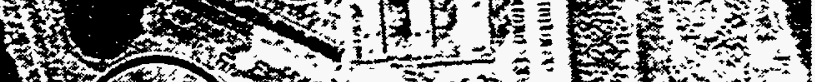

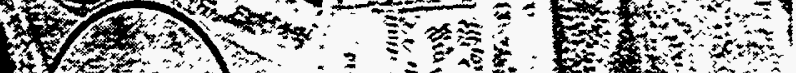
a 学 $40.2=1=0$

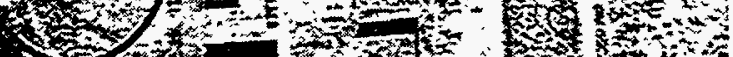
3

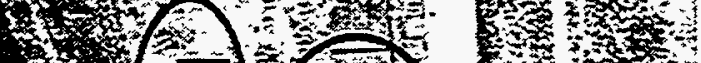

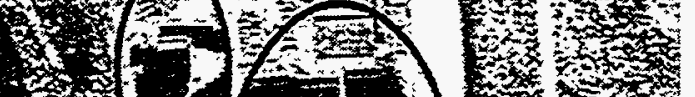
(1)

$\sin 3$

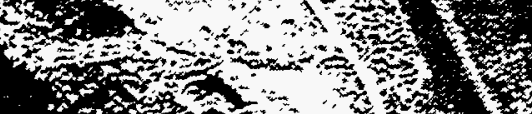

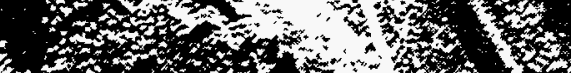

, 35

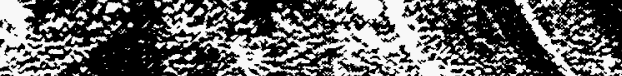

(3)

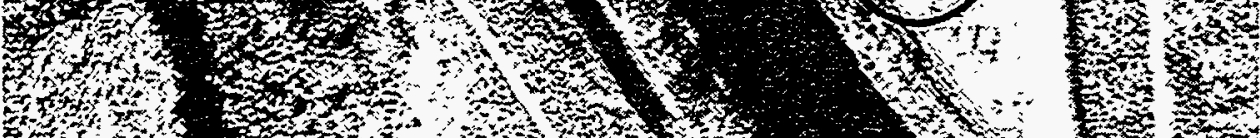

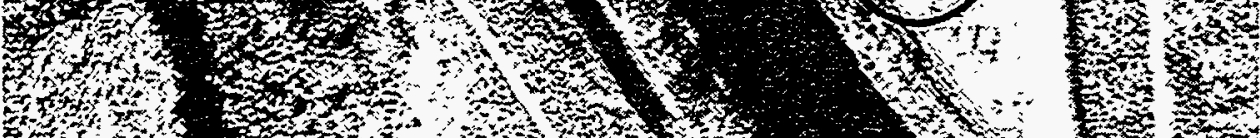

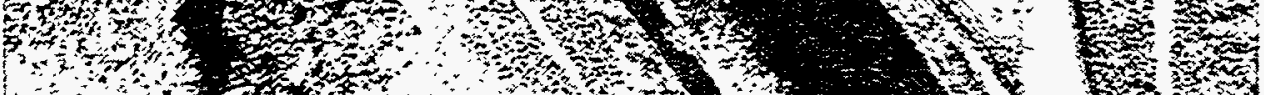

and

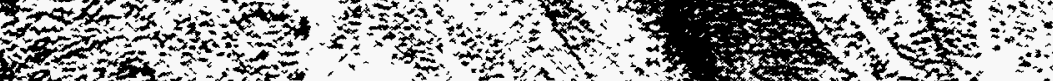
䊈 


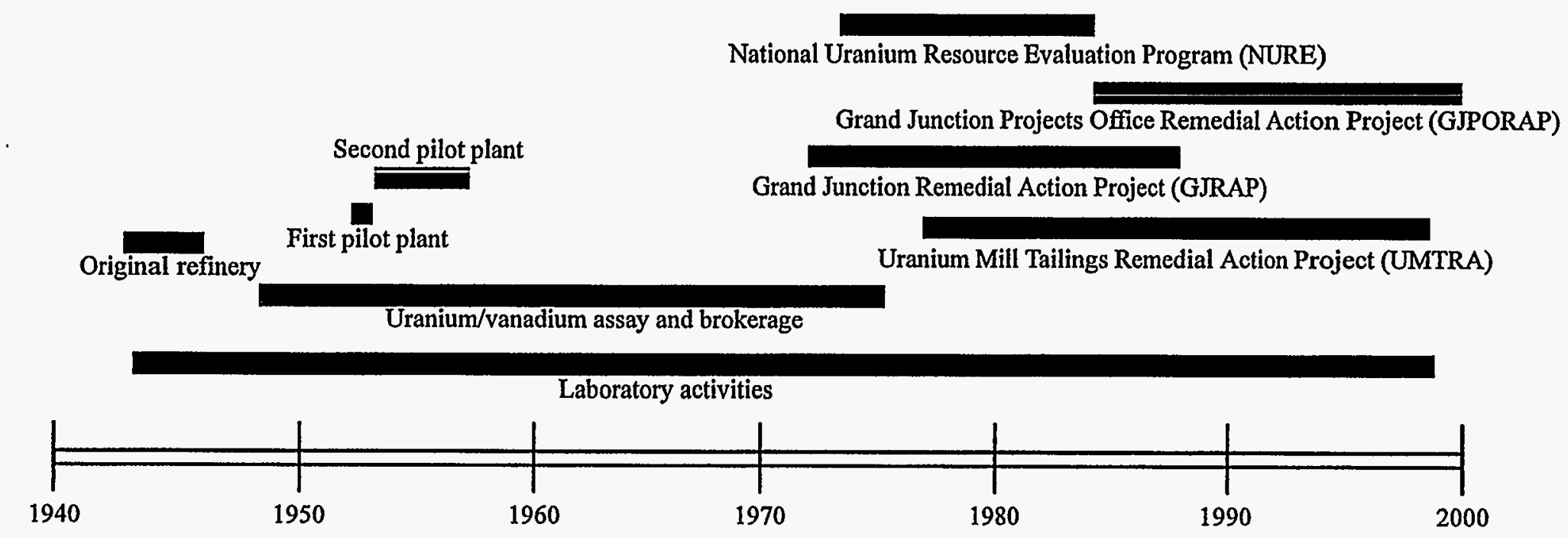

Fig. 1.5. Time line of major projects and operations conducted at GJPO. 


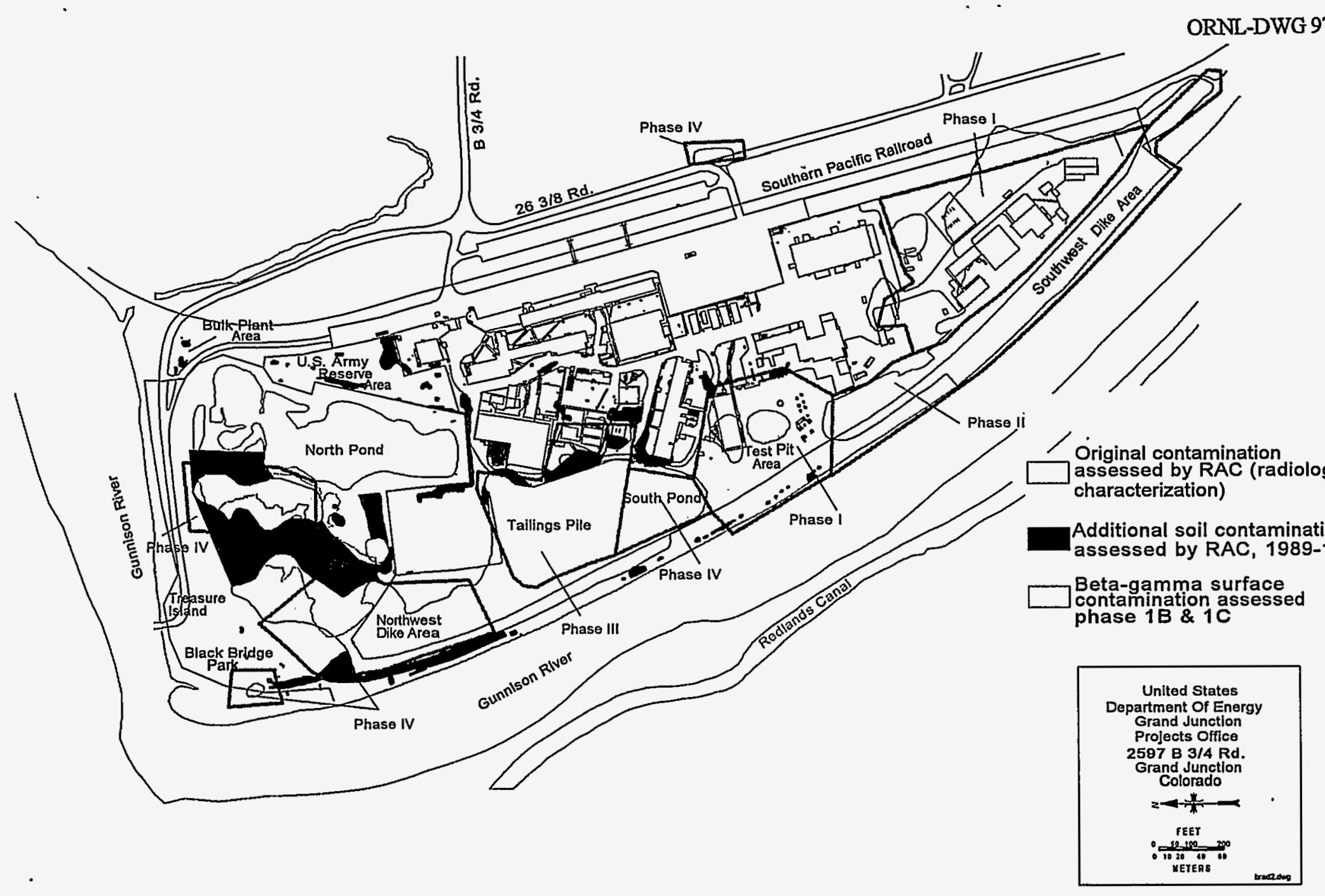

Fig. 1.6. Areas assessed as contaminated and original phase designators. 


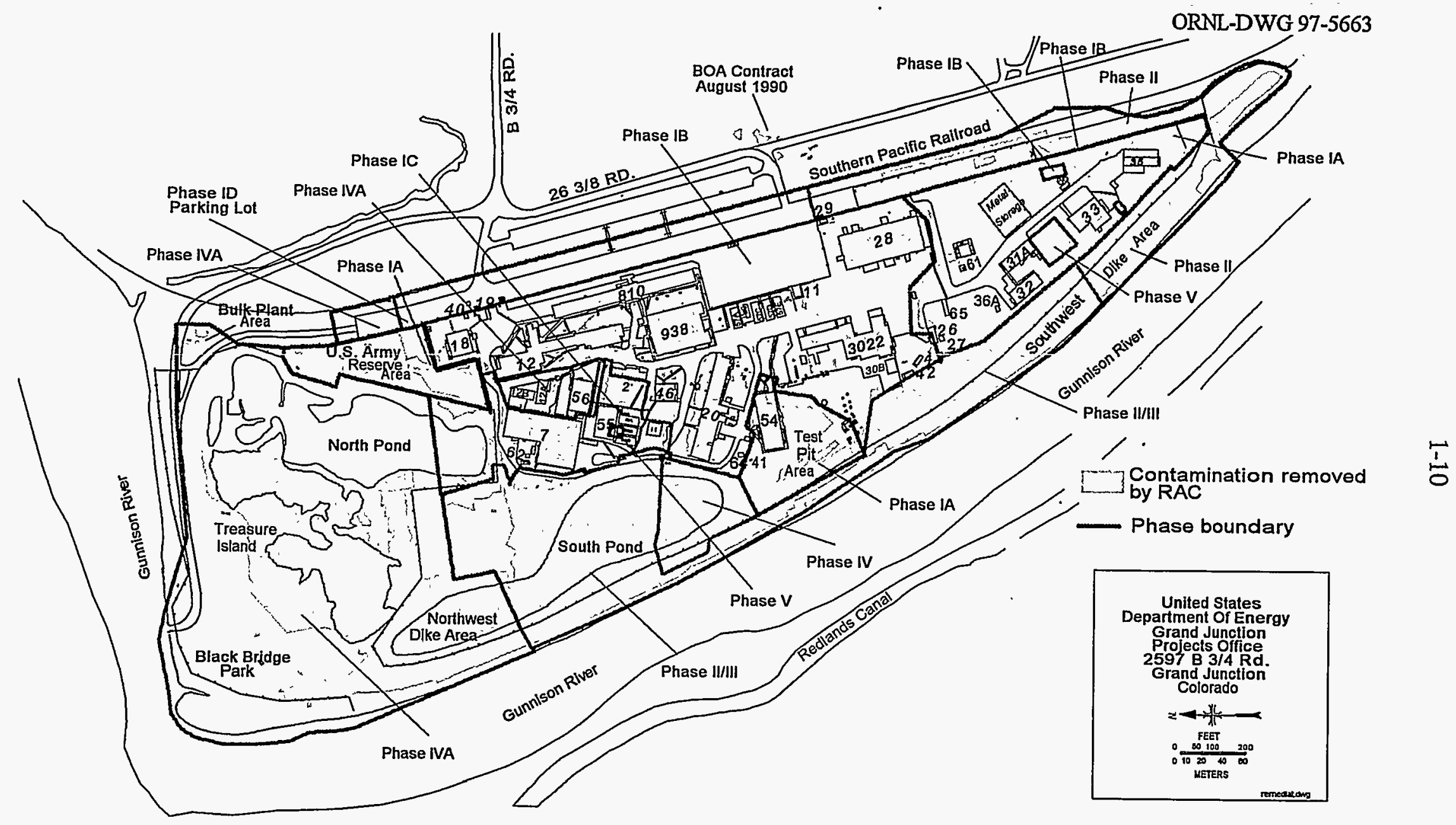

Fig. 1.7. Areas remediated by the remedial action contractor (RAC) and final phase designators. 
of uranium mill tailings located in the open-land areas and a few buildings. During Phase IA remediation, considerably more extensive contamination was identified than estimated. The RAC then determined a reassessment of the GJPO was necessary and found residual radioactive material in areas previously identified as uncontaminated. The phases of this initial work scope, which began in fiscal year (FY) 1989, and the increased scope, which was completed in FY1994, are discussed in Sect. 1.7. Although these phases are referred to as the "Exterior Area Phases," they included demolishing and remediating buildings. During the completion of the last phase of remediation in 1994, additional potentially contaminated buildings and comprehensive release surveys were added to the work scope. There is no phase designator for this additional indoor work which is referred to as the "Interior Area" although it will include limited outdoor remediation. The remediation of these additional contaminated buildings began in FY 1994 and will continue through FY 1998.

The site hydrology is discussed in detail in the RIFS (UNC 1989a). The shallow gravel aquifer underlying the GJPO facility is contaminated primarily by uranium mill tailings (with associated metal and radiological constituents) formerly located on site. Soil sample results indicate the source of the contamination has been effectively removed from the surface and near-surface soil. The effect of the remediation on the tailings potentially below the water table is currently being evaluated through groundwater modeling. The $\mathrm{RAC}$ is relying on passive restoration of the groundwater occurring over time as flow through the aquifer flushes contaminants from the system. The groundwater remedial measures will be independently verified by evaluation of the RAC's monitoring program and the groundwater flow and transport models used in the RI. The groundwater IV will be addressed in a separate report.

The recommended and DOE-approved remediation was the excavation of contaminated material using traditional construction techniques (U.S. DOE 1990b). Experienced contractors conducted remedial actions under contract to the RAC. Areas characterized by the RAC as contaminated were remediated using backhoes, front-end loaders, skidsters, bulldozers, and shovels. To confirm cleanup guidelines, health physics technicians monitored the excavations with the following instruments:

1) Portable gamma scintillation detector (Victoreen Model 490 THYAC III) and ratemeter with 489-55 $\mathrm{NaI}(\mathrm{Tl})$ scintillation probe to measure gamma radiation.

2) Ludlum 44-9 beta-gamma probe coupled to a Ludlum $2221 \mathrm{scaler} / \mathrm{ratemeter}$ to measure beta-gamma radiation on surfaces that are potentially contaminated with beta-emitting radionuclides.

3) Delta counter EL-0018 or EL-0018a to determine the difference (or delta) between the amount of gamma radiation emanating from adjacent sources of radiation and the amount of gamma radiation emanating from directly beneath the delta counter. 
4) Mobile opposed crystal, PCA- ${ }^{\text {Tx }} \mathrm{NaI}(\mathrm{Tl})$ detector systems, to perform on-site analysis of radionuclides in soil.

Fugitive dusts were held to a minimum by spraying with water. Health and safety technicians also monitored excavations for elevated radiation readings and other occupational concerns (Geotech 1992).

As the remediation progressed, contaminated material was stockpiled on the site until the record of decision (ROD) was signed in April 1990 (UNC 1990). Then, it was transported to the Cheney disposal cell for stabilization. Removal of the contaminated soil was completed in FY 1994. Revegetation and reconstruction of the soil of the "Exterior Area Phases" of the facility were completed in FY 1996.

Technicians screened the material with photoionization detectors (PIDs), and took representative samples for analysis of heavy metals in areas where hazardous wastes were suspected. In order to ensure that hazardous wastes were not transported off the site, the RAC did not remediate those areas until sample results were available (Rust 1993c). The contaminated material was stockpiled and loaded into dump trucks and then covered with tarps. Before leaving the facility, the trucks were washed down on the decontamination pad and monitored for removable radioactivity. Measurements were also collected to ensure that the activity of the load was in compliance with all applicable permits for transportation.

To meet disposal facility acceptance criteria, the size of certain debris was reduced before loading. The RAC shipped the material by truck to the state repository in Grand Junction, where MK Ferguson incorporated it with the uranium mill tailings from UMTRAP. MK Ferguson then shipped the material by rail and truck to the Cheney disposal facility. After rail transport ended for UMTRAP, material was hauled directly from the GJPO site to the Cheney disposal cell by truck.

\subsection{Description of Phases}

The RAC originally divided GJPORAP into four phases: I, II, III, and IV (Fig. 1.6). These phases, and subphase designators, are administrative tools used to simplify planning, budgeting, and contracting and have changed as the project has grown. The final phase designators for GJPORAP, presented in Fig. 1.7, are:

Phase IA: The test pit area, Army lease area, and Buildings 31, 33, 34, and 35 . The RAC remediated these areas in 1989 and 1990. Buildings 33, 34, and 35 will require further decontamination or demolition during future phases that are scheduled for completion before 2000. Contamination remains in hard-to-access areas, and is preventing release for unrestricted use, as required by the ROD (U.S. DOE 1990b). 
Phase IB: Portions of the facility (excluding buildings) inside the security fence not addressed in other phases. The RAC remediated these areas in 1991 and 1992. Current scope includes release of the buildings, and any soil not characterized in Phase IB and located adjacent to the buildings.

Phase IC/ID/V: Trailers 53-A, 53-B, and 53-C area, Building 7 area, Buildings 6 and 31, and parking lot. The RAC remediated these areas in 1991 and 1992. Buildings 6 and 31 were demolished as part of the remediation.

Phase II: Southwest dike area, southern half. The RAC remediated this area in 1991, and Phase II was terminated due to changes in the remediation contract. When the contamination exceeded the assessed amount by more than $25 \%$, this phase was terminated and rebid as Phase II/III.

Phase II/III: The remainder of the southwest dike area, tailings pile, and dike ditch area. The RAC remediated these areas from 1991 to 1993.

Phase IV: South Pond. The RAC remediated this area in 1993.

Phase IVA: Treasure Island landfill, northwest dike area, Black Bridge Park, Texaco Bulk Plant, north parking lot, and area north of Building 7. The RAC remediated Phase IVA in 1993 and 1994.

Phase VI: Revegetation and reconstruction of the site. This phase started in FY 1994 and was finished in FY 1996.

\subsection{Approach to Verification}

The IVC approach to IV of the GJPORAP remediation effort followed FUSRAP protocol and verification guidelines which are based on DOE Order 5400.5 (U.S. DOE 1990c), and incorporated applicable survey and analytical procedures from the IVC procedures manual (ORNL 1993). The IVC will address IV of the buildings and groundwater cleanup at GJPO in later reports.

Verification activities were coordinated through DOE/HQ. The IVC provided plans, progress reports, reports of interim findings, and monthly costs to DOE/HQ and DOE/GJ. In addition, the RAC and IVC held meetings regularly to help communication and resolve problems encountered as the project progressed.

The IVC followed appropriate chain-of-custody sequences on all independent and confirmatory analysis samples. Chain-of-custody forms and representative soil samples will be archived for use in the certification docket for the project. The RAC collected verification data for all remediated soils as discussed in the project closeout report (Rust 1995). 


\subsection{DOCUMENT REVIEW}

\subsection{Project Documents}

ORNL/ETS was assigned as the IVC by DOE in 1989; therefore, no IVC comments were submitted for project planning documents (such as the Final Remedial Investigation/Feasibility Study or the ROD) before 1989. The IVC suspended work from October 1989 to March 1990 due to funding problems. In August of 1990, DOE/HQ directed the IVC to conduct a document review of the work done by the RAC during that time (letter from Anthony Kluk, DOE/HQ, to Craig Little, ORNL, 8/10/90). The IVC questioned the work and the RAC added more comprehensive surveys of these buildings. This will be performed during the "Interior Area" work scope.

Subsequent document reviews followed FUSRAP protocol; that is, the IVC should comment on the remediation approach and resolve conflicts before implementation (U.S. DOE 1990a). The IVC received weekly progress reports and project documentation and attended weekly project meetings. This communication allowed for early identification of potential problems. Documents reviewed for the work scope included, but were not limited to, Exterior Beta-Gamma and Alpha Characterization of the U. S. Department of Energy Projects Office Facility (UNC 1989b), Radiological Assessment for Construction Phase IB of the Department of Energy Grand Junction Projects Office (UNC 1990), Grand Junction Projects Office Remedial Action Project Radiological Sampling and Verification Plan Phase IVA (Rust 1993a), Justification for Certifying 47 Large-Area Verification Areas at the Grand Junction Projects Office (Rust 1994), Final Report of the Decontamination and Decommissioning of the Exterior Land Areas at the Grand Junction Projects Office Facility (Rust 1995) and numerous radiological assessments for buildings and phases, health and safety plan revisions, and work plan addendums. The review of the PCB data was added to the scope of the original work and is discussed in Sect. 2.2. The review of the Treasure Island reports resulted in increased work scope for the IVC and is discussed in Sect. 2.3.

Changes to the project scope due to reassessments and the addition of buildings to the scope after the original planning stage, affected all stakeholders, including IVC. However, communication with the RAC, and review and input to draft documents by the IVC resulted in cost savings. By being involved early, potential certification problems were avoided. Two examples of successful document review that resulted in corrective action were suspension of the large-area verification (LAV) protocol procedure, and the recognition of cleanup standards for ${ }^{230} \mathrm{Th}$. The LAV is a soil sampling protocol for excavated areas exceeding 0.5 acres that relies on the approximate correlation between gamma scintillometer measurements and radium concentration in soil. The areas are scanned for the highest outdoor gamma (HOG), and these HOGs are then sampled, thereby providing a "worst case" scenario for ${ }^{226} \mathrm{Ra}$. In addition, the number of soil samples is 
reduced by a factor of ten because the LAV methodology is to composite one sample from each $100 \mathrm{~m}^{2}$ and let it represent $1000 \mathrm{~m}^{2}$. According to the Verification and Certification Protocol for FUSRAP and D\&D Program (U. S. DOE 1990a), the RAC will demonstrate for certification that each $100-\mathrm{m}^{2}$ area meets guidelines. By compositing the samples according to the LAV protocol, the radionuclide concentration that may exceed guidelines in one of the $100-\mathrm{m}^{2}$ areas can be diluted and shown to meet guidelines. Therefore, the IVC recommended suspension of this protocol.

Because ${ }^{230} \mathrm{Th}$ does not emit gamma radiation, ${ }^{226} \mathrm{Ra}$ gamma radiation was correlated with ${ }^{230} \mathrm{Th}$ contamination. If the LAV had not been discontinued and the cleanup standard for ${ }^{230} \mathrm{Th}$ had not been recognized, the cost to resample in order to show compliance at the time of certification would have been substantial. The LAV is discussed further in Sect. 3.9. Another potential problem was avoided when DOE/HQ solicited justification for the DOE/GJ request for changes to the remediation standards (Memorandum from Anthony Kluk, DOE/HQ to Joseph Virgona, DOE/GJ, 4/29/91). If approval had been given to stop remediation at the surface of the water table, cleansing of groundwater would not have occurred through natural flushing, as outlined in the ROD.

\subsection{PCB Area Analytical Review}

The following discussion is a summary of the IVC review of the contents of the analytical reports for the four rounds of sampling at the site of the PCB contamination and meetings with the RAC concerning this review.

During Phase 1A, two soil samples collected by the RAC from an area close to a transformer pad next to the mill building (Building 31/31A) (Fig. 1.3) yielded PCB concentrations of $110 \mathrm{ppm}$ and $920 \mathrm{ppm}$. These were surface samples taken before any excavation had occurred. Subsequently, this area was excavated to a depth of approximately $2 \mathrm{ft}(0.61 \mathrm{~m})$ and then backfilled. However, the excavated soil was inadvertently moved to the stockpile before the sample results were reviewed by the RAC.

As a result further attempts to delineate PCB contamination in this area were initiated and focused on the two pre-excavation sample locations. Auger refusal, however, prevented sample collection in four locations: lateral distances of $1 \mathrm{ft}(0.31 \mathrm{~m}), 2 \mathrm{ft}(0.61 \mathrm{~m}), 3 \mathrm{ft}$ $(0.92 \mathrm{~m})$, and $4 \mathrm{ft}(1.22 \mathrm{~m})$ from the original location of the 110-ppm pre-excavation PCB sample. However, two samples collected at distances of $1 \mathrm{ft}(0.31 \mathrm{~m})$ and $4 \mathrm{ft}(1.22 \mathrm{~m})$ from the 920-ppm PCB sample revealed PCB concentrations less than $2 \mathrm{ppm}$. The depths of these two samples were 2 to $5 \mathrm{ft}(0.61$ to $1.5 \mathrm{~m})$ and 2 to $4 \mathrm{ft}(0.61$ to $0.92 \mathrm{~m})$, respectively.

Because the PCB-contaminated soil had been commingled with non-PCB-contaminated soil, excavation and sampling of the stockpile were performed in four rounds to completely 
remove all tailings contaminated with greater than $0.08 \mathrm{ppm}$ PCBs. The RAC estimated that the volume of the original PCB-contaminated tailings was approximately $1 \mathrm{yd}^{3}$ $\left(0.8 \mathrm{~m}^{3}\right)$. However, because it was inadvertently mixed with the tailings on the stockpile, the total volume became $61 \mathrm{yd}^{3}\left(47 \mathrm{~m}^{3}\right)$. The PCB-contaminated tailings are currently contained in roll-off bins at GJPO, pending a decision on disposal.

The IVC received direction from DOE/HQ to perform a Type A review of the RAC sampling plan and results for the stockpile. In addition, the IVC was also requested to prepare a recommendation for IV of the PCB removal from the Phase IA area (letter from Dr. Anthony $\mathrm{Kluk}, \mathrm{DOE} / \mathrm{HQ}$, to Douglas Halford, ORNL, 3/26/91). Resampling in the area of the original PCB contamination was considered and was not recommended after cost-benefit analysis. A letter from DOE/GJ gave direction not to perform further verification in the Phase IA area (letter from R. Eldon Bray, DOE/GJ to Carl Jacobson, Geotech, 7/30/92). Therefore, the IVC only performed a Type A review of the sampling plan and the analytical results for the four rounds of sampling on the stockpile. The IVC agreed with the RAC conclusion that all material contaminated with PCBs to a level of $0.08 \mathrm{ppm}$ had been removed. However, the IVC recommends that after disposal, a report with the PCB analytical data attached should become part of the certification docket for GJPO.

\subsection{Treasure Island Landfill Document Review}

This discussion is a summary of meetings with the RAC and the IVC evaluation and subsequent proposal to DOE after review of the following: Trenching Investigation Report Treasure Island Area for the U.S. Department of Energy Grand Junction (Colorado) Projects Office Facility (Curtis et al. 1989); Grand Junction Projects Office Geophysical Survey of the Treasure Island Area (Jin et al. 1988); Trench Investigation in Treasure Island (Robison 1990); Final Report and Recommendation, GJPORAP Supplemental Radiological Characterization, Treasure Island and Black Bridge Park (Rust 1993b); and Final Remedial Investigation/Feasibility Study for the U.S. Department of Energy Grand Junction (Colorado) Projects Office Facility (UNC 1989a).

Original assessment and characterization data concluded that radiological contamination in the Treasure Island landfill area was limited to the upper $2 \mathrm{ft}(0.62 \mathrm{~m})$ of soil and that there was no known chemical contamination in the landfill. The ROD addressed only radiological contamination, therefore the Resource Conservation and Recovery Act (RCRA) action limits were used for guidance for chemical contamination. The original investigation included samples collected from one portion of Treasure Island that were analyzed for EP toxicity (UNC 1989a).

In 1988 the RAC conducted a geophysical survey that detected anomalous subsurface regions in the Treasure Island area. The higher subsurface electrical conductivity in this area appeared to be debris associated with the landfill activity between the early 1950s and the 
mid-1970s (Jin et al. 1988). Trenching investigations were also performed to delineate radiological contamination (Curtis et al. 1989; Robison 1990; Rust Geotech 1993b). In addition to the radiological contamination, the trenching investigations revealed trash, building debris, operations wastes, vehicle maintenance wastes; laboratory wastes, and incinerator ash. One soil sample was collected during the 1990 trenching investigation and analyzed for EP toxicity, in addition to volatile organic compounds (VOCs) and semivolatile organic compounds (SVOCs). Results of the sample analysis did not indicate hazardous substances above detection limits, with the exception of a common plasticizer found frequently where plastics are disposed of (Robison 1990).

In addition to the trenching investigations, the RAC conducted soil-boring efforts in 1989 that included portions of the Treasure Island area. Soil samples from the borings were analyzed for EP toxicity and $\mathrm{pH}$. In addition, some of the samples were analyzed for PCBs and pesticides. Although the results were not published, one area of commingled waste consisting of lead and mill tailings was identified. This was sampled in 1994 and determined to be less than the RCRA action limit of $5.0 \mathrm{mg} / \mathrm{L}$. Groundwater monitoring of the Treasure Island landfill had not detected hazardous substances in the groundwater at levels above guidance, with the exception of those contaminants associated with uranium mill tailings (uranium, molybdenum, selenium, arsenic) and common plasticizers found wherever plastics have been disposed of (Rust 1993c). The IVC reviewed the available data and worked with the RAC on the requirements for remediation of the landfill.

In addition to the RAC's monitoring of the remediation the IVC proposed to DOE/HQ that up to 20 samples be collected during excavation activities in the Treasure Island area and analyzed at an off-site laboratory for metals, VOCs, PCBs and pesticides, and SVOCs. This was proposed to help ensure that no unauthorized hazardous or radioactive wastes were unknowingly removed to the Cheney repository. A statistically-based software program (ELIPGRID-PC), developed by ORINL, was used to look at different sampling schemes using round and elliptical hot spots (see Appendix B). The ELIPGRID program suggested the estimated sampling costs to achieve a 80 to $95 \%$ confidence level would range from $\$ 770 \mathrm{~K}$ to $\$ 3,900 \mathrm{~K}$.

This method of sampling would have provided measurements that could be statistically analyzed to evaluate attainment of cleanup standards. However, because a systematic sampling of that area would have involved exorbitant analytical costs, the IVC instead proposed to obtain approximately 20 samples in locations identified by field-screening methods and visual observations by IVC personnel during excavation activities in that area. DOE/HQ directed the IVC to perform this proposed chemical sampling (letter from Gloria H. Stevens, ORNL, to J. W. Gatrell, DOE/HQ, February 15, 1994 with J.W. Gatrell's signature at concurrence on March 3, 1994). Although this sampling approach in no way replaced a systematic sampling of the area that is usually conducted during verification activities, it provided some quantitative data for the certification docket in addition to the samples collected by the RAC in areas that were suspect. 


\subsection{The Remedial Action Contractor (RAC) Completion Report}

The RAC issued a report entitled Final Report of the Decontamination and Decommissioning of the Exterior Land Areas at the Grand Junction Project Office Facility (Rust 1995) in September 1995. The IVC reviewed and commented on the draft version of the report and concurred that the outdoor portions of the facility assessed as contaminated have been remediated, in accordance with identified standards, and can be released for unrestricted use. However, the IVC considers the potential for residual deposits of uranium contamination still exists under paved areas because the assessment was not designed to identify uranium shielded by asphalt. The IVC has recommended that these assessments be conducted by the RAC in a later phase of the project. Areas within $3 \mathrm{~m}$ of structures will be recertified, if necessary, as part of the remediation and release of buildings. Further discussion is presented in Sect. 4.0 of this report.

\subsection{Administrative Record and Certification Docket}

The IVC and the RAC will review the Administrative Record to verify that its contents meet the requirements of the Comprehensive Environmental Response Compensation and Liability Act. The FUSRAP protocol lists document requirements for the certification docket of the site (U.S. DOE 1990a). All relevant documents have been located by the RAC and should be placed in the Administrative Record or assembled for the certification docket of the site before project closeout in FY01. 


\subsection{RESULTS AND DISCUSSIONS}

\subsection{Background Radiation Measurements}

Background radiation values in GJ were determined by the IVC in conjunction with the UMTRAP program in GJ (Myrick and Berven 1981). Background gamma radiation exposure rates range from 10 to 14 microroentgen per hour $(\mu \mathrm{R} / \mathrm{h})$. Background soil concentrations for ${ }^{226} \mathrm{Ra}$ range from 1.0 to 1.4 picocuries per gram ( $\left.\mathrm{pCi} / \mathrm{g}\right)$. Background values of $12 \mu \mathrm{R} / \mathrm{h}$ and $1.4 \mathrm{pCi} / \mathrm{g}{ }^{226} \mathrm{R}$ a were used for GJPORAP by IVC. Background values for ${ }^{230} \mathrm{Th}$ and ${ }^{\text {tor }} \mathrm{U}$ of $2.0 \mathrm{pCi} / \mathrm{g}$ were developed by the RAC and used by IVC for the project (UNC 1990).

\subsection{Field Verifications}

IV surveys were performed over approximately $20 \%$ of the facility area. Due to changes in scope, complications encountered with the remediation, and use of the LAV procedure by the RAC, the IVC conducted more field verifications than the $10 \%$ originally planned.

The IVC did not perform IV of airborne emissions monitoring or release of materials from the site. Radon flux measurements will be collected and reported in a final report at the end of the project. IV of buildings and groundwater cleanup will be addressed in separate reports.

Some excavations were below the water table and required special measures, such as pumping water to keep the excavated area open. The RAC notified the IVC when a segment of the facility was remediated and ready for IV. After IV measurements were collected, the segment was backfilled above the water table, and the next segment was prepared for remediation and IV. When possible, remediation continued away from areas to be verified, in order to reduce gamma emanation from the remaining contamination. In areas where this was not possible, IV was based on sample analysis and delta-gamma measurements.

Maps were prepared from facility drawings showing the reference grid and prominent features. The reference grid was established in the excavations by the RAC, often using standard land surveying practices. Area identifiers $\left(100-\mathrm{m}^{2} \mathrm{~V}\right.$-areas) were designated by the RAC. The IVC followed the same nomenclature when possible, in order to avoid confusion. In areas where the RAC utilized the LAV protocol, the IVC added additional identifiers to delineate specific $100-\mathrm{m}^{2}$ segments. 


\section{3-2}

\subsection{Gamma Scans and Delta Measurements}

A total of 674 areas that were $\leq 100 \mathrm{~m}^{2}$ were scanned to measure gamma radiation. Gamma radiation exposure rates ranged from 9 to $1,355 \mu R / h$, with an average of $16 \mu R / h$, and a median of $13 \mu \mathrm{R} / \mathrm{h}$. Areas of elevated gamma exposure rate ranges were attributed to emanation from adjoining deposits or emanation from the test pits and sample storage areas. All areas with elevated gamma exposure rates were verified using soil sample analysis and supplemental delta-gamma measurements. Data are summarized in Table 3.1 and presented in Appendix C. Delta measurements and locations are listed in Appendix C, Table C.1. One delta measurement, V531I.H, indicated high radiation emanating from directly beneath the detector, not from adjacent sources. However, when averaged over $100 \mathrm{~m}^{2}$, this area met applicable guidelines.

Table 3.1 Summary of gamma exposure rate ranges

\begin{tabular}{|c|c|c|c|c|}
\hline \multicolumn{5}{|c|}{$\begin{array}{l}\text { Gamma exposure rates, } \mu R / h \\
(n=674)\end{array}$} \\
\hline \multicolumn{2}{|c|}{ Range } & \multirow[t]{2}{*}{$\bar{x}$} & \multirow[t]{2}{*}{$s$} & \multirow[t]{2}{*}{ Median } \\
\hline From & To & & & \\
\hline 9 & 1355 & 16 & 11 & 13 \\
\hline
\end{tabular}

Gamma radiation scans were performed with $\mathrm{NaI}$ scintillation detectors coupled to ratemeters, which recorded thousands of counts per minute $(\mathrm{kcpm})$. Counts were converted to $\mu \mathrm{R} / \mathrm{h}$ by using a conversion factor developed for UMTRAP in GJ, and is outlined in IVC procedure TE-030 (ORNL 1993). This conversion factor was developed by cross-calibration to a pressurized ionization chamber (PIC). In areas where uranium yellow cake was a suspected contaminant, cursory scans were made with beta-gamma GM detectors coupled to ratemeters. Beta-gamma surface measurements on soil are suspect, due to the attenuation and shielding by the soil. These measurements were qualitative in nature and used for screening. In a few areas, soil remediation ended at foundation surfaces or pipes, sidewalks, etc. Surface scans were conducted at these locations to identify potential areas of residual contamination that could be investigated further.

\subsection{Measurements and Surface Activity Levels}

Surface activity measurements were collected from selected $1-\mathrm{m}^{2}$ grid blocks in areas where the excavation ended against concrete. The highest activity measurement for beta was approximately $4100 \mathrm{dpm} / 100 \mathrm{~cm}^{2}$. All measurements were below the guideline of 
$5000 \mathrm{dpm} / 100 \mathrm{~cm}^{2}$. No smears for removable activity were collected because surfaces were outdoors and cleaned of potential removable contamination before being surveyed. Data and locations are presented in Appendix D.

Measurements to detect surface activity levels on hard surfaces encountered during remediation (i.e., pipes, foundations) were made on either a systematic or biased basis at random locations, according to IVC procedure TE-026 (ORNL 1993). One-minute counts collected with pancake detectors coupled to ratemeter-scalars were then converted to dpm and compared with guidelines. As a qualitative measure, static measurements were taken at random grid-point intersections and soil sample locations in the Treasure Island area to screen for potential yellow cake contamination.

\subsection{Soil Samples}

Soil samples were collected from a total of 183 verification areas $\leq 100 \mathrm{~m}^{2}$. Two areas (R499 and V502) were sampled over areas larger than $100 \mathrm{~m}^{2}$. A total of 354 samples was analyzed for ${ }^{226} \mathrm{Ra}, 271$ analyzed for ${ }^{230} \mathrm{Th}$, and 251 for ${ }^{\text {tot }} \mathrm{U}$. Soil sample data are summarized in Table 3.2 and presented in Appendix E.

Results of the soil sample analyses show that the site has been effectively remediated and is in compliance with regulatory requirements for radionuclides in soil.

Sample locations were noted on fieldsheets and maps and in project logbooks. All the samples collected by the IVC during the IV of the facility were considered to be subsurface samples, because they were obtained from a depth of $15 \mathrm{~cm}$ or greater. All sampling activities followed strict chain-of-custody procedures as outlined in the IVC procedure TE-034 (ORNL 1993).

Sampling was conducted by collecting nine systematically-located plugs from each $100-\mathrm{m}^{2}$ $\mathrm{V}$-area and compositing the plugs into one sample. The sample collection methodology was adopted from UMTRAP and is described in IVC procedure TE-030 (ORNL 1993). Also described in this procedure is the methodology for calculating the net estimated area-weighted average (NEAWA) for soil activity. The protocol is designed to show compliance for average levels of residual radioactivity in a given $100-\mathrm{m}^{2}$ area. Although the FUSRAP/SFMP guidelines and DOE Order 5400.5 both have a requirement for demonstrating compliance with a hot-spot criteria (U.S. DOE 1987, 1990a), the UMTRAP standard does not. However, the sampling protocol changed as the project progressed, due to many factors, including the presence of groundwater, disequilibrium of ${ }^{226} \mathrm{Ra}$ and ${ }^{230} \mathrm{Th}$ in the IVC samples, lack of characterization data for yellow cake, and the introduction of the large-area protocol by the RAC.

The UMTRAP soil sampling protocol was acceptable for GJPORAP in areas where there was good correlation between ${ }^{226} \mathrm{Ra}$ and ${ }^{230} \mathrm{Th}$. In areas where the correlation was suspect (i.e., contaminants were below the water table and in the landfill area) or where uranium was a 
Table 3.2 Summary of soil sample analyses

\begin{tabular}{|c|c|c|c|c|c|c|}
\hline \multirow[b]{2}{*}{$\begin{array}{l}\text { Analytical } \\
\text { categories }\end{array}$} & \multicolumn{2}{|c|}{${ }^{226} \mathrm{Ra}$ concentration, $\mathrm{pCi} / \mathrm{g}$} & \multicolumn{2}{|c|}{${ }^{230} \mathrm{Th}$ concentration, $\mathrm{pCi} / \mathrm{g}$} & \multicolumn{2}{|c|}{ Tot $\mathrm{U}$ concentration, $\mathrm{pCi} / \mathrm{g}$} \\
\hline & $\begin{array}{c}100-\mathrm{m}^{2} \\
\text { composite }^{a}\end{array}$ & $\begin{array}{c}100 \mathrm{~m}^{2} \\
\text { averaged } \\
\text { arithmetically }\end{array}$ & $\begin{array}{c}100-\mathrm{m}^{2} \\
\text { composite }^{a}\end{array}$ & $\begin{array}{c}100 \mathrm{~m}^{2} \\
\text { averaged } \\
\text { arithmetically }\end{array}$ & $\begin{array}{c}100-\mathrm{m}^{2} \\
\text { composite }\end{array}$ & $\begin{array}{c}100 \mathrm{~m}^{2} \\
\text { averaged } \\
\text { arithmetically }\end{array}$ \\
\hline $\begin{array}{l}\text { Number of soil } \\
\text { samples }\end{array}$ & 354 & 59 & 271 & 42 & 251 & 40 \\
\hline Minimum & 0.54 & 0.90 & 0.00 & 0.27 & 0.19 & 1.28 \\
\hline Maximum & 34.25 & 4.32 & 35.10 & 7.20 & 82.42 & 33.38 \\
\hline Average & 2.22 & 1.83 & 1.66 & 1.56 & 7.62 & 7.41 \\
\hline $\begin{array}{l}\text { Standard } \\
\text { deviation }\end{array}$ & 2.30 & 0.86 & 2.89 & 1.49 & 10.76 & 7.23 \\
\hline Median & 1.63 & 1.49 & 0.76 & 1.11 & 5.60 & 4.46 \\
\hline
\end{tabular}

aSamples consisted of nine systematically located plugs per $100 \mathrm{~m}^{2}$, composited into one sample.

${ }^{6}$ Discrete samples were collected, analyzed individually and averaged arithmetically over $100 \mathrm{~m}^{2}$ to show compliance to hot-spot criteria. 
contaminant of concern, the UMTRAP methodology alone may not have been sufficient to demonstrate compliance. However, because the RAC remediated to as low as reasonably achievable (ALARA) levels, there was no contamination left in place that exceeded the applicable guidelines in remediated V-areas that underwent IV. Therefore, the hot-spot guideline was not invoked. The RAC did leave minimal contamination that required area averaging as described in the closeout report (U.S. DOE 1995). Those areas were sampled appropriately by the RAC to show compliance to the hot-spot guideline.

In areas where the RAC used the LAV procedure (Rust 1994), the IVC sampling methodology was amended. A plug of soil was collected from the HOG of each $100-\mathrm{m}^{2}$ section of the LAV area. Those plugs were composited into one HOG sample. These samples were collected for comparison to the RAC's sampling results, although the comparison was complicated by differences in methodologies used by the RAC and IVC (the RAC blended the cobbles and fines; IVC did not).

In addition to the HOG samples, systematic samples were collected by the IVC from approximately half the $100-\mathrm{m}^{2}$ segments in the LAV areas. Those samples followed the UMTRAP protocol previously described. The IVC believes that the LAV protocol provides insufficient data, because it could not be used to show comparison to the requirements in DOE Order 5400.5. To meet these requirements, the IVC increased the frequency of independent sampling from approximately $10 \%$ to $50 \%$. The LAV protocol is further discussed in Sect. 3.9 of this report.

The IVC sampling methodology was also amended for the Treasure Island landfill area, where uranium was a contaminant of concern. The soil moisture and attenuation factors increased the minimum detectable concentration of the instrumentation in finding potential hot spots of uranium. In this area, four systematically-located samples were collected from each $100-\mathrm{m}^{2}$ area. The samples were analyzed individually and the results were averaged arithmetically. In addition to demonstrating compliance with the average standard, this methodology provided reasonable assurance that a round hot spot with an area of $25 \mathrm{~m}^{2}$ would be detected 95\% of the time (Davidson 1995).

All the samples collected by the IVC were dried, crushed, and blended in accordance with IVC procedures TE- 035 and TE- 036 in the IVC sample preparation laboratory. After the samples were prepared, approximately $5 \%$ were split, packaged, and shipped to Oak Ridge, Tennessee for radionuclide analysis by alpha spectroscopy for ${ }^{\text {tor }} \mathrm{U}$, and by inductively coupled plasma/mass spectroscopy analysis for ${ }^{230} \mathrm{Th}$. All samples were analyzed by the IVC using gamma spectroscopy for ${ }^{226} \mathrm{Ra},{ }^{232} \mathrm{Th}$, and ${ }^{40} \mathrm{~K}$. The samples analyzed in GJ for ${ }^{226} \mathrm{Ra}$ analysis were allowed to in-grow for 28 days to establish an equilibrium of radon daughters. Split samples from approximately $12 \%$ of the samples collected by the RAC were also requested from the RAC archive for analysis by the IVC.

Comparison of results from split samples provided by the RAC and analyzed by IVC show compliance with the guidelines and are presented in Appendix F. A statistical comparison 
(a nonparametric sign test and Wilcoxon signed rank test) of the GJPORAP soil sample results from the ORNL laboratory and the Geotech laboratory was performed. The comparison showed a-difference between the results of the analyses of the laboratories. However, quality assurance/quality control checks demonstrated that both laboratories were in compliance. The analytical results for both sets of data are below the applicable soil contamination guidelines.

\subsection{USRADS ${ }^{\circledR}$ Survey}

In addition to gamma radiation scans conducted in excavations for IV purposes, a complete gamma radiation scan of the facility was conducted by the IVC by using the Ultrasonic Ranging and Data System (USRADS ${ }^{3}$ ) method to document the final condition of the outdoor portions of the facility. USRADS is a patented, computerized data acquisition system developed by ORNL to correlate the radiological surveyor's location with instantaneous radiation data taken during a walk-on survey (Berven et al. 1991).

From the period beginning June 1991 through January 1996, ORNL performed gamma radiation exposure rate surveys using USRADS. When the excavation and backfilling stages were complete, USRADS was used to verify the adequacy of remedial action performed at GJPO. The USRADS survey was designed to detect uranium mill tailings and was not sensitive enough to detect uranium yellow cake. The remediation process at GJPO is still in progress, particularly the remediation of buildings. Some surveyed areas have since been affected by site operations, and some buildings were removed or scheduled for demolition. These areas are noted in the survey discussion and will be resurveyed when the remediation and restoration at GJPO is complete.

ORNL developed USRADS as an advanced field survey technique for characterizing UMTRAP vicinity properties. The system patent currently belongs to Chemrad, Inc., Knoxville, Tennessee. The USRADS survey is advantageous over conventional methods for a number of reasons. First, survey coverage was instantly verified, allowing the survey team to confirm complete survey coverage. Second, the data were analyzed on-site, enabling the team to identify areas of elevated gamma radiation exposure rates and verify the source of the readings. Finally, USRADS provided both high-quality graphical illustrations for permanent documentation and data storage that can be easily retrieved for verification and certification purposes.

The USRADS survey showed gamma exposure rates reduced to background levels over the areas assessed as contaminated, indicating the successful removal of uranium mill tailings. Fourteen areas with elevated gamma exposure rate readings were found during the walk-on survey, many attributed to site operations not within the scope of GJPORAP. Other elevated gamma exposure rates are attributed to buildings, and will be addressed during the current phase of the project. These areas are presented on Fig. 3.1 and explained as follows: 


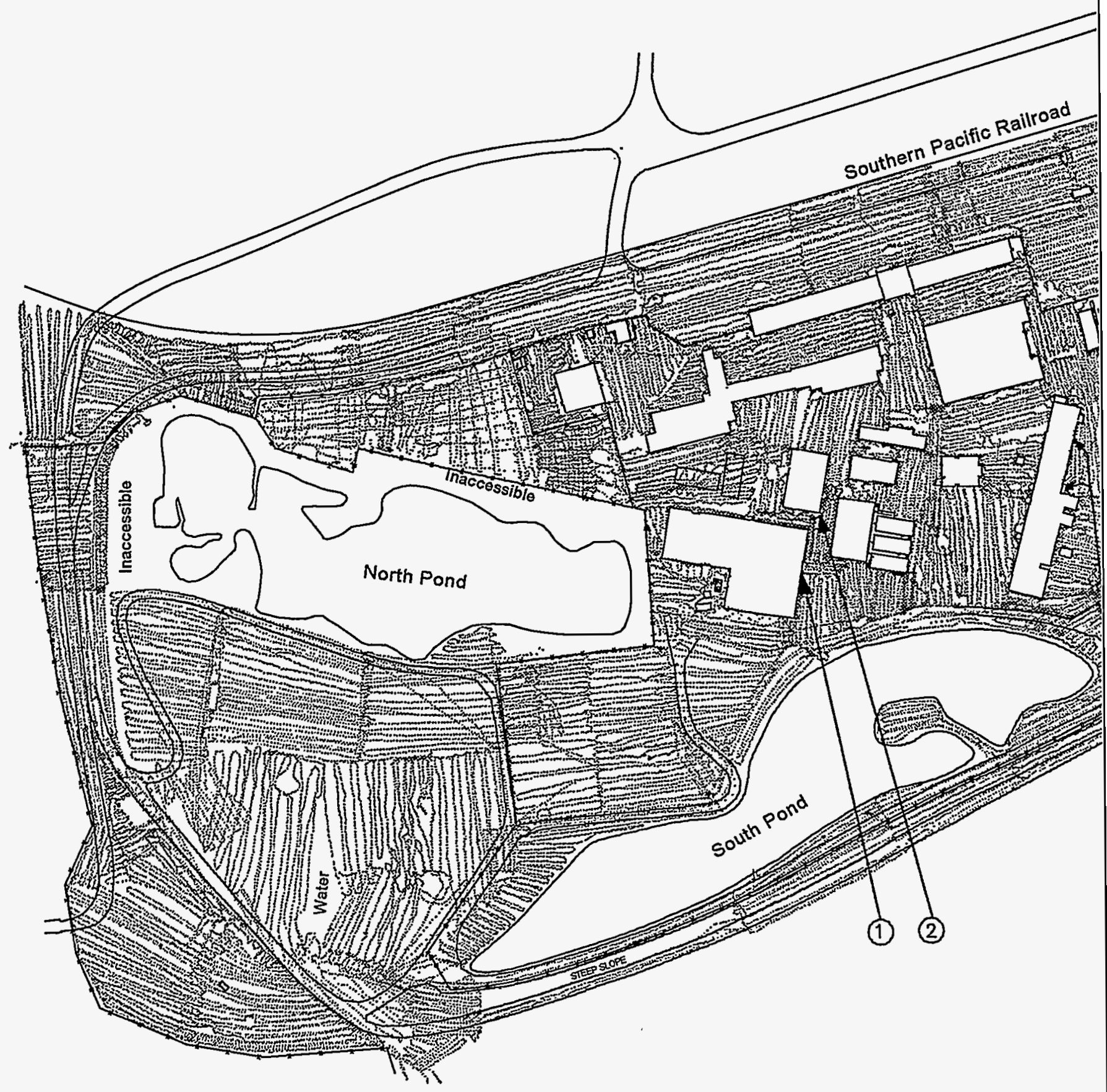

Fig. 3.1. Track map of GJPO USRADS gamma exposure rate survey. 


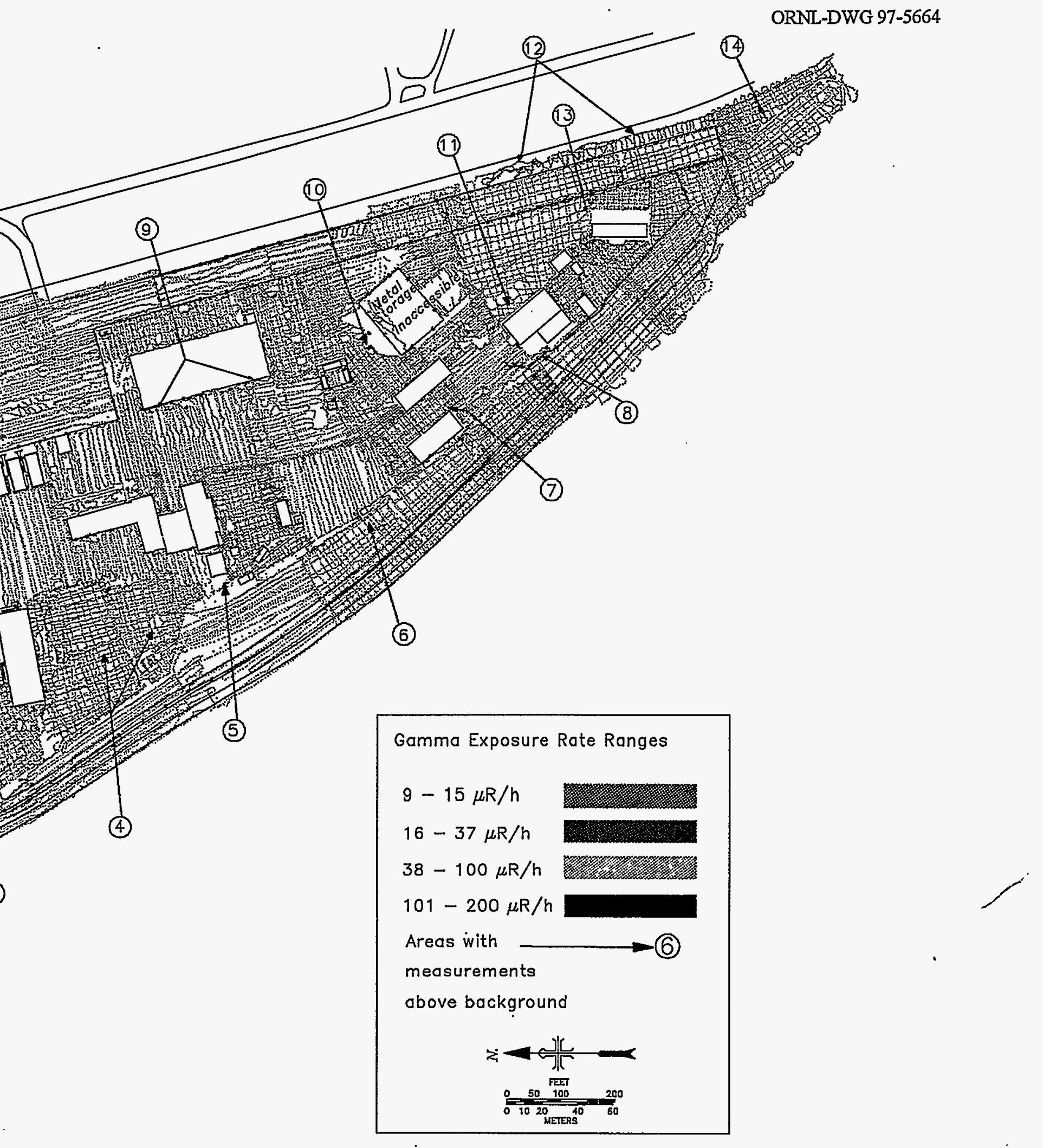


Area 1 The south wall of Building 7 has elevated gamma exposure rate readings ranging from 15 to $20 \mu \mathrm{R} / \mathrm{h}$. The sources of the readings are radiologic samples stored inside the building.

Area 2 The southwest corner of Building 56 has elevated gamma exposure rate readings ranging from 15 to $50 \mu \mathrm{R} / \mathrm{h}$. The source of these readings is the ORNL radiologic sample storage area. These readings vary during the year, depending upon the activity of the stored samples.

Area 3 The south wall of Building 30 has elevated gamma exposure rate readings ranging from 15 to $17 \mu \mathrm{R} / \mathrm{h}$. The source of these readings may be naturally-occurring radiation, from bricks in the wall, or shine from radiologic sources inside the building.

Area 4 At the time of the survey in October 1993, the Test Pit Area had elevated gamma exposure rate readings ranging from 15 to $150 \mu \mathrm{R} / \mathrm{h}$. The Test Pit Area has since been changed, some radioactive sources have been removed, and some pits have been reconfigured for different projects.

Area 5 At the time of the survey, a geophysical logging truck with a radiologic source inside was parked at this location; the truck is no longer there. .

Area 6 At the time of the survey in July 1993 Building 36 was located here. The building was used for the storage of radiologic material. The building has since been removed and the area remediated to background levels. This area has been resurveyed. The results will be presented in a future report.

Area 7 The east wall of Building 32 had elevated gamma exposure rates ranging from 15 to $16 \mu \mathrm{R} / \mathrm{h}$. The source of the readings was emanation from a radiologic source stored inside the building.

Area 8 The northwest corner of Building 33 is used for the storage of radiologic material. Elevated gamma exposure rates ranged from 15 to $185 \mu \mathrm{R} / \mathrm{h}$ at the time of the survey in July 1993. Building 33 is scheduled for demolition in FY 1997. The area will be resurveyed after remediation and restoration.

Area 9 Spotty areas along the west wall and the southwest corner of Building 28 have elevated gamma exposure rates ranging from 15 to $20 \mu \mathrm{R} / \mathrm{h}$. The source of the readings may be in the building materials. Portions of the interior of the building have since been remediated.

Area 10 Radioactive material is stored in this area as part of site operations. Elevated gamma exposure rates ranging from 15 to $30 \mu \mathrm{R} / \mathrm{h}$ were detected on material stored in this area. The type, quantity, and activity associated with these materials changes over 
time. The areas of soil that were accessible in this area showed background gamma exposure rates. This area is controlled by site activities and is not part of GJPORAP.

Area 11 At the time of the survey in July 1993 radioactive material was stored inside Building 33. Building 33 has since been designated as the repository for the PCB-contaminated mill tailings. This building is scheduled for demolition. A new USRADS survey will be performed after remediation and restoration are complete.

Area 12 Elevated gamma exposure rates ranging from 15 to $17 \mu \mathrm{R} / \mathrm{h}$ were detected along the base of the berm below the railroad. At the time of the survey (September 1991) emanation from Building 35 was also detected. Building 35 has since been partially remediated, and the area below the railroad has been graded. At the time of this report the gamma exposure rate in this area is $12 \mu \mathrm{R} / \mathrm{h}$, with spotty $15 \mu \mathrm{R} / \mathrm{h}$ readings. No visible signs of tailings were present. This area was below the NEAWA action level for collection of soil samples. The area will be resurveyed when Building 35 has been demolished and the area restored.

Area 13 At the time of the survey in November 1991 Building 35 was slightly contaminated with radioactive material. The building has since been partially remediated and is scheduled for demolition in FY 1997. It was used to store drums of radiological samples that were contributing to the emanation. Those samples will be removed prior to demolition of the building. The area will be resurveyed when remediation and restoration are complete.

Area 14 Elevated gamma exposure rates ranging from 15 to $16 \mu \mathrm{R} / \mathrm{h}$ were detected in the ground surface in this area. No visible signs of tailings were present. This area was below the NEAWA action level for collection of soil samples.

\subsection{Other Measurements and Samples}

The IVC collected soil samples and measurements to supplement characterization data for the Treasure Island landfill. These samples were analyzed by a commercial laboratory. The purpose of the sampling effort was to determine if hazardous substances were in the soil. The IVC was concerned that the previous screening and sampling efforts were incomplete. Therefore, four soil samples were collected at a depth of $4 \mathrm{ft}(1.2 \mathrm{~m})$ and analyzed for volatile, semivolatile, and inorganic constituents (ORNL 1994).

Because the slope of some excavations did not conform to Occupational Safety and Health Act (OSHA) specifications, due to inadequate space and groundwater intrusion, safe work permits written for these excavations did not allow workers to enter the excavations. In those situations, excavation control was guided by a modified gamma radiation scintillometer that allowed remote operation (Field Procedure 5.0 in RUST, undated). In addition, soil samples were obtained by the RAC from the backhoe bucket (Rust 1993a). 
Remediation in the Treasure Island area were performed in increments or lifts of $0.30 \mathrm{~m}$ (12 in.). Trash and debris in the landfill were removed as required for radiological remediation and IV. Individual items suspected of being hazardous were segregated and placed in appropriate storage containers by the RAC (Rust 1993a).

In addition to radiological screening, the Treasure Island area was monitored for potentially hazardous substances. The remediation was monitored visually by the RAC to identify any staining and discoloration, the presence of free liquids, sludges, or source materials, or varied soil textures that could have indicated hazardous substances. Each lift was field-screened by the RAC for potential hazardous substances using PIDs for the detection of organic vapors and meters for detection of combustible gases. Identified deposits of hazardous or commingled waste found in the Treasure Island area were individually managed on a case-by-case basis, due to their variability (Rust 1993a). The IVC also monitored activities in the Treasure Island area, with input from the RAC and Colorado Department of Health and Environment (CDH\&E) staff when possible. Five soil samples were collected and analyzed for metals, PCBs/pesticides, VOCs, SVOCs, and total petroleum hydrocarbons (TPH) from areas of suspected contamination by the IVC.

Because portions of Treasure Island were remediated based only on radiological measurements to a depth of only $2 \mathrm{ft}(0.61 \mathrm{~m})$, a post-remediation trenching effort was undertaken by the IVC in these areas to further verify that no potentially hazardous material remained below $2 \mathrm{ft}(0.61 \mathrm{~m})$. Another concern was the lack of quantifiable, laboratory-quality data to support the qualitative field screening data for the certification docket. The IVC was concerned that potentially hazardous material could be buried in the interval between $2 \mathrm{ft}$ $(0.61 \mathrm{~m})$ and the top of the water table. Therefore, the IVC performed investigative trenching to ascertain that there was no nonradiological material between the bottom of the excavation and groundwater. Additionally, the IVC provided DOE with a limited number of samples.

The first four soil samples collected from the Treasure Island area are identified as EPA samples 1001 to 1004 , and on Fig. 3.2 as ORNL samples 001 to 004 . These samples were collected to establish a baseline for potential soil contaminants in the Treasure Island area. Results showed no contaminants above regulatory guidelines. During the period between sampling and receipt of the analytical data, the areas from which the samples were collected and buffer zones $20 \mathrm{ft}$ in diameter from the sample locations were not disturbed by excavation activities. This procedure ensured that the RAC did not remove any potential contaminants to the Cheney repository before analytical results were received. This procedure was followed for all of the IVC samples taken in the Treasure Island area.

The fifth soil sample, identified as EPA 1005 and ORNL-005, was collected from an area of soil staining about $5 \mathrm{ft}$ below the ground surface, just below an orange-brown oxidized zone of debris material in an exposed trench. This sample was analyzed by the toxicity characteristic leaching procedure (TCLP) for metals only, because no indication, such as soil staining or elevated PID measurements, of organic contamination of the soil was noted. No inorganic contamination above regulatory guidelines was noted in the analytical results for sample ORNL-005. 
ORNL-DWG 97-5665
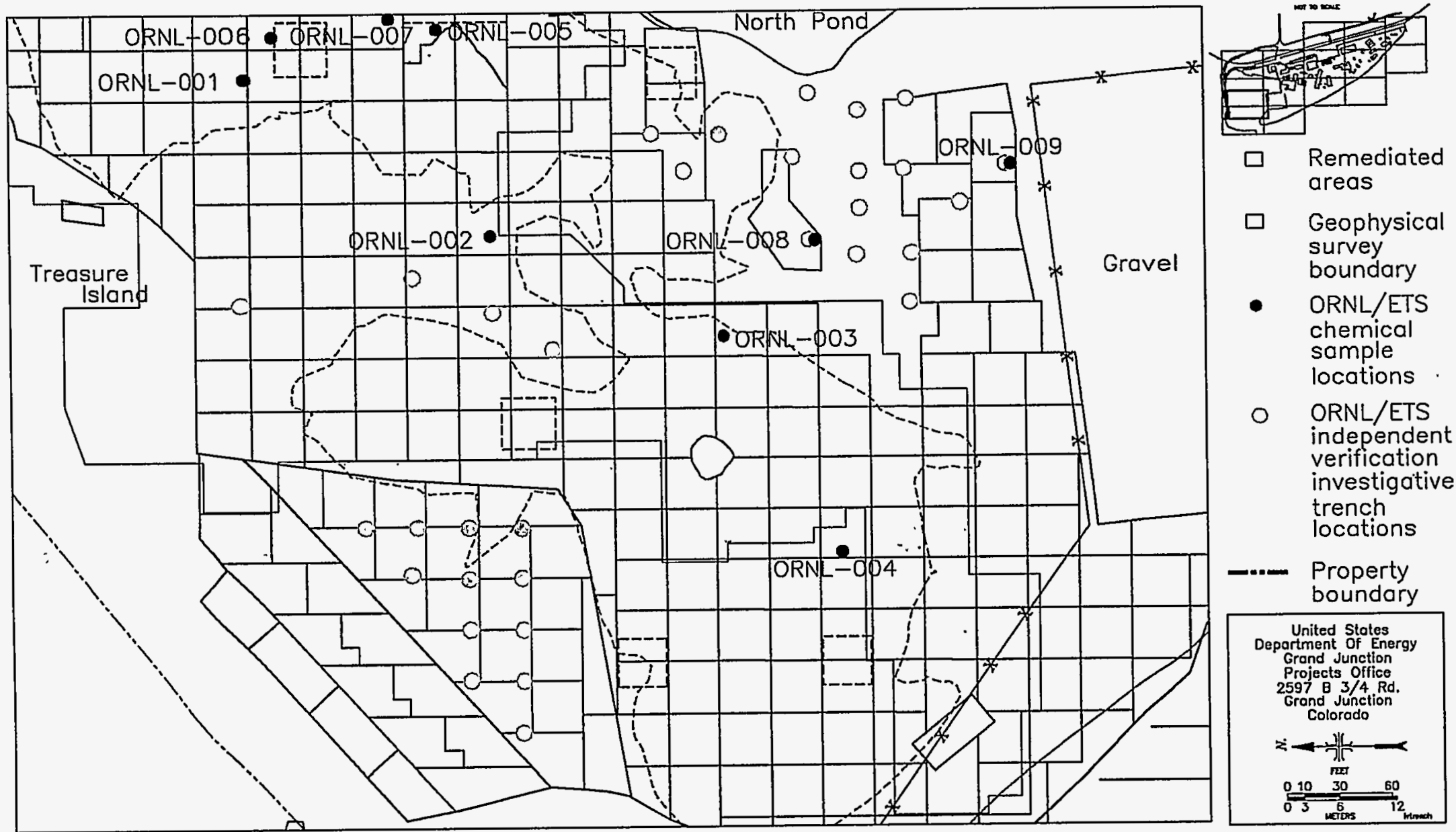

Fig. 3.2. IVC IV investigative trenches and chemical sampling locations. 
EPA sample 1006 (ORNL-006) was collected from an area approximately $30 \mathrm{ft}(9.3 \mathrm{~m})$ northnortheast of sample ORNL-001 (Fig. 3.2). A hydrocarbon odor was noted in this area, in addition to obvious staining. The area showed elevated gamma scintillometer readings, and read about $7 \mathrm{ppm}$ on the PID used by IVC personnel. Therefore, a sample was collected and analyzed with the on-site gas chromatograph (GC) in an attempt to determine whether or not additional samples should be collected for quantitative analysis at the off-site laboratory. Results of the GC analysis suggested that this area had very low levels of petroleum contamination and, according to guidance, could be released to the Cheney repository.

EPA sample 1008 (ORNL-007) was collected from an area of soil staining and petroleum odors exposed by the backhoe during removal activities in the area (Fig. 3.2). Readings on the PID were between 15 and $20 \mathrm{ppm}$ near the stained area. The IVC collected a grab sample from the soil-stained area of approximately $30 \mathrm{ft}(9.3 \mathrm{~m}) \times 20 \mathrm{ft}(6.2 \mathrm{~m})$. This sample was field screened by the on-site GC and also analyzed for VOCs, SVOCs, PCBs/pesticides, and high boiling point hydrocarbons. Analytical results showed no target analytes above regulatory guidelines.

Portions of Treasure Island did not undergo remediation below $2 \mathrm{ft}(0.61 \mathrm{~m})$ from the surface because characterization and excavation control data did not show radiological contamination below that depth. However, historical information suggests $2 \mathrm{ft}(0.61 \mathrm{~m})$ of backfill over the disposal trenches (UNC 1989a). Therefore, the RAC may not have uncovered all waste disposal trenches. To eliminate any doubt of additional waste disposal trenches, the IVC, with cooperation from the RAC, dug 32 small investigative trenches approximately $4 \mathrm{ft}(1.2 \mathrm{~m})$ below the bottom of the remedial excavations with a backhoe. The trenches were inspected visually for indication of waste, screened for gamma and beta activity, and monitored with a PID for potential VOCs. There was no visual indication of additional waste trenches. No elevated radiological readings were noted; however, $\mathrm{PID}$ readings of approximately $4 \mathrm{ppm}$ were noted in Trench 46 at a depth of $3.5 \mathrm{ft}(1.1 \mathrm{~m})$ below the remediated excavation so it was sampled. A sample representative of the downgradient condition was taken from Trench 60 . EPA sample 1010 (ORNL-008 on Fig. 3.2) was taken and used to confirm or deny the presence of VOCs in the Trench 46 area. EPA sample 1011 (ORNL-009) was collected to further document the subsurface condition of the area. Except for ubiquitous laboratory contaminants such as acetone, results of samples 1010 and 1011 yielded no organic or inorganic contaminants above regulatory guidelines. EPA samples 1007 and 1009 were trip blanks for quality control and not representative of field conditions.

\subsection{Radon Flux}

Radon flux measurements at GJPORAP will be conducted by IVC in FY 98. The RAC collects radon data from outdoor locations of the compound on an ongoing basis. The IVC will review the results of the RAC's radon monitoring program. No areas of the facility currently exhibit elevated gamma exposure rates except operational activities (i.e., drum storage, test pits). 


\subsection{Large-Area Verification Protocol}

The LAV protocol was first proposed for use at GJPORAP in 1991 (letter from $\mathrm{H}$. Perry, Geotech, to E. Bray, DOE/GJPO, May 22, 1991). The IVC sent a letter to the RAC with concerns about the procedure (letter from P.V. Egidi, IVC to Jim Aggson, Geotech, September 3, 1991). Another letter expressing concern was sent to DOE/GJPO and DOE/HQ in 1992, when it became apparent that these concerns could not be resolved with the RAC (letter from D.K. Halford, IVC, to M.K. Tucker, DOE/GJPO, February 10, 1992). DOE/HQ recommended discontinuance of the procedure in 1993 (letter from D. Mathes, DOE/HQ to M.K. Tucker, DOE/GJPO, July 9, 1993). However, the RAC had used the procedure during the intervening time period.

The LAV protocol can be found in the RAC's Field Assessments Procedures Manual (Rust, undated). The protocol as originally implemented utilized a gamma screening level that was not conservative enough for guiding excavation of ${ }^{230} \mathrm{Th}$, due to disequilibrium with ${ }^{226} \mathrm{Ra}$. Seven of the LAV areas had to be remediated a second time before the ${ }^{230} \mathrm{Th}$ levels were below the soil standard. Therefore, the RAC decreased the gamma screening level so that the radium in soil concentrations were near background levels. Consequently, this resulted in ${ }^{230} \mathrm{Th}$ concentrations that were below guidelines. Another IVC concern was the use of the LAV protocol in conjunction with a procedure which allowed for sampling of large cobbles along with finer material. The RAC was remediating the river alluvium where cobbles are mixed with fines. The sampling method used was to sample cobbles with the fines, crush the cobbles, mix with the fines, and thereby dilute the activity of the sample. Thus the soil standard was met. The Remedial Investigation groundwater model assumes that the source will be completely removed, and the remaining groundwater contamination will be flushed by the ambient groundwater. Since soils in contact with groundwater will contain high contaminant concentrations, larger amounts can be dissolved into the groundwater. Consequently, the basic assumption of the contaminant transport model is invalidated, and cleansing of groundwater will not occur as outlined in the Record of Decision. The IVC believed that the synergistic effects of using the two procedures could yield data not representative of actual site conditions.

Samples collected from areas where LAV was used (Fig. 3.3) indicate that the remediation was effective. Remediated areas verified by the RAC using the LAV protocol should be considered for unrestricted release by DOE, based on results of the risk analysis (Rust 1994) and IVC samples. It appears that the authorized limits established for the site have been met; however, the documentation traditionally assembled (data based on $100-\mathrm{m}^{2}$ areas) is not complete, due to the use of the LAV procedure. The IVC reviewed the pathway analysis and statistical data presented by Rust (1994) and agreed that the LAV areas at GJPO pose no threat to public health or the environment (Appendix G).

Instead of resampling all the areas subjected to the LAV protocol, pathway analysis and risk assessments were conducted by the RAC using data from both the RAC and the IVC. The results of that effort are described in a separate document (Rust 1994). 

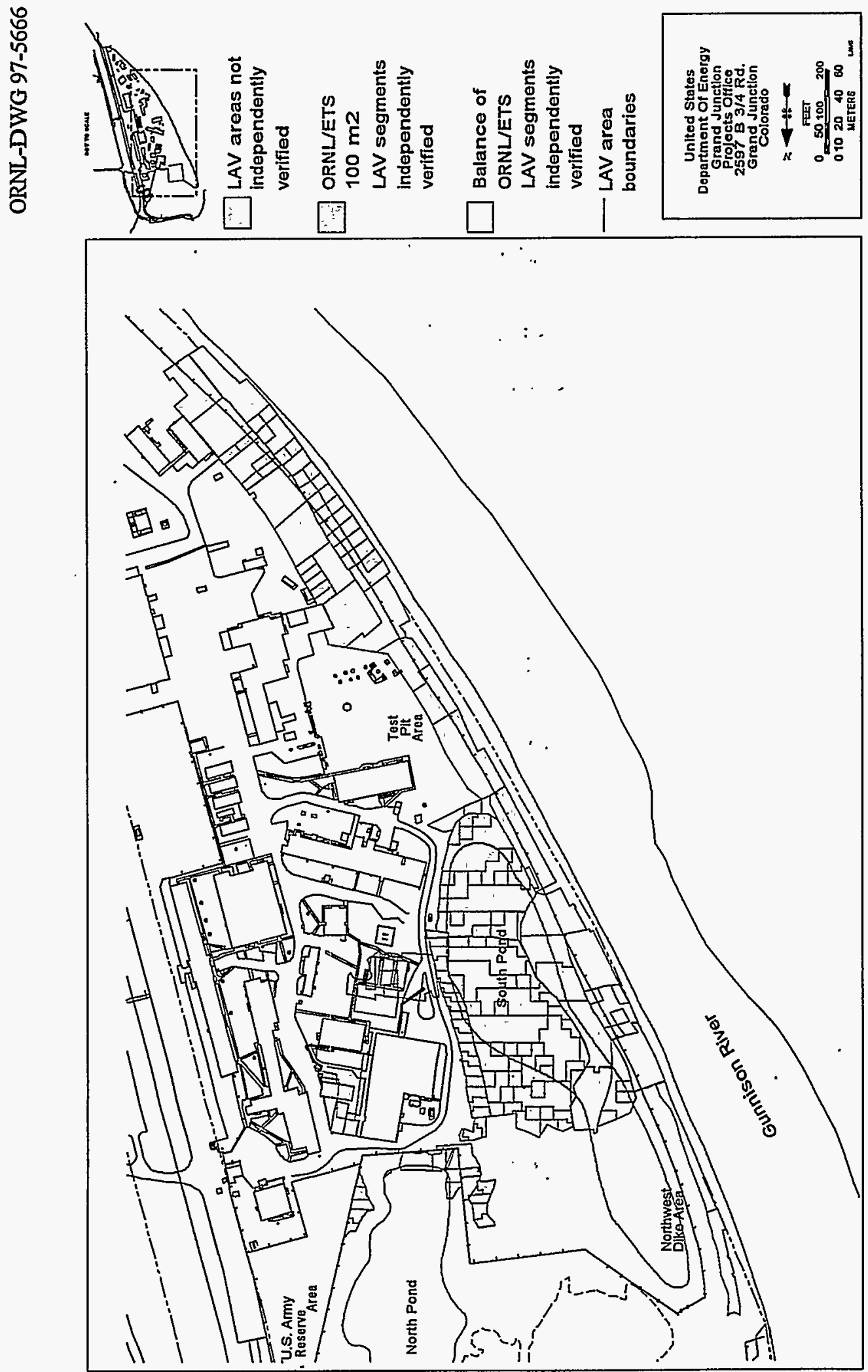

䓪 


\subsection{Sample Archive}

An archive of samples representative of the area that has been remediated to date has been established by IVC consisting of split samples obtained from the RAC as well as samples collected by IVC. The archive will have additional samples added to it as the project continues. The final archive will contain representative samples documenting site conditions as outlined in the FUSRAP Certification and Verification protocol (U.S. DOE 1990a). 


\subsection{DISCUSSIONS AND CONCLUSIONS}

In order to document the adequacy of remedial actions, the IVC performed IV on the exterior areas of the GJPO. IV activities included document reviews, independent measurements, sampling, and confirmatory laboratory analyses. Field activities were performed from Fall 1989 through Fall 1994. The IV surveys confirmed that the remedial action performed on areas assessed as contaminated reduced contaminant levels well below applicable guidelines so that the public and environment are thereby protected. Additional data for release of the remainder of the facility (including areas not completely assessed) will be presented in subsequent reports. A statement of verification has been issued by the IVC for exterior areas of GJPO (Appendix A).

Three main focus areas, as outlined in the FUSRAP protocol (U.S. DOE 1990a), were reviewed by the IVC.

- Accuracy and completeness of field measurements:

Quality control and quality assurance were maintained for the duration of the project. The RAC generated data to demonstrate cleanup of radiologic contamination using gamma exposure rates, soil sample results, and pathway analysis. Deficiencies in data collection for surface activity, ${ }^{230} \mathrm{Th}$, and ${ }^{\mathrm{Tor}} \mathrm{U}$ were noted by the IVC and subsequently addressed by the RAC. Screening and sampling of potentially hazardous substances was conducted where appropriate. Complete characterization of potentially hazardous substances was limited by funding problems, but sampling upon completion of remedial action indicates no hazardous substances remain.

- Credibility of followed procedures:

Additional sampling and analysis were conducted to demonstrate compliance for cleanup of ${ }^{230} \mathrm{Th}$ and with the site-specific guideline for uranium. Traditional construction techniques worked well on the remediation of the exterior areas of the facility.

Procedures for measuring alpha and beta surface contamination were adopted by the RAC after the IVC found contamination on concrete during an IV. Prior to this time the RAC was using gamma scintillation detectors for all screening.

The LAV procedure was not appropriate as originally carried out at GJPORAP. The procedure could not demonstrate compliance with the $100-\mathrm{m}^{2}$ average guideline and relied on a gamma exposure rate action level that was not conservative enough to guide the remediation effectively. The procedure was 
stopped at GJPORAP after DOE/HQ reviewed the procedure and directed that it no longer be used. Subsequent pathway analysis demonstrates that there is minimal possibility of any contamination remaining that could result in a dose to a receptor (Rust 1994).

- Accuracy and adequacy of supporting documentation describing the remediation:

Final documentation of the cleanup of outdoor areas provided by the RAC consists of two main reports. They are the Justification for Certifying 47 Large-Area Verification Areas at the Grand Junction Projects Office (Rust 1994), and the Final Report of the Decontamination and Decommissioning of the Exterior Land Areas at the Grand Junction Projects Office Facility (Rust 1995). With other referenced documents, the RAC shows that all exterior areas assessed as contaminated have been remediated according to the soil cleanup standards and can be released for unrestricted use. The potential for isolated deposits of uranium contamination still exists under asphalt because the characterization was not designed to identify them. The IVC has recommended that this be addressed in later phases of the project.

Review of contents of the administrative record show that all pertinent records documenting the basis for the cleanup of the outdoor areas required for the certification of the site are available. The ROD may need to be addressed because the scope and complexity of the project have changed due to the addition of buildings, substantial additional tailings and discovery of commingled hazardous waste (PCBs). All pertinent data documenting the cleanup of the facility are available for the certification docket.

\subsection{Lessons Learned}

Lessons learned by the IVC during this project that would enhance the success of a future $\mathrm{D} \& \mathrm{D}$ project include the following.

1. The IVC should be assigned at the beginning of the project, in order to provide input to planning documents in the draft stage and help identify any potential problems.

If an IVC had been involved earlier, it would have been able to identify that the characterization was incomplete because it followed UMTRA protocols that did not meet project needs including data for ${ }^{230} \mathrm{Th}$ and uranium. Also, the authorized limits for these radionuclides and requirements of FUSRAP/SFMP and RCRA could have been identified as appropriate for addition to the list of applicable guidelines and regulations. The estimated volume of contamination would have been more accurate if the additional radionuclides had been added to the scope of 
the characterization. A well-scoped characterization would have resulted in cost savings because more accurate volume estimates would have prevented contracts from having to be canceled due to contractual changes.

An IVC could also have recommended a characterization to identify all potentially contaminated buildings at the beginning of the project. Because this was not performed, the scope increased from 3 to 15 buildings, with associated delays to the schedule and funding.

2. A timely transfer of funds is critical to maintaining the continuity of IV tasks.

Delays in transfer of funds to ORNL/ETS for IVC activities resulted in suspension of IV work, although remedial activities continued. After the funding issue was resolved, the IVC reviewed the work already performed and questioned some of the activities.

3. If the project requirements change, possible impacts to the project schedule and budget need to be identified and addressed quickly.

This project was impacted by the implementation of the FUSRAP/SFMP guidelines (U.S. DOE 1987), the requirements of which were not reflected in the RI/FS and ROD. Characterization and planning for remediation of outdoor areas at GJPORAP were based on ${ }^{26} \mathrm{Ra}$ concentrations found in the UMTRA standard (40 CFR 192) only. When additional project release requirements were implemented, the RAC was not able to obtain funds for a characterization that would identify small hot spots or disequilibrium. Additionally, if funds had been directed for a characterization of the Treasure Island landfill when requested by the RAC, significant delays in the project would have been avoided.

4. A remedial action and verification plan should be considered during the engineering and planning portions of the project.

The RAC did not distribute a verification sampling and analysis plan until Phase IVA. This made it difficult for the IVC to identify deficiencies before remediation was underway. If the sampling and analysis plan had been in place and reviewed by the IVC before the work began, the IVC could have pointed out that the use of a LAV protocol at GJPO was inappropriate, because it could not be used to show compliance with the guidelines. However, because it was used until DOE/HQ directed it be discontinued, it required that pathway analysis and risk assessments be performed to justify the certification and release of areas where the LAV procedure was used. The pathways analysis and statistical data presented by the RAC showed that the LAV areas pose no threat to public health or the environment. This justification was considered site-specific, and not as justification 
for future use of the LAV at GJPORAP or at any other site.

5. Improved understanding of the requirements for storage and archival of samples must be acquired. It was difficult for the IVC to obtain enough samples for statistical evaluation of split-sample analysis. Comparison of IVC and RAC split sample results was complicated by various factors, including:

- loss of IVC funding for a portion of the project when no IVC samples were collected,

- RAC sample collection and preparation methodologies changed over the course of the project,

- the RAC disposed of samples from early phases of the project before splits and the archive were assembled, thus limiting the number of samples available for split analysis,

- many samples requested could not be located by the RAC because of storage and logistical problems, and

- split samples were chosen on the basis of representation of the site for archival purposes; direct comparison to ORNL/ETS results was secondary.

6. To accurately reflect site conditions, proper instrumentation needs to be selected based on contaminants of concern and detection sensitivity.

With the introduction of surface activity guidelines, the RAC had to use radiation detection instruments in addition to the gamma scintillometer. This was addressed and corrected early in Phase 1A.

7. Coordination and communication between the RAC and IVC are essential to project success.

The RAC provided this coordination especially during the remediation of the landfill area when both the RAC and IVC data were essential for the certification docket, and it was important to prevent delays to the project schedule. Also, because the RAC prepared a sampling and analysis plan for Phase IVA early, the IVC was able to provide comments before the start of work in that phase. 


\subsection{REFERENCES}

Berven, B. A., C. A. Little, and M. S. Blair. 1991. A method to automate radiologic surveys: The Ultrasonic Ranging and Data System. Health Physics, 60(3):367-373.

Geotech 1992. Grand Jinction Projects Office Remedial Action Project Health and Safety Plan. P-GJPO-144, Rev. 5. Chem-Nuclear Geotech, Grand Junction, Colorado.

Curtis, Michael R, D.J. Jin, RR Appel, D.M. Naski. 1989. Trenching Investigation Report Treasure Island Area for the U.S. Department of Energy Grand Junction (Colorado) Projects Office Facility. UNC Geotech, Grand Junction, Colorado.

Davidson, J. 1995. ELIPGRID-PC: Upgraded Version. ORNL/TM-13103. Oak Ridge National Laboratory, Oak Ridge, Tennessee.

Henwood, P., and C. Ridolfi. 1986. Radiologic Characterization of the Department of Energy Grand Junction Projects Office. GJ-41. Bendix Field Engineering Corporation, U. S. Department of Energy, Grand Junction Projects Office, Grand Junction, Colorado.

Jin, Doo Jung, J.E. Bennett, R.D. Dayvault, J.W. Dickerson, and K.D. Mitchell. 1988. Grand Junction Projects Office Geophysical Survey of the Treasure Island Area. UNC Geotech, Grand Junction, Colorado.

Myrick and Berven, 1981. Determination of Radionuclide Concentrations in Surface Soils and External Gamma Exposure Rates in the United States. Oak Ridge National Laboratory, Oak Ridge, Tennessee.

ORNL. 1993. Environmental Technology Section (Formerly Pollutant Assessments Group) Procedures Marmal. ORNL-6645/R2. Oak Ridge National Laboratory, Grand Junction, Colorado.

ORNL. 1994. Addendum to Work Plan for Independent Verification of the Grand Junction Projects Office Remedial Action Project, Phase IVA. Oak Ridge National Laboratory, Grand Junction, Colorado. May, 1994.

Robison, Wally. 1990. Trench Investigation in Treasure Island, Memorandum. UNC Geotech, Grand Junction, Colorado.

Rust, undated. Field Assessments Procedures Manual. U.S. Department of Energy, Grand Junction Projects Office, Grand Junction, Colorado. 
Rust 1993a. Grand Junction Projects Office Remedial Action Project Radiological Sampling and Verification Plan Phase IVA. P-GJPO-148. Rust Geotech, Grand Junction, Colorado.

Rust 1993b. Final Report and Recommendation, GJPORAP Supplemental Radiological Characterization, Treasure Island and Black Bridge Park. Rust Geotech, Grand Junction, Colorado.

Rust 1993c. Construction Management Work Plan for the "Treasure Island" Area of the Grand Junction (Colorado) Projects Office Facility Remedial Action Project. Rust Geotech, Grand Junction, Colorado.

Rust 1994. Justification for Certifying 47 Large-Area Verification Areas at the Grand Junction Projects Office. GJ-GJPO-94-1. Rust Geotech, Grand Junction, Colorado.

Rust 1995. Final Report of the Decontamination and Decommissioning of the Exterior Land Areas at the Grand Junction Projects Office Facility. Rust Geotech, Grand Junction, Colorado.

UNC. 1989a. Final Remedial Investigation/Feasibility Study for the U.S. Department of Energy Grand Junction (Colorado) Projects Office Facility. DOE/ID/12584-16, UNC/GJ-GRAP-1. U.S. Department of Energy, Surplus Facilities Management Program, Grand Junction, Colorado.

UNC. 1989b. Exterior Beta-Gamma and Alpha Characterization of the U. S. Department of Energy Projects Office Facility. UNC Geotech, Grand Junction, Colorado.

UNC. 1990. Radiological Assessment for Construction Phase IB of the Department of Energy Grand Junction Projects Office. UNC Geotech, Grand Junction, Colorado.

U.S. DOE. 1987. U.S. Department of Energy Guidelines for Residual Radioactive Material at Formerly Utilized Sites Remedial Action Program and Remote Surplus Facilities Management Program Sites. U.S. Department of Energy, Washington, D.C.

U.S. DOE 1990a. Verification and Certification Protocol for the Formerly Utilized Sites Remedial Action Program (FUSRAP) and Decontamination and Decommissioning Program, Division of Eastern Area Programs, Revision 3, Draft. Office of Environmental Restoration, U.S. Department of Energy, Washington, D.C.

U.S. DOE 1990b. Record of Decision for the Grand Junction (Colorado) Projects Office Remedial Action Project. U. S. Department of Energy, Idaho Falls, Idaho. 


\section{$5-3$}

U.S. DOE 1990c. Radiation Protection of the Public and Environment. DOE Order 5400.5. U.S. Department of Energy, Washington, D.C.

U.S. DOE. 1995. Final Report of the Decontamination and Decommissioning of the Exterior Land Areas at the Grand Junction Projects Office Facility. DOE/m/12584-220. GJPO-GJ-13. Rust Geotech, Grand Junction, Colorado. 


\section{APPENDIX A}

STATEMENT OF VERIFICATION FOR THE OUTDOOR AREAS AT THE GRAND JUNCTION PROJECTS OFFICE REMEDIAL ACTION PROJECT, GRAND JUNCTION, COLORADO 


\section{APPENDIX A \\ Statement of Verification for the Outdoor Areas at the Grand Junction Projects Office Remedial Action Project, Grand Junction, Colorado}

An independent verification (IV) of remedial action activities of the outdoor areas at the Grand Junction Projects Office has been accomplished by the Oak Ridge National Laboratory (ORNL) Environmental Technology Section (ETS), the appointed independent verification contractor (IVC). The purpose of the IV was to confirm the site's compliance with applicable U.S. Department of Energy (DOE) guidelines. The IV included document reviews of data provided by the remedial action contractor (RAC). In addition, IV surveys were performed during the remedial action by the IVC.

The IV surveys included visual inspections, gamma and beta-gamma radiation scans, static measurements, and volatile organic compound monitoring. In addition, soil samples were analyzed for chemical and radiological constituents. Split samples were obtained from the RAC and analyzed to confirm compliance with the guidelines. Remediated areas that did not have sufficient data for release and certification have been addressed through pathway analysis and risk assessment; the IVC recommends that these areas also be considered for certification by DOE.

Based on the results of the IV, it can be concluded that the measurements collected from remediated areas at this site are within the established guidelines. ORNL reviewed the RAC data following this remediation and agrees that the remediation was effective in removing the identified sources of contamination. The potential for remaining uranium contaminated areas under asphalt still exists because the original characterization was not designed to find them, and subsequent characterizations were limited. Those areas should be addressed under another phase of the project.

Independent verification for the release of the building and utilities, as well as modeling of the groundwater cleanup, will be presented in future reports; this is a partial verification of the site. Changes in scope which have occurred on the project may necessitate revisitation of the Record of Decision for the project. 
APPENDIX B

\section{ELIPGRID-PC}




\section{APPENDIX B}

\section{ELIPGRID-PC}

\section{B.1 Introduction}

Evaluating the need for and the effectiveness of remedial cleanup at waste sites often includes finding average contaminant concentrations and identifying pockets of contamination called hot spots. The standard approach for calculating the probability of detecting elliptical hot spots is based on ELIPGRID, a FORTRAN IV program developed by Don Singer in the early seventies. This program was based on a mathematical procedure published by Singer and Wickman in 1969 at Pennsylvania State University. Designed to calculate the probability of success in locating elliptical targets with square, rectangular, and hexagonal (triangular) grids, ELIPGRID employs data input and code designed for the then-standard punch-card computer.

Recently, the Environmental Technology Section made the ELIPGRD algorithm available for the $\mathrm{IBM}^{\oplus}$ personal computer (PC) or compatible, producing ELIPGRID-PC. During this process, two problems with the original algorithm were uncovered: the results of running the ELIPGRID algorithm did not match the published results for certain rectangular grid cases and the original algorithm was found to produce negative probabilities of missing a hot spot for a range of triangular grid cases. These problems were resolved by correcting the code and using a Monte Carlo simulation-based validation of a modified ELIPGRID-PC version of the algorithm.

This article reviews previous work and describes the final, upgraded version of ELIPGRID-PC, which includes corrections for the problems described above and for those found during beta testing.

\section{B.2 Previous Work}

In 1969 Singer and Wickman published a mathematical procedure for determining the probability of locating elliptical geological deposits (Singer and Wickman 1969). Using this procedure, five computer programs were written to calculate values published as probability tables for various target shapes, grid types, and grid sizes. These programs were run on an IBM System 370/67 computer.

In 1972 Singer published ELIPGRID, a FORTRAN IV program based on Singer and Wickman's mathematical procedure (Singer 1972). This program calculated the probability of success in locating elliptical targets with square, rectangular, and hexagonal (triangular) grids. 
Zirschky and Gilbert developed a nomographic procedure based on ELIPGRID to assist with the detection of highly contaminated areas at chemical- or nuclear-waste disposal sites (Zirschky and Gilbert 1984). Gilbert used these nomographs as the basis for the chapter "Locating Hot Spots" in his widely referenced book on environmental statistical methods (Gilbert 1987). These nomographs were subsequently used by the U.S. Environmental Protection Agency (EPA) to develop tables for calculating the probability of missing various hot-spot shapes using triangular and square sampling grids (U.S.EPA 1989).

Gilbert's nomographs and the EPA tables have some inherent limitations not in the original ELIPGRID program. Three limitations are:

1. Probabilities for only one rectangular sampling grid are given in Gilbert's nomographs; no data for rectangular grids are given in the EPA tables.

2. Specific orientation angles for suspected hot spots are not allowed. For example, if the probability of detecting a given target with a given grid for a specific orientation angle is desired, the tables and nomographs do not provide this information.

3. Data extracted from a graph are less likely to be accurate than output from a computer program, given the same input information.

ELIPGRID-PC removes these limitations by: 1) allowing a large number of rectangular grids, 2) allowing orientation angles for suspected hot spots to be specified, and 3) calculating the results with a computer algorithm.

\section{B.3 Program Assumptions}

The following assumptions underlie both the original ELIPGRID and ELIPGRID-PC:

1. The target (hot spot) is assumed to be circular or elliptical. See Fig. B.1 for an illustration of an elliptical subsurface pocket of contamination.

2. Samples or measurements are taken on a square, rectangular, or triangular grid. Fig. B.2 illustrates the various grid configurations.

3. The distance between grid points is much larger than the size of the sample being measured or cored at grid points; that is, a very small portion of the area being studied can actually be measured.

4. The definition of a hot spot is clear and unambiguous. 


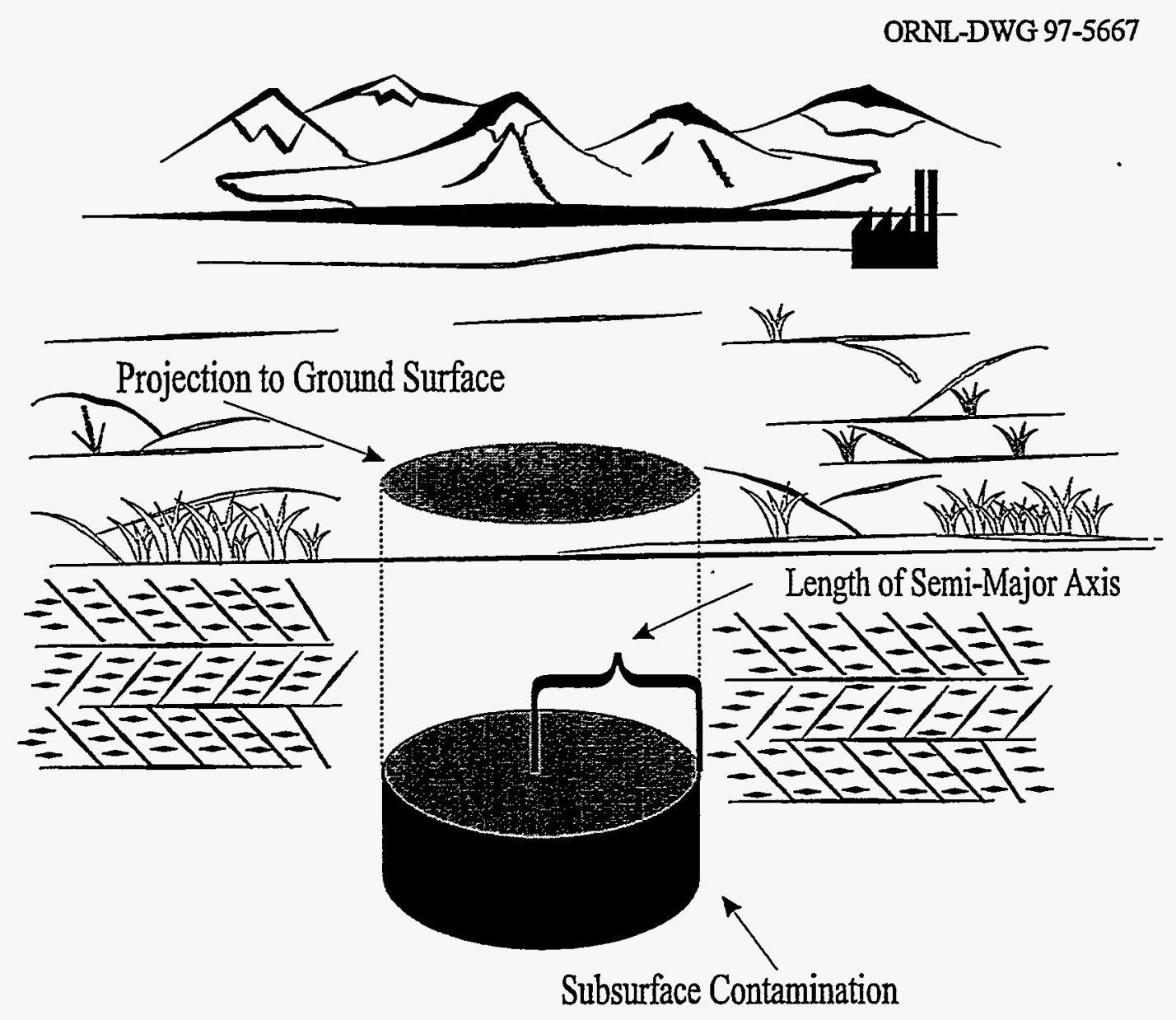

Fig. B.1. Hypothetical subsurface pocket of contamination. 


\section{B-4}

Square

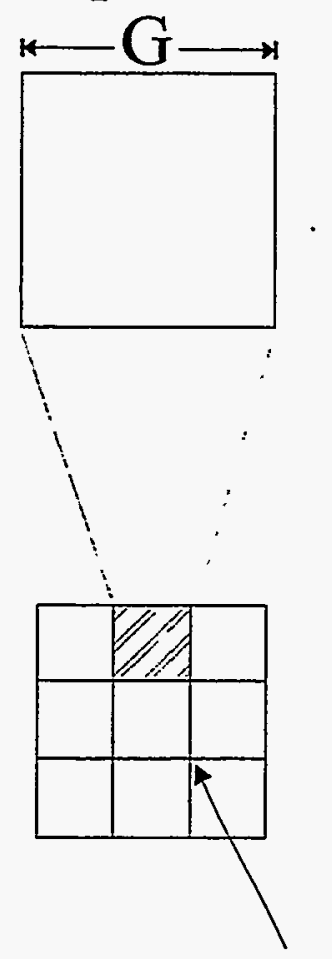

Rectangular

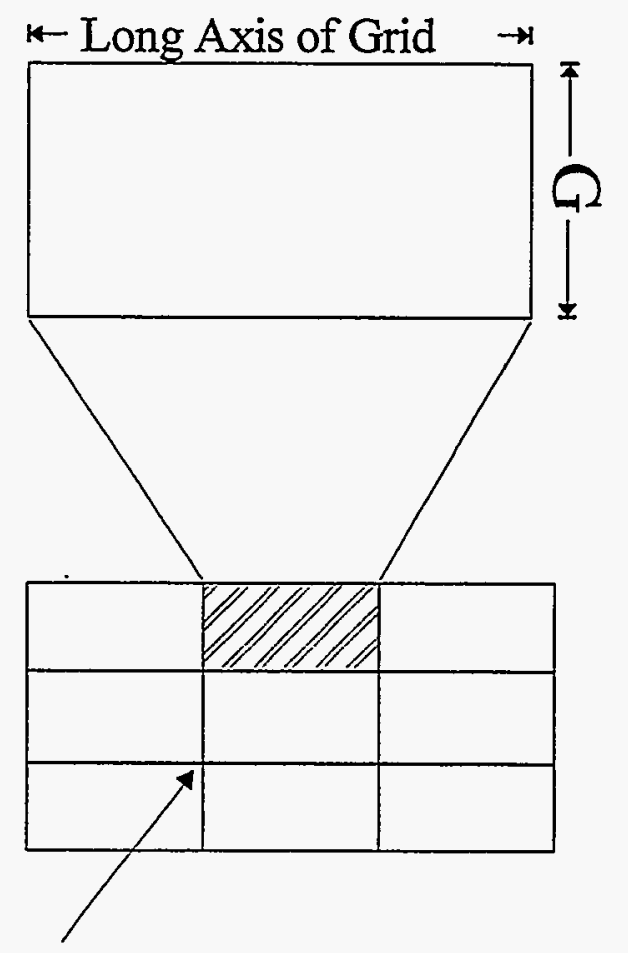

Samples are collected at grid nodes

Triangular

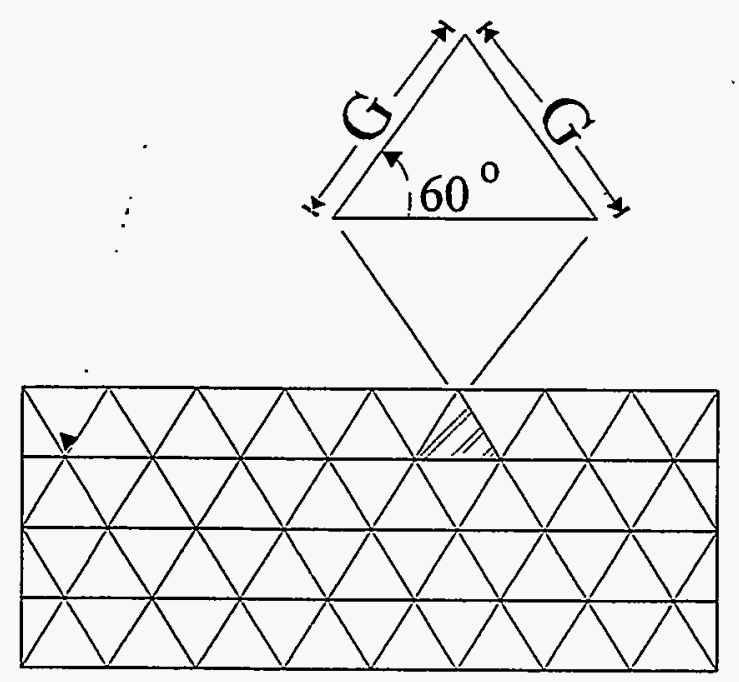

Fig. B.2. Grid configuration for finding hot spots. 


\section{B-5}

5. There are no measurement misclassification errors; that is, no errors are made in deciding when a hot spot has been detected.

\section{B.4 Program Description}

ELIPGRID-PC is a new computer program incorporating the corrected version of the ELIPGRID algorithm found in the Monte Carlo test version of ELIPGRID (Davidson 1995a). Among the new features provided by ELIPGRID-PC are:

- ELIPGRID-PC calculates a grid size, given the desired probability of detecting a specified hot spot.

- ELIPGRID-PC calculates an approximate grid size, given desired cost and hot-spot specifications. Note that this is an approximate grid size since the underlying EPA formula for determining the number of samples for a given area is itself approximate (U.S.EPA 1989).

- ELIPGRID-PC calculates the smallest hot spot that can be detected with a given probability and grid size.

- ELIPGRID-PC provides the capability for graphing the probability of detection versus cost for various scenarios of interest to decision makers. Fig. B.3 is an example for a square grid.

Designed to be user-friendly, ELIPGRID-PC includes the following features:

- A simplified input format (SIF) file option. SIF files provide an easier-to-use input file structure than the ELIPGRID format input files.

- Screen input and output in either meters or feet.

- Conversion from acres to $\mathrm{m}^{2}$ or to $\mathrm{ft}^{2}$ using the $\mathrm{F} 10 \mathrm{key}$. The program also calculates the length of the hot spot semi-major axis from the area of the hot spot.

- Change of the basic unit of length from meters to feet using a command-line option.

- Input and output files located on any drive and subdirectory.

- Temporary exit to DOS. DOS commands or other programs may then be executed.

- May be run using Microsoft ${ }^{\star}$ Windows $^{\text {Tx }} 3.1$ in a DOS box as well as with MS-DOS $^{\circledast} 5.0$ or later version.

- Will run under MS-DOS on any IBM-compatible PC with just $640 \mathrm{~KB}$ of RAM. 
ORNL-DWG 97-5669

\section{Probability of Hit vs Cost}

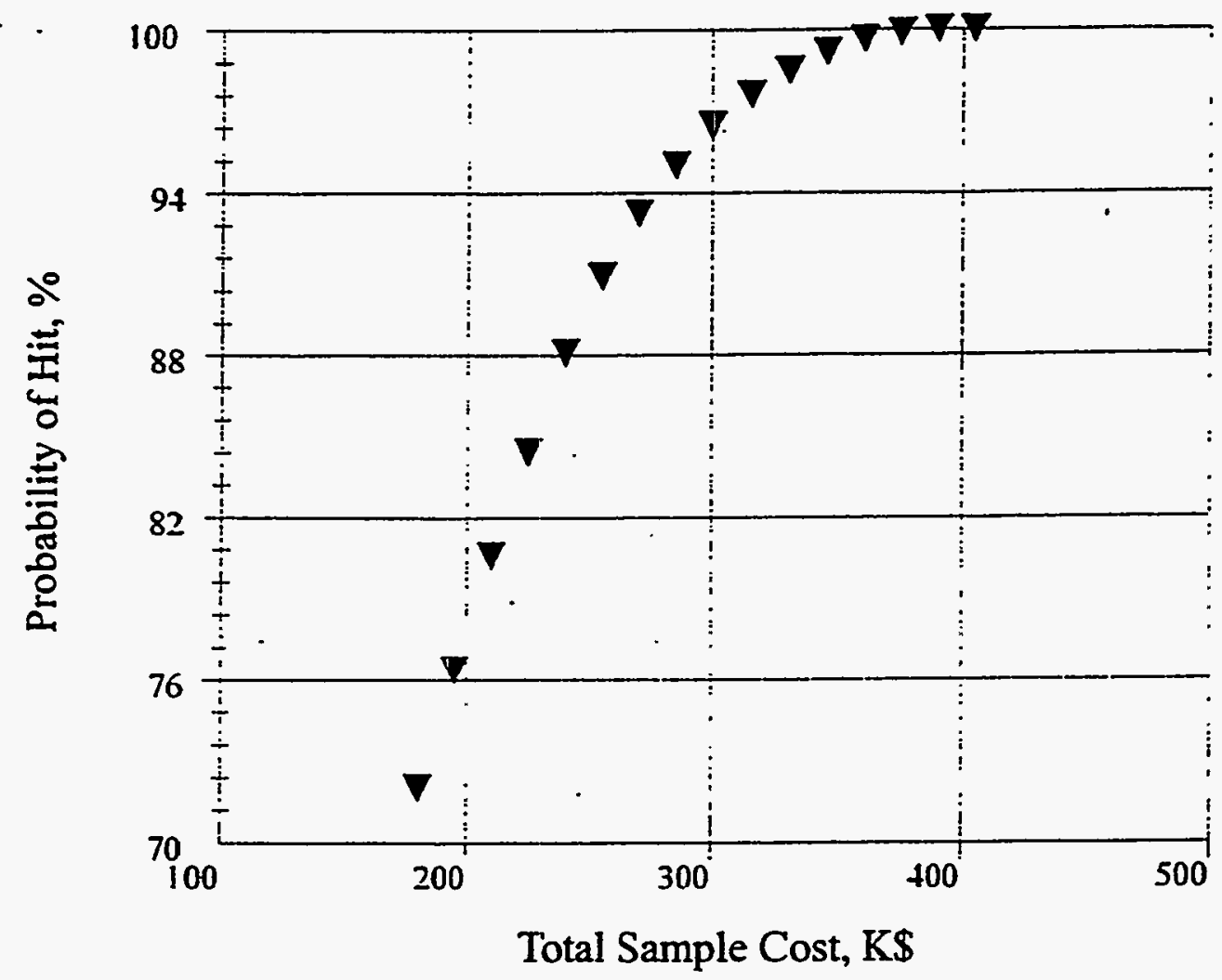

Grid type:...................................... Square

Shape of the elliptical hot spot:... 0.8

Length of semi-major axis:........... 3.15m

Angle of orientation to grid:.......... $0.0 \%$

Total area to sample:........................ $8093.0 \mathrm{~m} 2$

Individual sample cost:................... $\$ 700.00$

Fig. B.3. Probability of hit versus total sample cost for a square grid. 
(If run using Windows, the computer should have at least $4 \mathrm{MB}$ of RAM.)

An ORNL document, ELIPGRID-PC: Upgraded Version (Davidson 1995b), has recently been published providing step-by-step examples, with color screen shots, of the program being used to solve example problems found in Richard Gilbert's chapter on hot spots (Gilbert 1987). ELIPGRID-PC is available by contacting Jim Davidson at ORNL's GJ office by: phone (970) 248-6259, fax (970) 248-6270, or e-mail qgi@ornl.gov.

\section{B.5 Summary}

Singer and Wickman's ELIPGRID algorithm for calculating hot-spot sampling probabilities has been successfully made available to the PC environment. The program additionally calculates the grid size required for specified conditions, the smallest hot spot that can be sampled with a given probability, and the approximate grid size resulting from specified conditions and sampling cost. ELIPGRID-PC also provides graphs of the probability of detection versus cost for various scenarios of interest to decision makers.

\section{B.6 References}

Davidson, J. R. 1995a. Monte Carlo Tests of the ELIPGRID-PC Algorithm. ORNL/TM-12899. Oak Ridge National Laboratory, Oak Ridge, Tennessee.

Davidson, J. R. 1995b. ELIPGRD-PC: Upgraded Version. ORNL/TM-13103. Oak Ridge National Laboratory, Oak Ridge, Tennessee.

Gilbert, R. O. 1987. Statistical Methods for Environmental Pollution Monitoring. Van Nostrand Reinhold, New York.

Singer, D. A. 1972. ELIPGRID, a FORTRAN IV program for calculating the probability of success in locating elliptical targets with square, rectangular, and hexagonal grids. Geocom Programs, 4:1-16.

Singer, D. A, and F. E. Wickman. 1969. Probability Tables for Locating Elliptical Targets with Square, Rectangular and Hexagonal Point Nets. Pennsylvania State University, University Park, Pennsylvania.

U.S.EPA. 1989. Methods for Evaluating the Attainment of Cleamup Standards. Volume 1. Soils and Solid Media. EPA/230/02-89/042. U. S. Environmental Protection Agency.

Zirschky, J., and R. O. Gilbert.1984. Detecting hot spots at hazardous-waste sites. Chemical Engineering, 91: 97-100. 
Table C.1. Delta-gamma measurements

\begin{tabular}{|c|c|c|c|c|c|}
\hline $\begin{array}{c}\text { Area } \\
\text { identifier }\end{array}$ & ${ }^{226} \mathrm{Ra}, \mathrm{pCi} / \mathrm{g}$ & Area identifier & ${ }^{226} \mathrm{Ra}, \mathrm{pCi} / \mathrm{g}$ & $\begin{array}{c}\text { Area } \\
\text { identifier }\end{array}$ & ${ }^{226} \mathrm{Ra}, \mathrm{pCi} / \mathrm{g}$ \\
\hline V379 1 & 2.47 & V $527 \mathrm{~K} .6^{4}$ & 2.80 & V531A. $H^{3}$ & 2.75 \\
\hline $\mathrm{V} 380^{1}$ & 4.62 & V $527 \mathrm{~K} .7^{4}$ & 4.38 & V5311..$^{3}$ & 6.18 \\
\hline $\mathrm{V} 380^{1}$ & 1.54 & V527K. $8^{4}$ & 3.47 & V531I. $H^{3}$ & 31.24 \\
\hline V384 ${ }^{1}$ & 1.43 & V527K. $9^{4}$ & 0.67 & V531I. $2^{3}$ & 2.86 \\
\hline $\mathrm{V}^{2} 85^{1}$ & 3.14 & V527K. $10^{4}$ & 3.51 & V $531 \mathrm{~K} .1^{3}$ & 1.16 \\
\hline $\mathrm{V} 385^{1}$ & 3.75 & V527K. $11^{4}$ & -1.80 & $\mathrm{~V} 531 \mathrm{~K} .2^{3}$ & 3.14 \\
\hline V386 ${ }^{1}$ & 7.44 & V527K. $12^{4}$ & -1.05 & V531K. $\mathrm{H}^{3}$ & 5.04 \\
\hline V387 ${ }^{1}$ & 4.92 & V527K. $13^{4}$ & -2.81 & V531L. $1^{3}$ & 6.33 \\
\hline V388 ${ }^{1}$ & 3.98 & V527K. $14^{4}$ & 4.37 & V531L. $2^{3}$ & 2.11 \\
\hline V389 & 2.50 & V527L. $1^{4}$ & 1.71 & & \\
\hline $\mathrm{V} 525 \mathrm{H}^{2}$ & 1.79 & V527L. $2^{4}$ & 3.72 & & \\
\hline $\mathrm{V}^{2} 25 \mathrm{~J}^{2}$ & 2.54 & V527L. $3^{4}$ & 5.44 & & \\
\hline$V 525 L^{4}$ & 1.34 & V527L. $4^{4}$ & 7.17 & & \\
\hline$V_{527 B^{4}}$ & 2.18 & V527L. $5^{4}$ & $5.74^{\circ}$ & & \\
\hline V527E. $1^{4}$ & 8.28 & V527L. $6^{4}$ & 2.42 & & \\
\hline V527E. $2^{4}$ & 4.71 & V527L. $1^{4}$ & 1.71 & & \\
\hline V527E. $3^{4}$ & 9.07 & V527L. $2^{4}$ & 3.72 & & \\
\hline V527E. $4^{4}$ & 2.11 & V527L. $3^{4}$ & 5.44 & & \\
\hline V527E. $5^{4}$ & 1.91 & V527L. $4^{4}$ & 7.17 & & \\
\hline V527K. $1^{4}$ & 8.09 & V527L. $5^{4}$ & 5.74 & & \\
\hline V527K. $2^{4}$ & 3.73 & V527L. $6^{4}$ & 2.42 & & \\
\hline V527K. $3^{4}$ & -1.75 & V530A. $1^{2}$ & 2.98 & & \\
\hline V527K. $4^{4}$ & $2.87^{\circ}$ & V530A. $\mathrm{H}^{2}$ & 10.34 & & \\
\hline V527K. $5^{4}$ & 3.32 & V531A. $1^{2}$ & 0.81 & & \\
\hline
\end{tabular}

${ }^{1}$ These locations are found on Fig. C.Ic.

${ }^{2}$ These locations are found on Fig. C.lj.

${ }^{3}$ These locations are found on Fig. C.1k.

${ }^{4}$ These locations are found on Fig. C.In. 


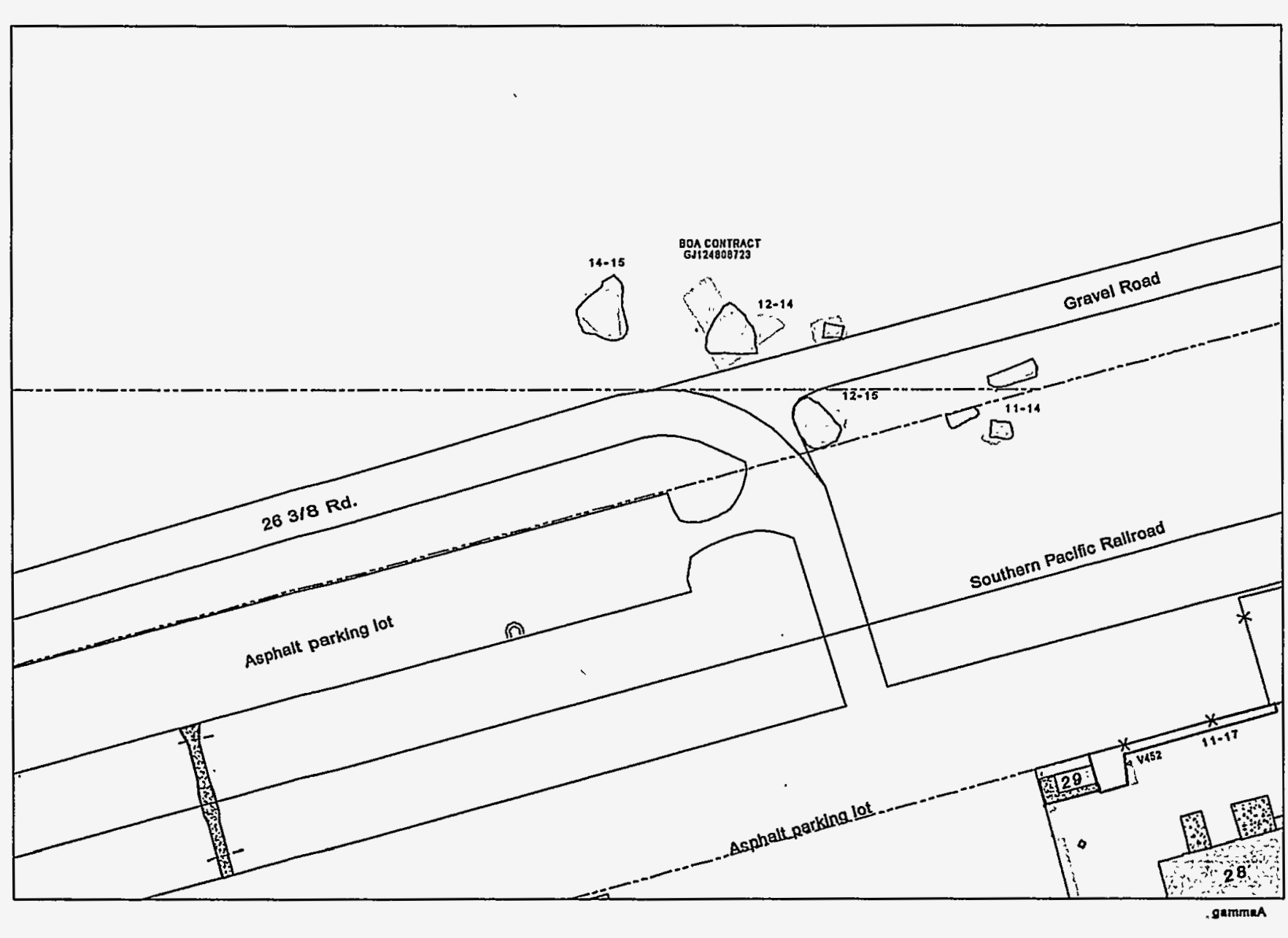

ORNL-DWG 97-5670

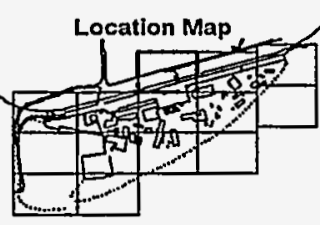

[] Remediation boundary

$\square$ v-area boundary

- Property boundary

[7] Concrete

Reodings in $\mu \mathrm{R} / \mathrm{h}$

United States

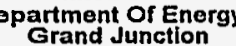
Projects Office 2597 B $3 / 4$ Rd. Grand Junction
Colorado

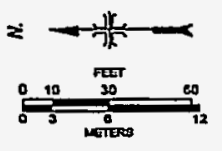

Fig. C.1a. Gamma exposure rate ranges and delta-gamma measurement locations. 


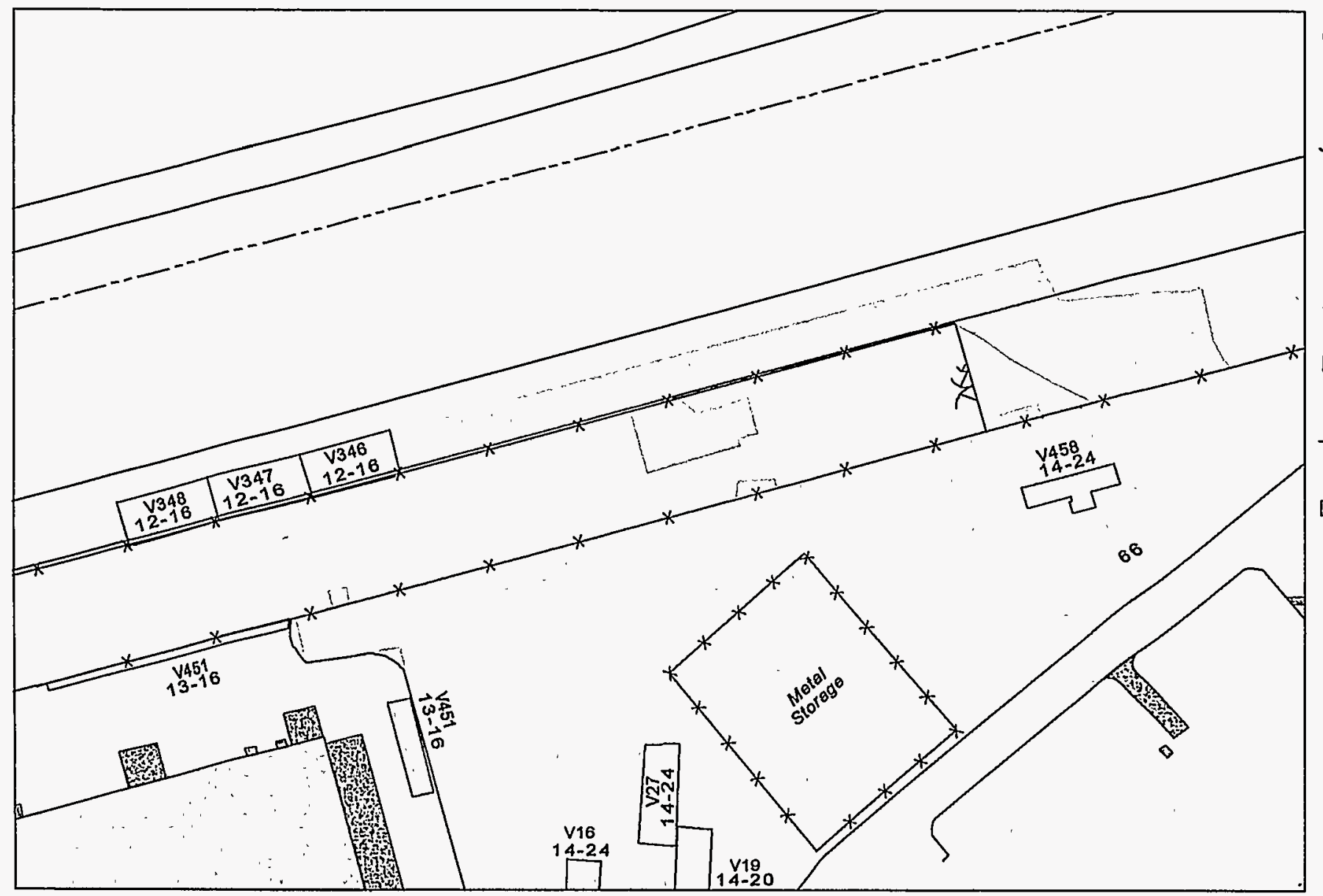

ORNL-DWG 97-5671

Location Map
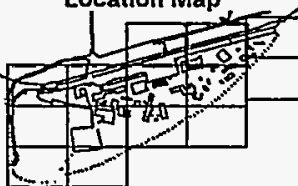

Demediation boundary

$\square$ V-area boundary

\section{- Property}

boundary

Concrete

Roadings in $\mu \mathrm{R} / \mathrm{h}$

United States

epartment Of Energy

Projects Office

597 B 3/4 Rd.

Grand Junction

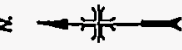

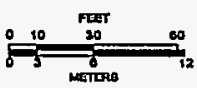

Fig. C.1b. Gamma exposure rate ranges and delta-gamma measurement locations. 


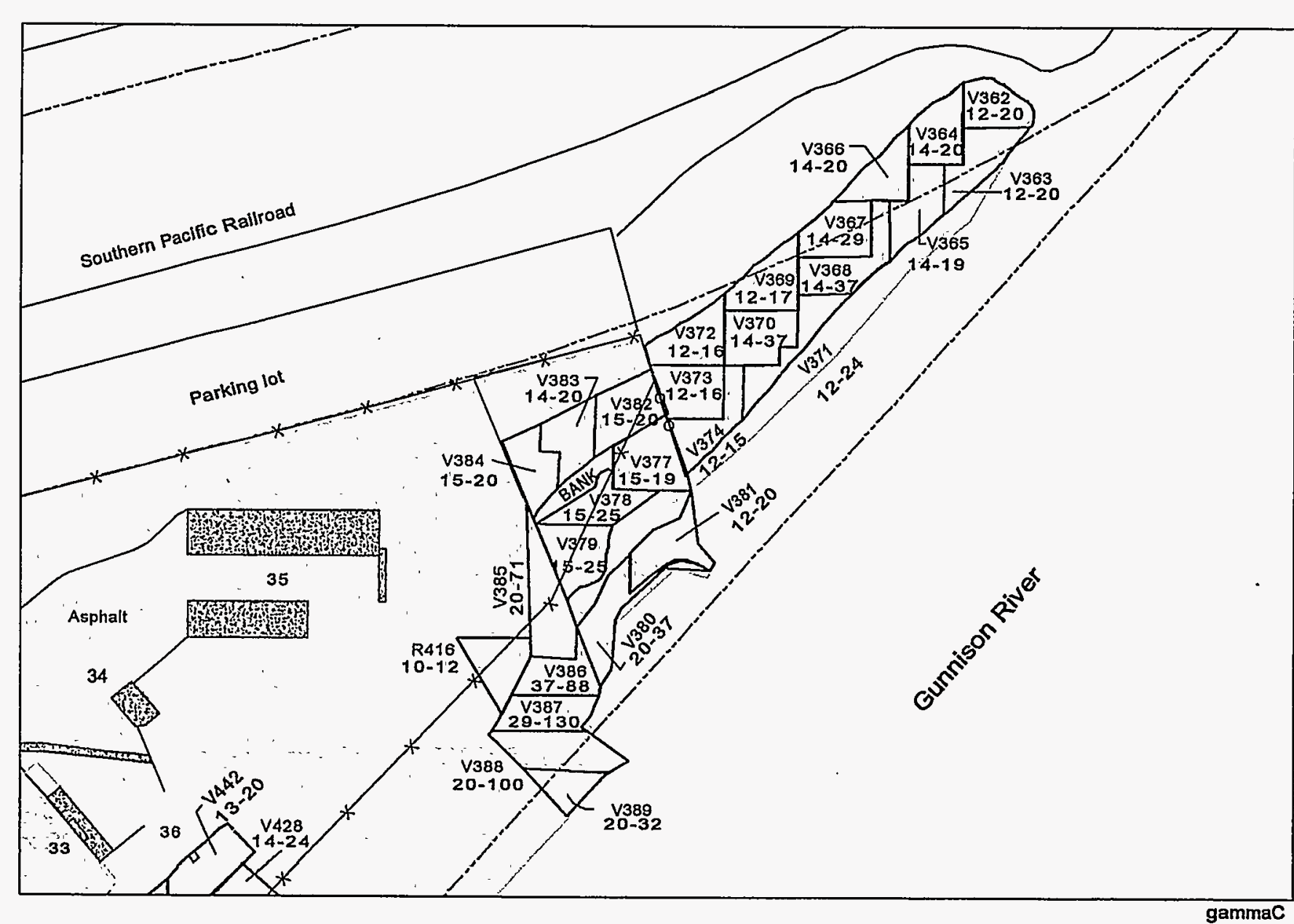

ORNL-DWG 97-5672

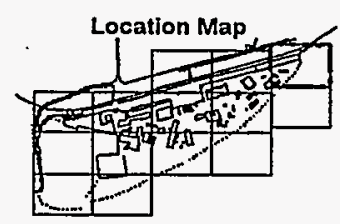

$\square$ Remediation boundary

D V-area boundary

- Property boundary

Concrete

Location of

Delta-gamma measurements Readings in $\mu \mathrm{R} / \mathrm{h}$

United States

Department Of Energy

Projects Office 2597 B 3/4 Rd Grand Junction
Colorado

$z-n^{2}-$

12

gammaC

Fig. C.1c. Gamma exposure rate ranges and delta-gamma measurement locations. 


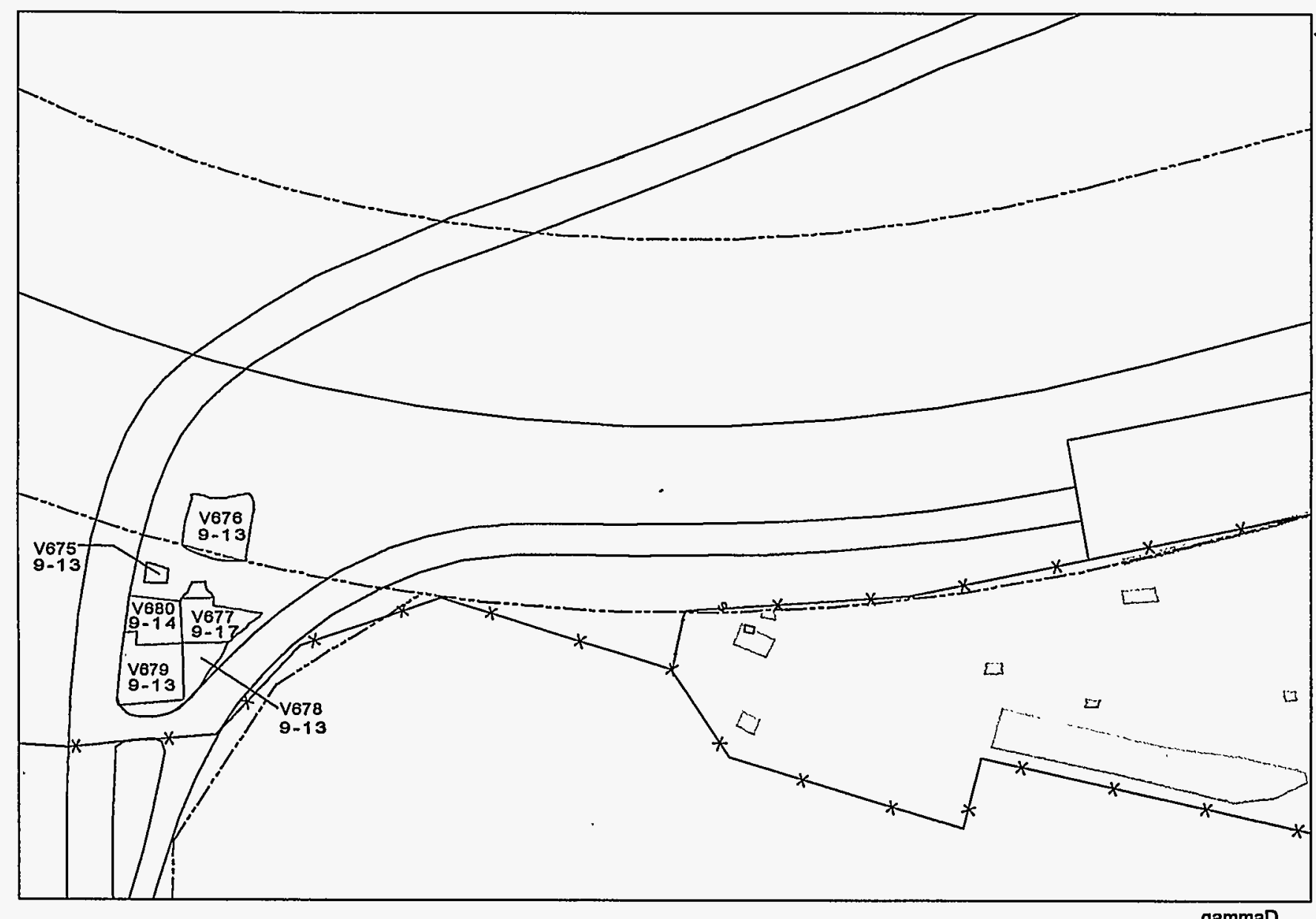

ORNL-DWG 97-5673

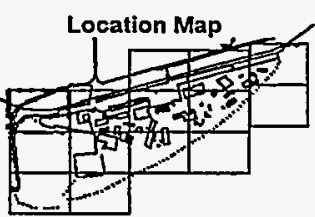

$\square$ Remediation boundary

$\square$ V-area

boundary

- Property

boundary

Concrete

Reodings in $\mu \mathrm{R} / \mathrm{h}$

United States

Department Of Energy

Grand Junctlon

Projects Office
2597 B $3 / 4$ Rd

Grand Junction

$\geq$

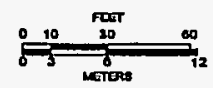

gammaD

Fig. C.1d. Gamma exposure rate ranges and delta-gamma measurement locations. 


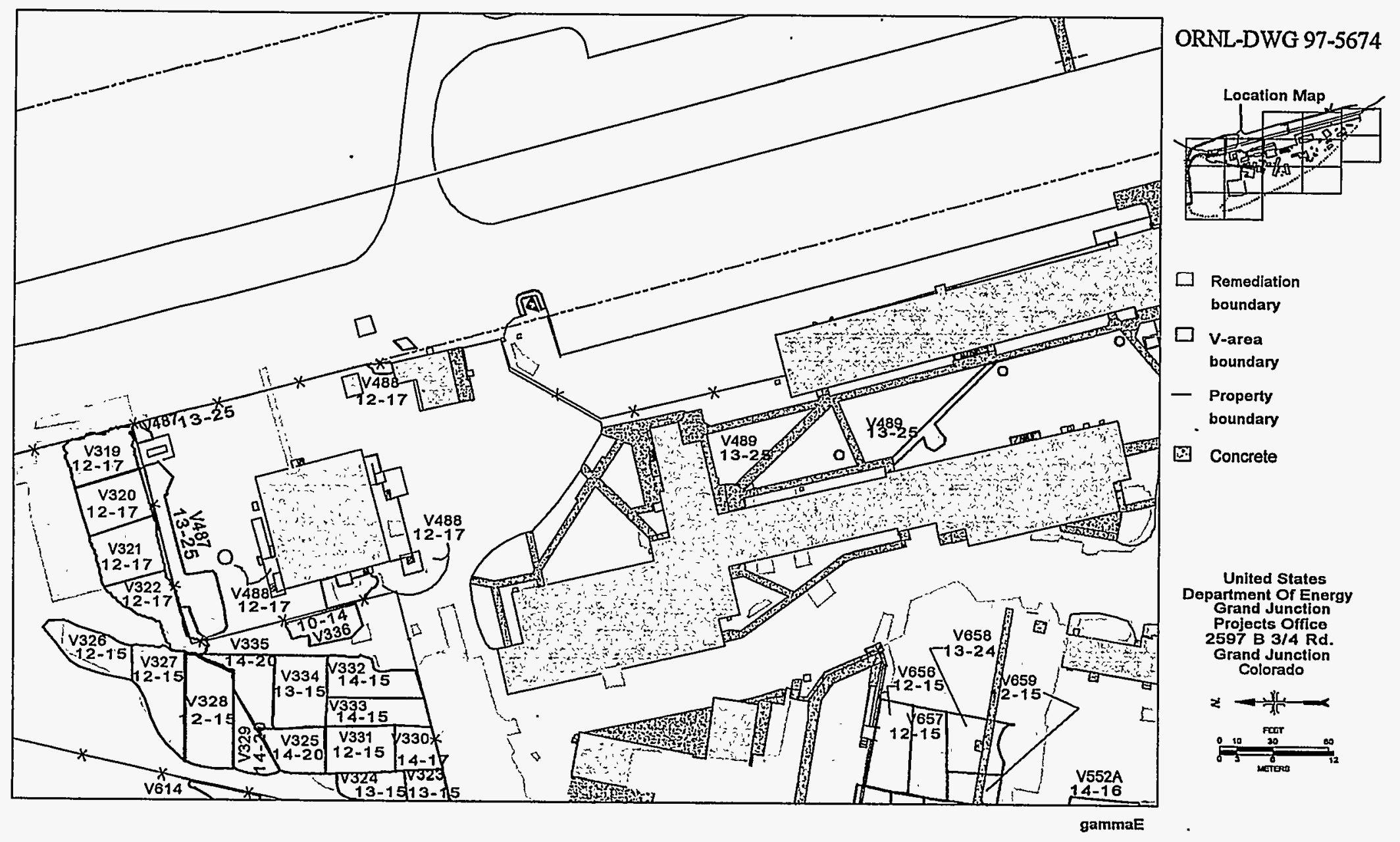

Fig. C.1e. Gamma exposure rate ranges and delta-gamma measurement locations. 


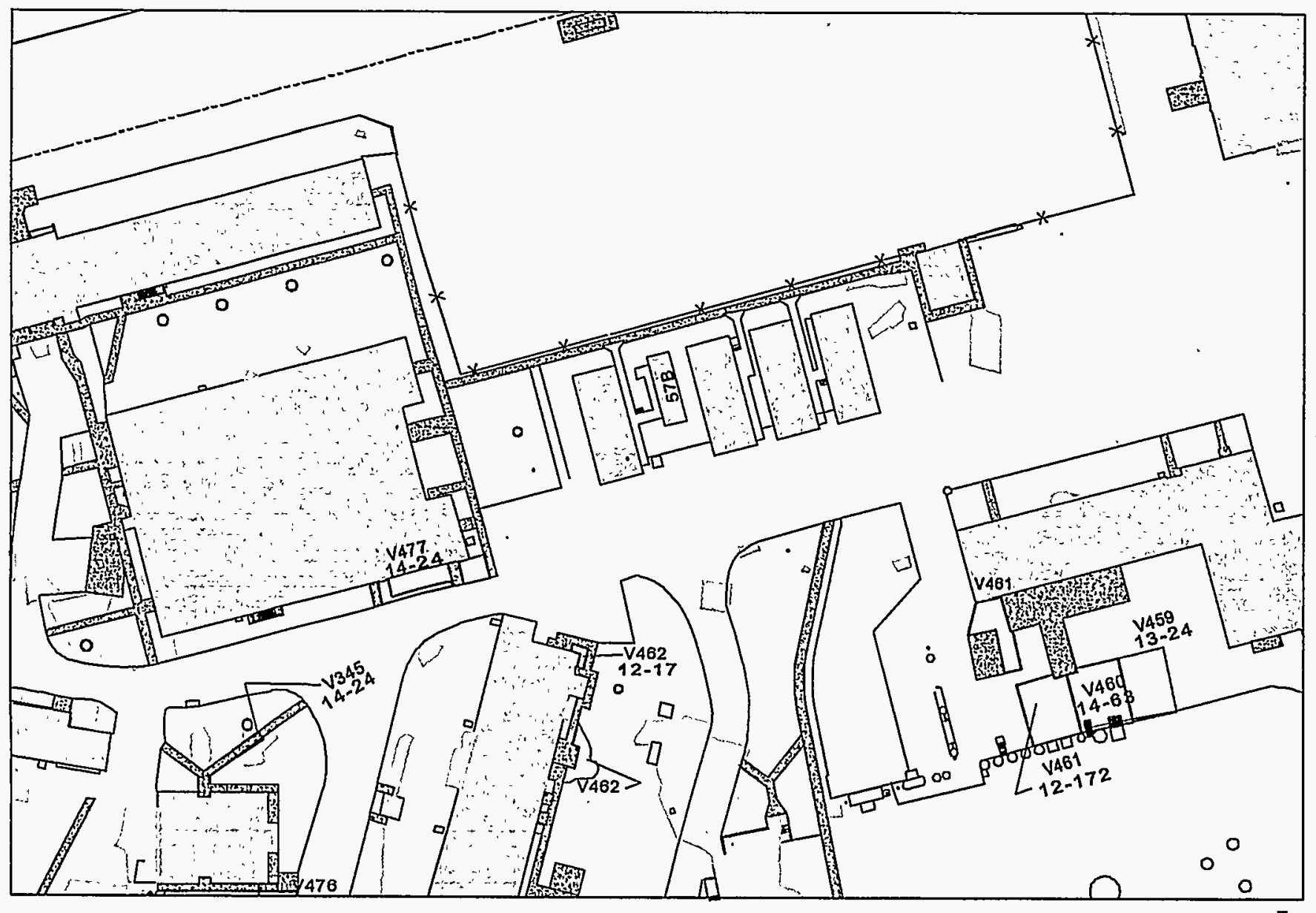

ORNL-DWG 97-5675

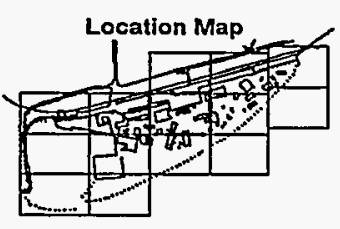

[.] Remediation boundary

$\square$ V-area

boundary

- Property

boundary

Concrete

I

Readings in $\mu \mathrm{R} / \mathrm{h}$

United States

Department Of Energy

Grand Junction

Projects Office
2597 B 3/4 Rd.

Grand Junction

$\approx \rightarrow-x^{\prime}$

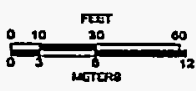

Fig. C.1f. Gamma exposure rate ranges and delta-gamma measurement locations. 


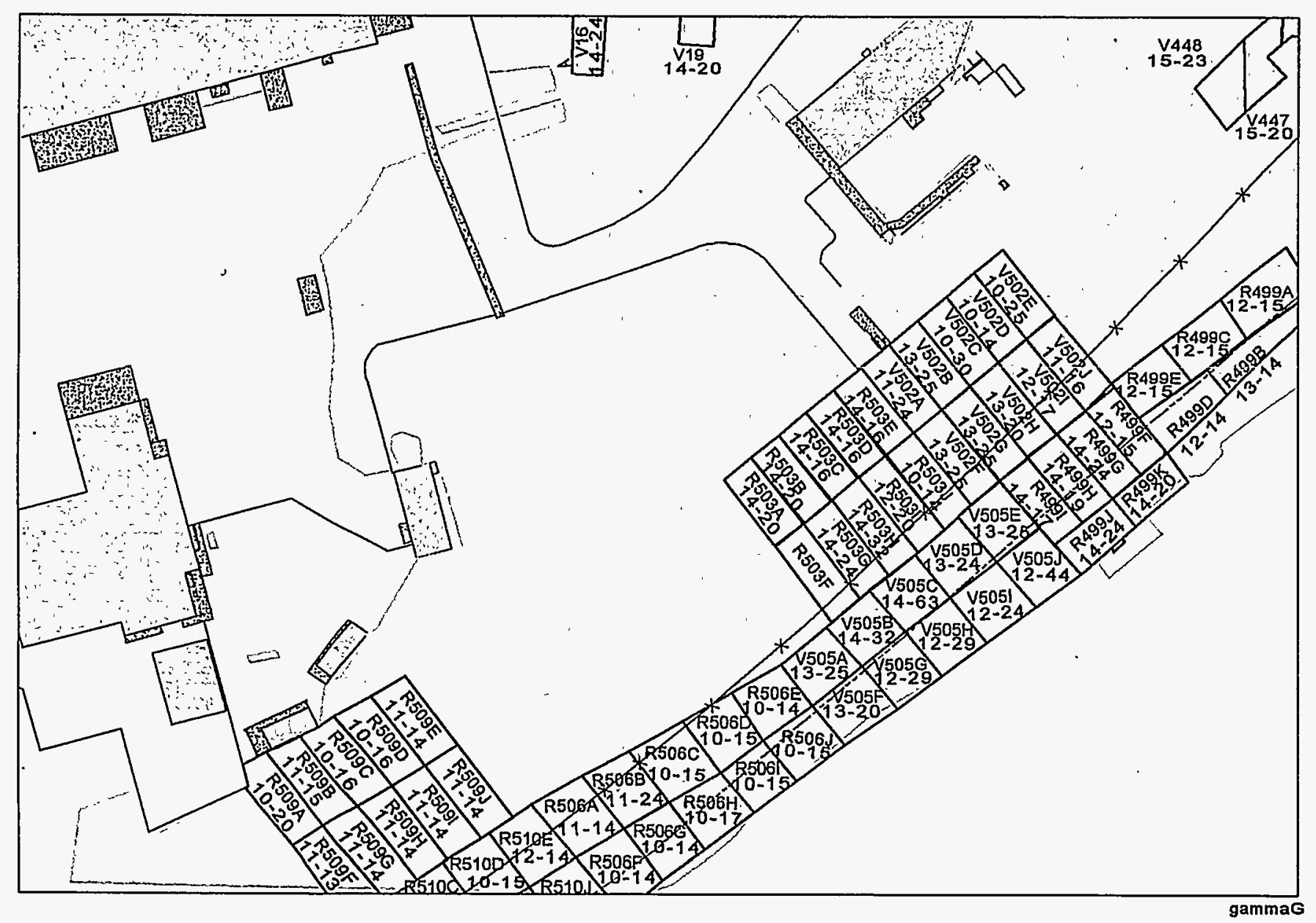

ORNL-DWG 97-5676

Location Map

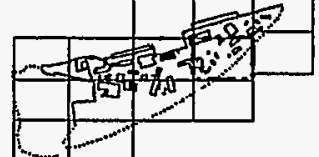

Remediation

boundary

घ-area

boundary

- Property

boundary

20ncrete

Location of

Delta-gamma

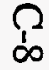

\section{Readings in $\mu \mathrm{R} / \mathrm{h}$}

United States

Gepartment Of Energy
Grand Junction

Projects Office
2597 B 3/4 Rd.

Grand Junction

$z-\underbrace{}_{12}$

Fig. C.1g. Gamma exposure rate ranges and delta-gamma measurement locations. 


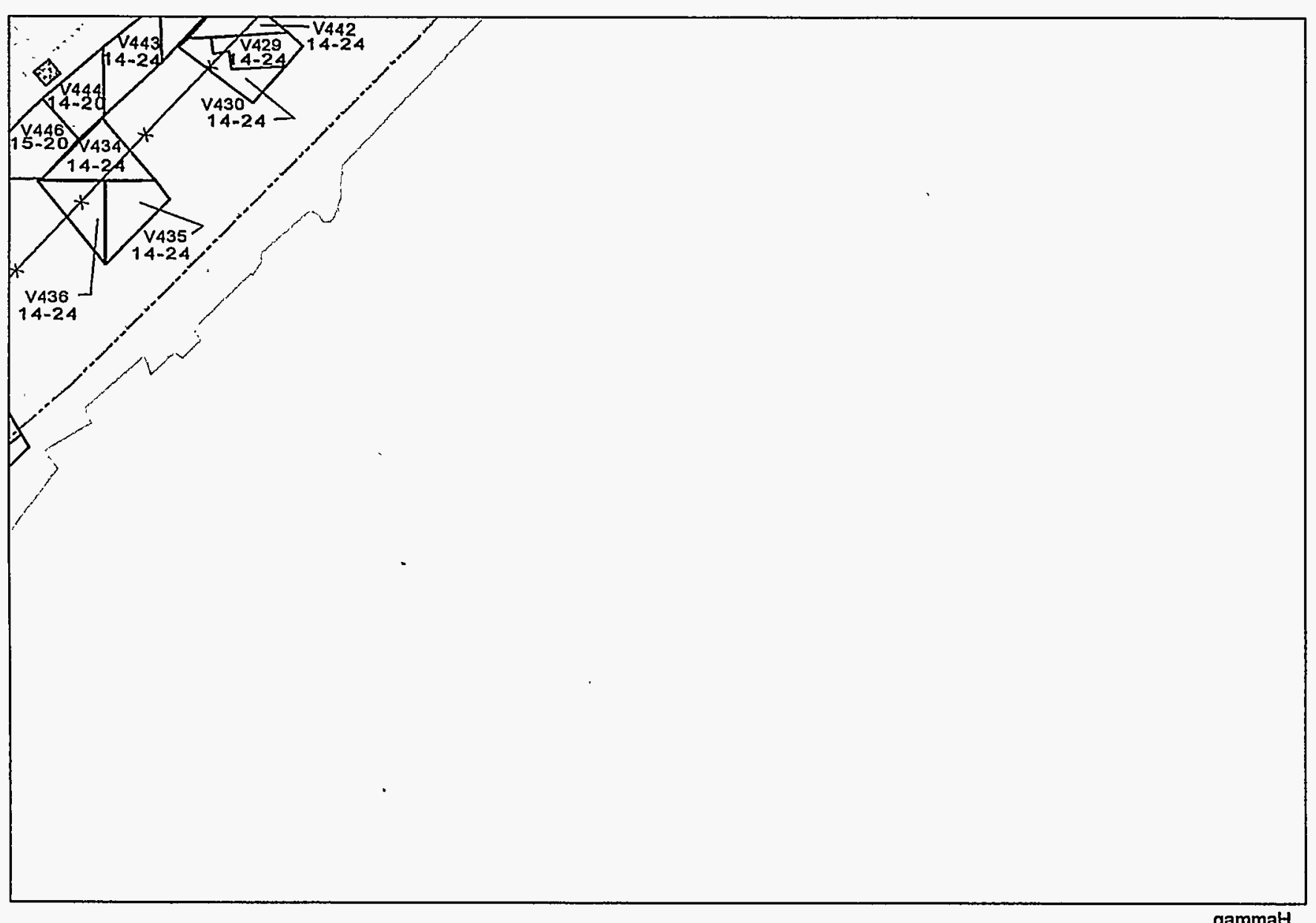

ORNL-DWG 97-5677

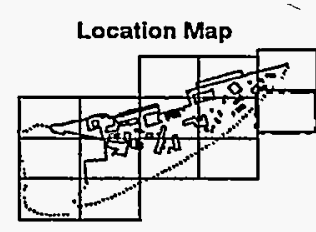

$\square$ Remediation boundary

$\square$ V-area boundary

- Property boundary

ㄱ. Concrete

Readings in $\mu \mathrm{R} / \mathrm{h}$

United States

Dopartment Of Energy

Projects Office

2597 B $3 / 4 \mathrm{Rd}$

Grand Junction

$=-x^{\prime}-$

$\overbrace{-120}^{10}$

gammar

Fig. C.1h. Gamma exposure rate ranges and delta-gamma measurement locations. 


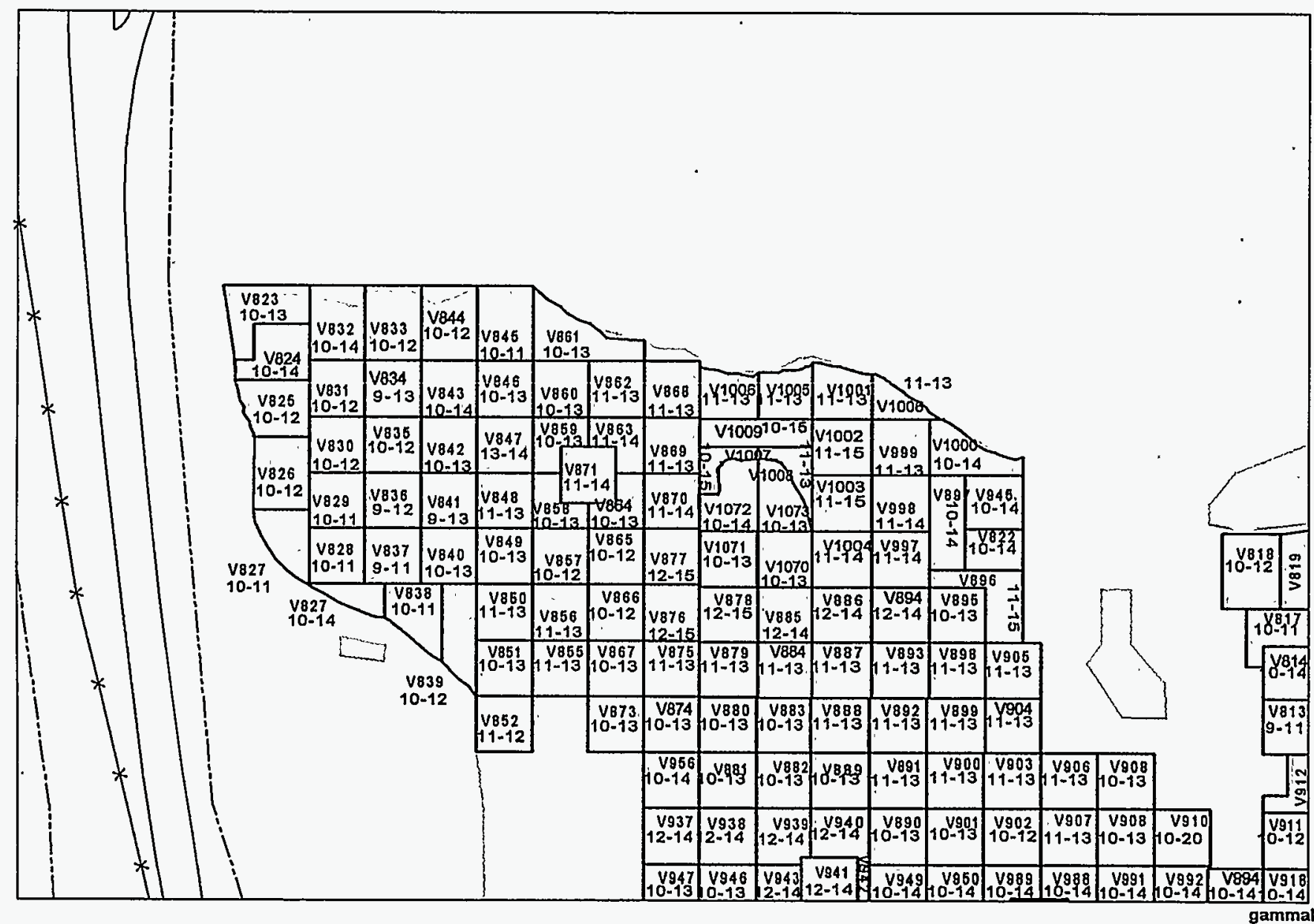

ORNL-DWG 97-5678

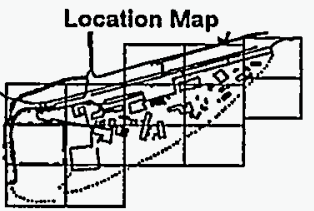

$\square$ Remedlation

boundary

$\square$ V-area

boundary

- Property

boundary

[2] Concrete

Readings in $\mu \mathrm{R} / \mathrm{h}$

$\stackrel{2}{\circ}$

Fig. C.li. Gamma exposure rate ranges and delta-gamma measurement locations. 


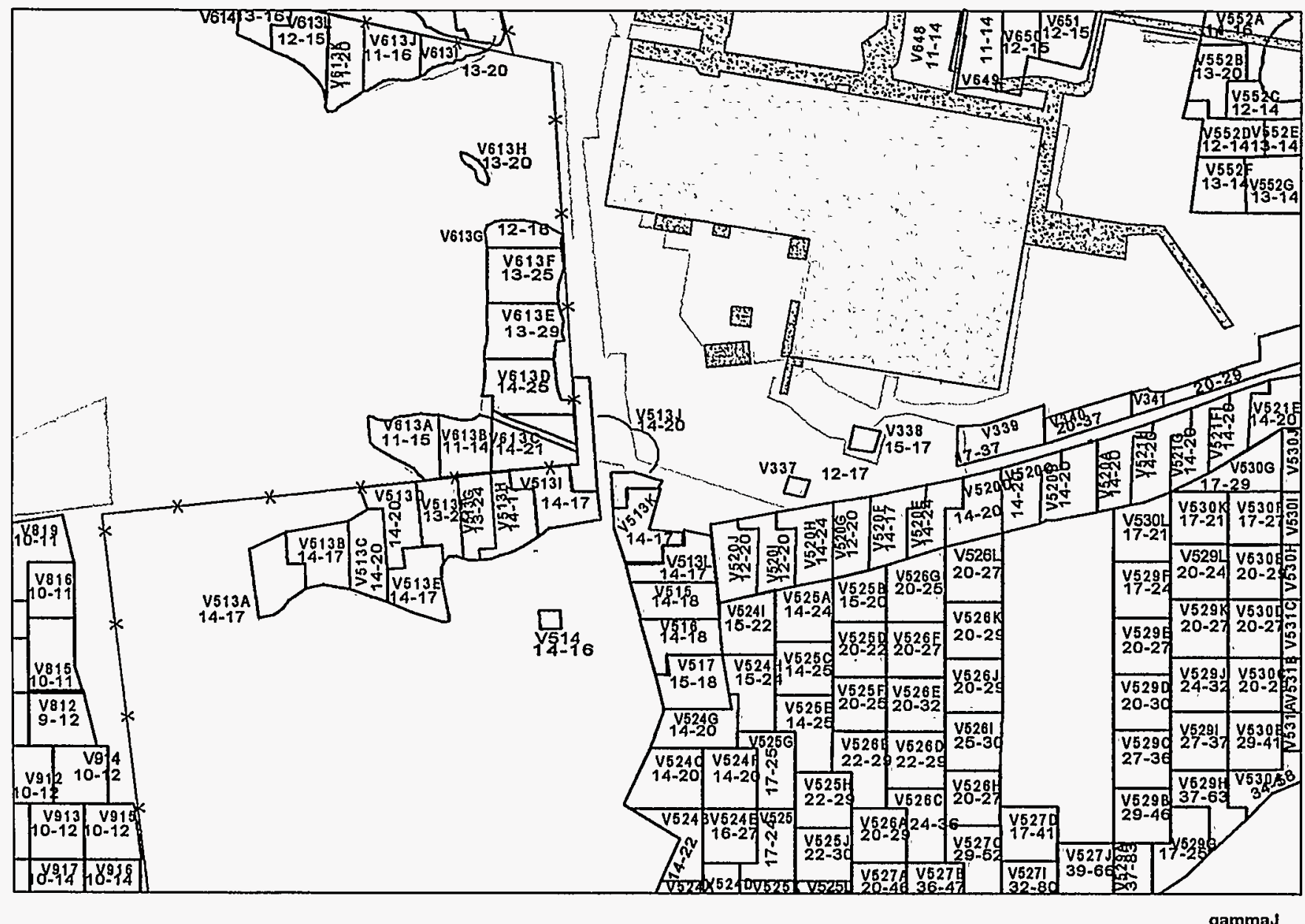

ORNL-DWG 97-5679

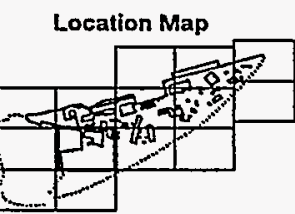

$\square$ Remediation boundary

V V-area boundary

- Property boundary

ㅇ. Concrete

- Location of Delta-gamma measurements

United States

Department Of Energy

Projects Office

2597 B 3/4 Rd.

Grand Junction
Colorado

$<-$ -

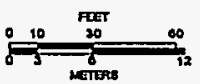

gamma

Fig. C.1j. Gamma exposure rate ranges and delta-gamma measurement locations. 


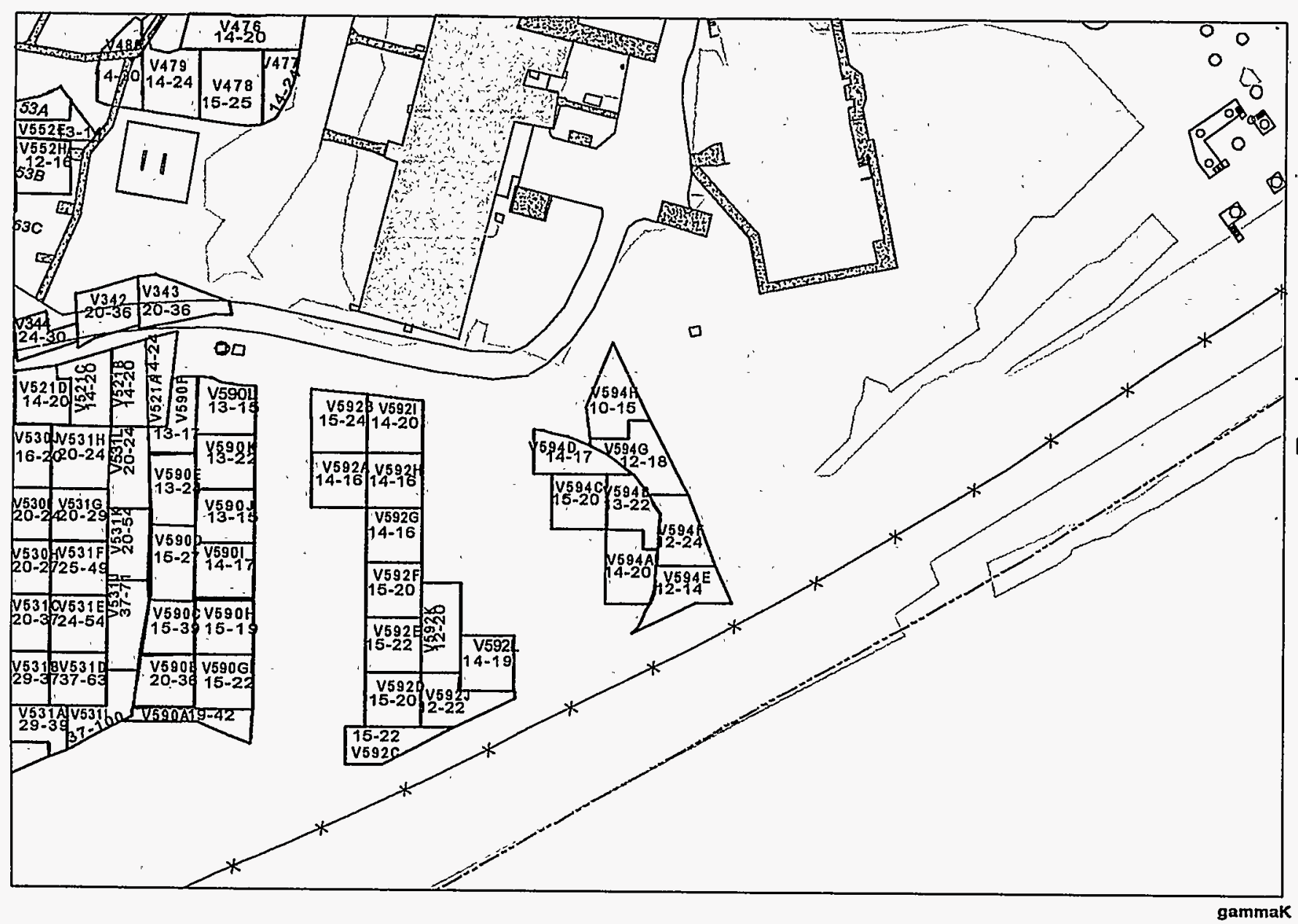

ORNL-DWG 97-5680

Location Map

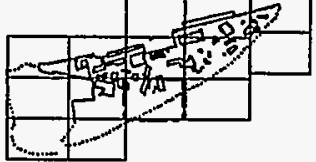

Remediation boundary

口 v-area boundary

Property boundary

[8. Concrete

Location of

Delta-gamma

measurements

Readings in $\mu \mathrm{R} / \mathrm{h}$

United States

opartment Of Energy

Projects Office

2597 B 3/4 Rd.

Grand Junction

Colorado

$z-4$

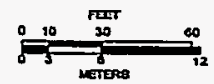

Fig. C.1k Gamma exposure rate ranges and delta-gamma measurement locations. 


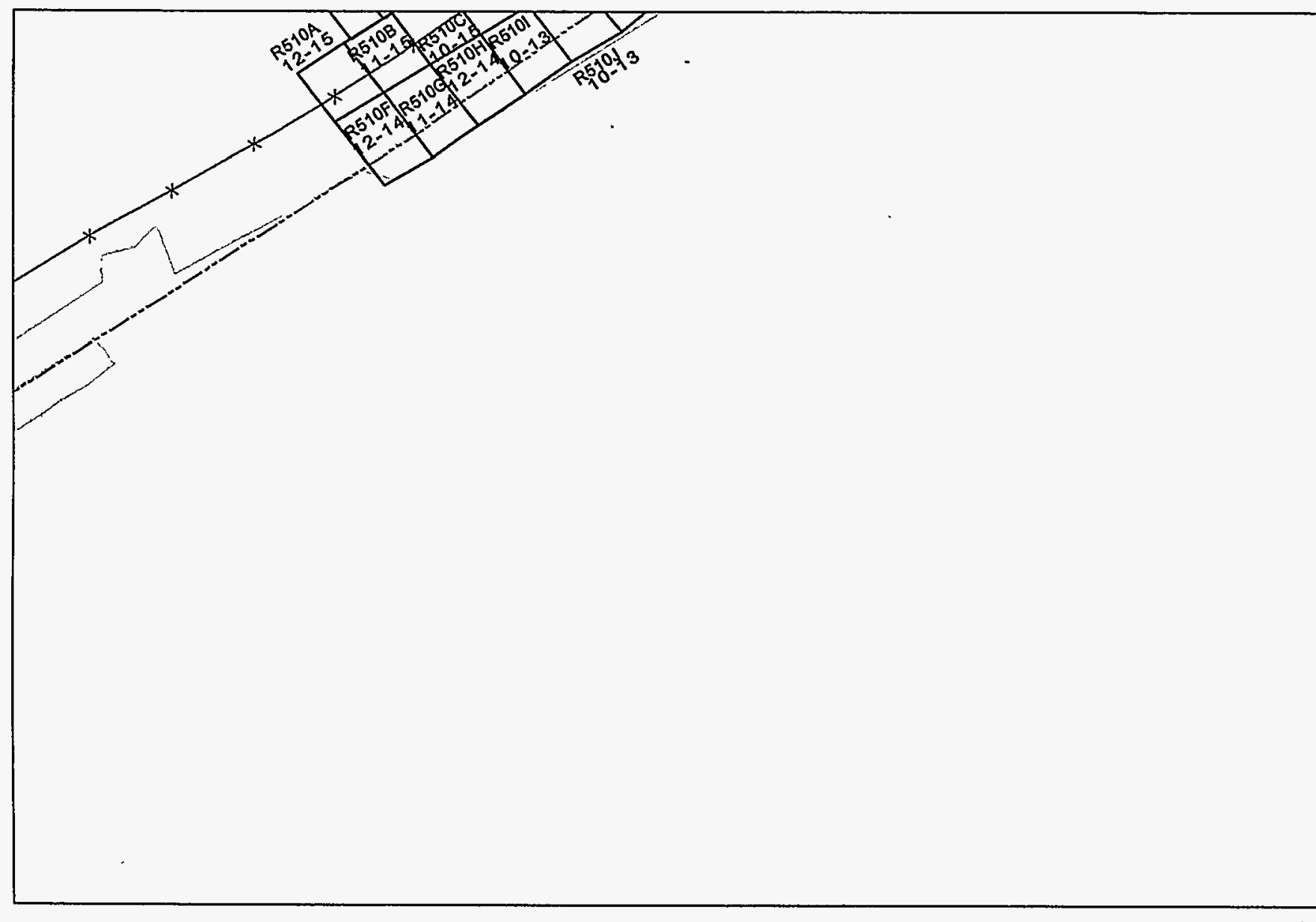

ORNL-DWG 97-5681

Location Map

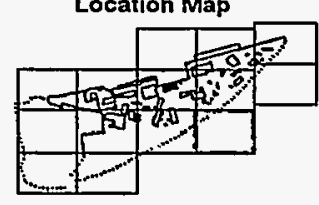

$\square$ Remediation boundary

$\square$ V-area boundary

- Property boundary

요 Concrete

Readings in $\mu \mathrm{R} / \mathrm{h}$

United States

Department Of Energ

Projects Office

2597 B 3/4 Rd.

Grand Junction

Colorado

$\approx \rightarrow *-$

10

gammal.

Fig. C.11. Gamma exposure rate ranges and delta-gamma measurement locations. 

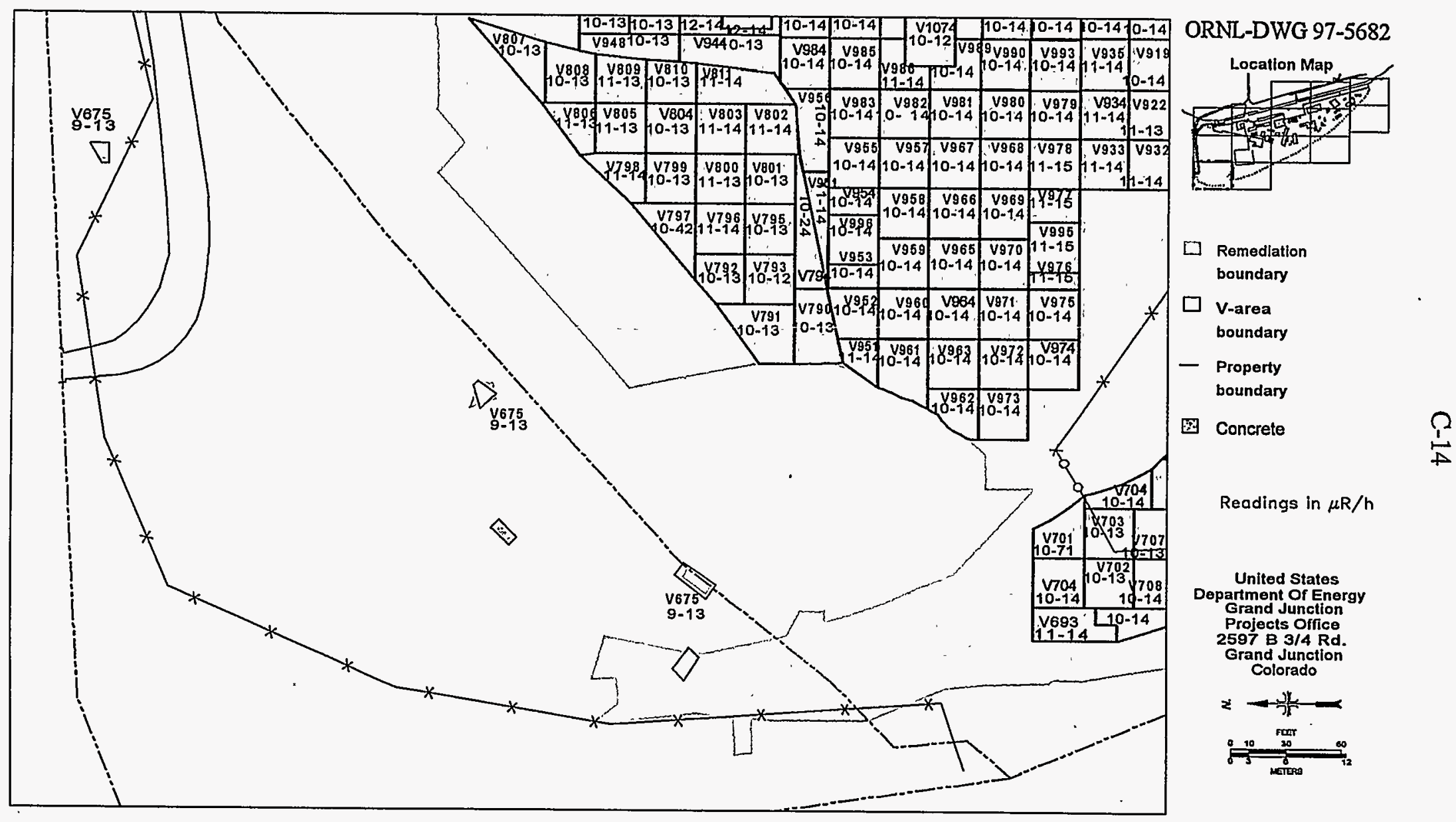

Readings in $\mu \mathrm{R} / \mathrm{h}$

United States

Department Of Energy

Projects Offico

2597 B 3/4 Rd.

Grand Junction

Colorado

$=-\frac{x}{x}-$

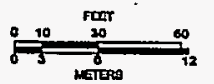

gammaM

Fig. C.1m. Gamma exposure rate ranges and delta-gamma measurement locations. 

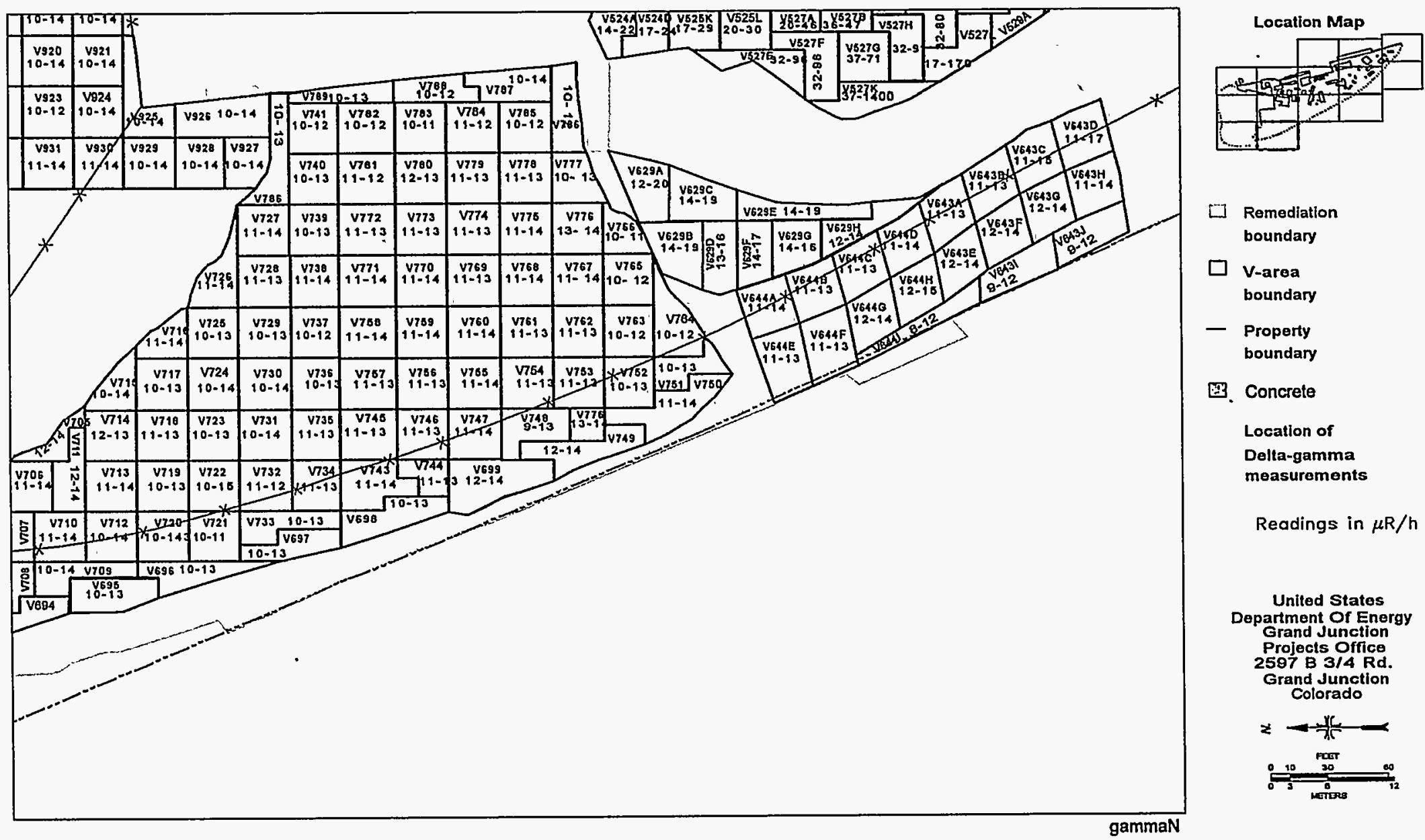

$\square$ Remediation boundary

$\square$ V-area boundary

\section{- Property} boundary

2. Concrete

Location of

Delta-gamma

measurements

Readings in $\mu \mathrm{R} / \mathrm{h}$

United States

Dopartment Of Energy

Projects Offic

2597 B 3/4 Rd.

Grand Junction

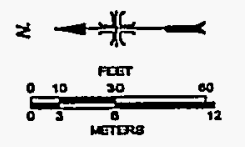

$\underbrace{-10 \quad 000}_{0}$

Fig. C.1n. Gamma exposure rate ranges and delta-gamma measurement locations. 


\section{APPENDIX D}

\section{SURFACE ACTIVITY MEASUREMENTS AND LOCATIONS}


Table D.1. Surface activity measurements

\begin{tabular}{|c|c|c|}
\hline V-area & Measurement number & $\mathrm{dpm} / 100 \mathrm{~cm}^{2 a, b}$ \\
\hline V648 & 1 & 2229 \\
\hline V648 & 2 & 1437 \\
\hline V648 & 3 & 1320 \\
\hline V649 & $\dot{4}$ & 1232 \\
\hline V649 & 5 & 3871 \\
\hline V649 & 6 & 1261 \\
\hline V649 & 7 & 4106 \\
\hline V656 & 1 & 31 \\
\hline V656 & 2 & 307 \\
\hline V656 & 3 & 184 \\
\hline V656 & 4 & 584 \\
\hline V656 & 5 & 707 \\
\hline V656 & 6 & 338 \\
\hline V656 & 7 & 829 \\
\hline V656 & 8 & 645 \\
\hline V656 & 9 & 553 \\
\hline V656 & 10 & 0 \\
\hline V656 & 11 & 553 \\
\hline V656 & 12 & 246 \\
\hline V656 & 13 & 1014 \\
\hline V656 & 14 & 737 \\
\hline V656 & 15 & 276 \\
\hline V656 & 16 & 430 \\
\hline V656 & 17 & 92 \\
\hline & & $\begin{array}{l}\text { No. of } \\
\text { Eneasurenturnts } \\
\text { Eaken }\end{array}$ \\
\hline & & M Mnimum $191.0 \%$ \\
\hline & & Maximum 104 \\
\hline
\end{tabular}

${ }^{a}$ All counts were $1 \mathrm{~min}$.

${ }^{b} \beta \mathrm{dpm} / 100 \mathrm{~cm}^{2}=\frac{N}{\mathrm{~T} \times \mathrm{ExG}}$

$\mathrm{N}=$ Net counts

$\mathrm{T}=$ Count time, $\min$

$\mathrm{E}=$ Detector efficiency, counts per disintegration

$\mathrm{G}=$ Probe area, $\mathrm{cm}^{2}$ divided by 100 


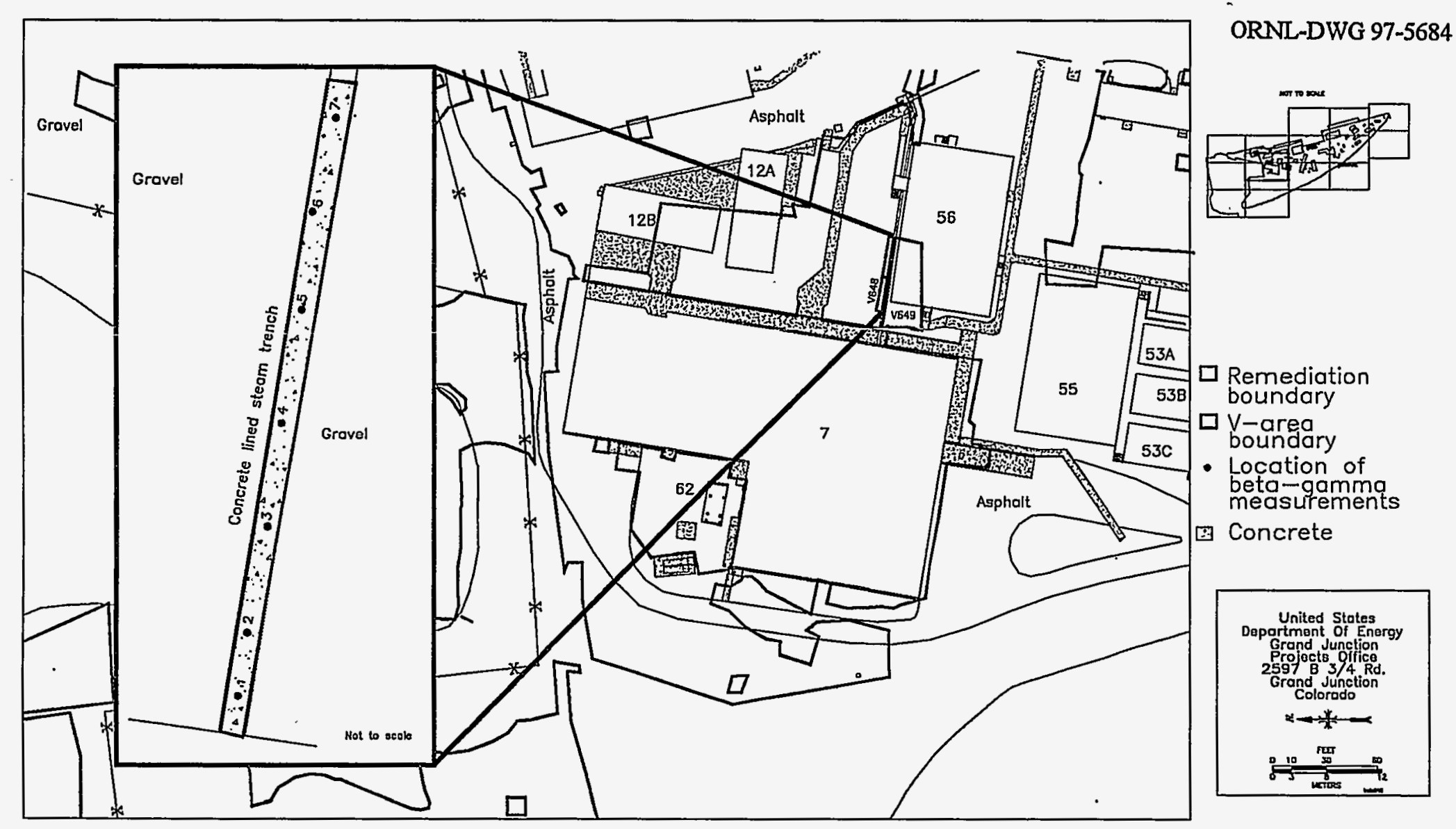

Fig. D.1. Surface activity measurement locations, V648 - V649. 
ORNL-DWG 97-5685
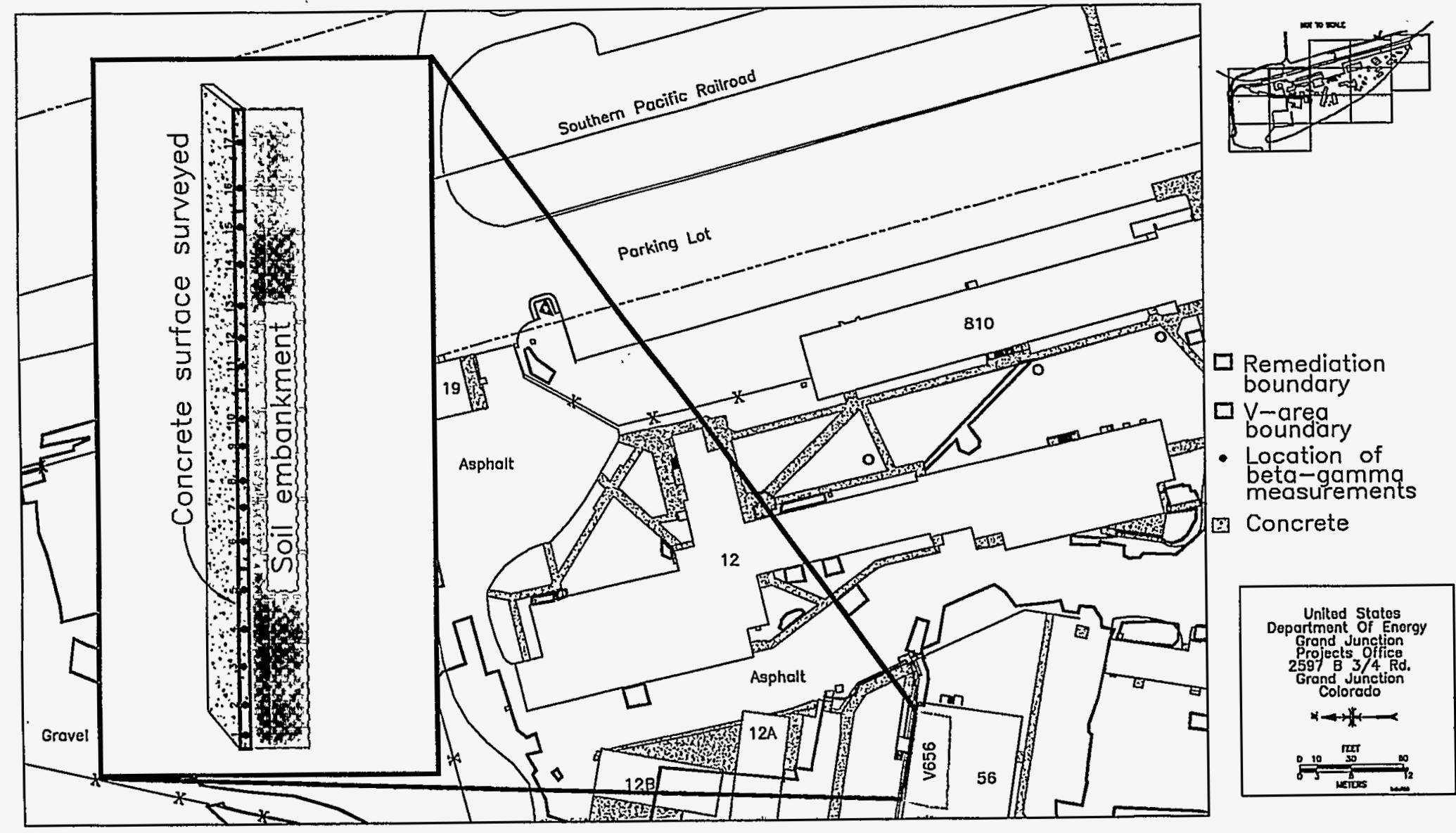

boundary

Location of

measurements

Fig. D.2. Surface activity measurement locations, V656. 
APPENDIX E

\section{SOL SAMPLE RESULTS}


Table E.1. Soil sample results

\begin{tabular}{||c|c|c|c|c|c|c|c|c|c||}
\hline \multirow{2}{*}{$\begin{array}{c}\text { Area } \\
\text { ID }\end{array}$} & $\begin{array}{c}\text { Depth, } \\
\text { in. }\end{array}$ & $\begin{array}{c}\text { ORNL/ETS } \\
\text { sample } \\
\text { identifier }\end{array}$ & \multicolumn{2}{|c|}{${ }^{226} \mathrm{Ra}$ concentrations, $\mathrm{pCi} / \mathrm{g}$} & \multicolumn{2}{|c||}{${ }^{230} \mathrm{Th}$ concentrations, $\mathrm{pCi} / \mathrm{g}$} & \multicolumn{2}{|c|}{ TotU concentrations, $\mathrm{pCi} / \mathrm{g}$} \\
\cline { 5 - 9 } & $\begin{array}{c}100 \mathrm{~m}^{2} \\
\text { composited }\end{array}$ & $+/-$ & $\begin{array}{c}100 \mathrm{~m}^{2} \\
\text { averaged } \\
\text { arithmetically }\end{array}$ & $\begin{array}{c}100 \mathrm{~m}^{2} \\
\text { composited }\end{array}$ & $+/-$ & $\begin{array}{c}100 \mathrm{~m}^{2} \\
\text { averaged } \\
\text { arithmetically }\end{array}$ & $\begin{array}{c}100 \mathrm{~m}^{2} \\
\text { composited }\end{array}$ & $\begin{array}{c}100 \mathrm{~m}^{2} \\
\text { averaged } \\
\text { arithmetically }\end{array}$ \\
\hline
\end{tabular}

\begin{tabular}{|c|c|c|c|c|c|c|c|c|c|}
\hline V16 & 20 & GP1AV0016 & 1.77 & 0.30 & & & & & \\
\hline V19 & 18 & GP1AV0019 & 1.19 & 0.30 & & & & & \\
\hline V27 & 18 & GP1AV0027 & 1.38 & 0.30 & 0.62 & 0.03 & & 3.57 & \\
\hline V319 & 40 & GP1AV0319 & 1.21 & 0.30 & 0.12 & 0.02 & & 2.88 & \\
\hline V323 & 77 & GP1AV0323 & 1.16 & 0.30 & & & & & \\
\hline V325 & 123 & GP1AV0325 & 1.16 & 0.30 & 0.21 & 0.02 & & 1.65 & \\
\hline V326 & 24 & GP1AV0326 & 1.15 & 0.30 & & & & & \\
\hline V332 & 125 & GP1AV0332 & 1.36 & 0.30 & 0.3 & 0.03 & & 2.88 & \\
\hline V335 & 120 & GP1AV0335 & 1.01 & 0.30 & & & & & \\
\hline RR01 & 6 & GP40VRR01 & 1.07 & 0.30 & & & & & \\
\hline RR02 & 6 & GP40VRR02 & 0.54 & 0.30 & & & & & \\
\hline RR03 & 6 & GP40VRR03 & 3.78 & 0.30 & & & & & \\
\hline V345 & 7 & GP1BV0345 & 2.34 & 0.30 & & & & & \\
\hline V343 & 76 & GP30V0343 & 3.65 & 0.30 & & & & & \\
\hline V344 & & GP30V0344 & $\begin{array}{l}\cdot \quad 10.88 \\
\end{array}$ & 0.30 & & & & & \\
\hline V347 & 12 & GP20V0347 & 2.28 & 0.30 & & & & & \\
\hline
\end{tabular}


Table E.1 (continued)

\begin{tabular}{||c|c|c|c|c|c|c|c|c|c||}
\hline \hline \multirow{2}{*}{$\begin{array}{c}\text { Area } \\
\text { ID }\end{array}$} & $\begin{array}{c}\text { Depth, } \\
\text { in. }\end{array}$ & $\begin{array}{c}\text { ORNL/ETS } \\
\text { sample } \\
\text { identifier }\end{array}$ & \multicolumn{2}{|c|}{${ }^{226} \mathrm{Ra}$ concentrations, $\mathrm{pCi} / \mathrm{g}$} & \multicolumn{2}{|c|}{${ }^{230} \mathrm{Th}$ concentrations, $\mathrm{pCi} / \mathrm{g}$} & \multicolumn{2}{|c|}{ Tol $\mathrm{U}$ concentrations, $\mathrm{pCi} / \mathrm{g}$} \\
\cline { 5 - 8 } & & $\begin{array}{c}100 \mathrm{~m}^{2} \\
\text { composited }\end{array}$ & $+/-$ & $\begin{array}{c}100 \mathrm{~m}^{2} \\
\text { averaged } \\
\text { arithmetically }\end{array}$ & $\begin{array}{c}100 \mathrm{~m}^{2} \\
\text { composited }\end{array}$ & $+1 /$ & $\begin{array}{c}100 \mathrm{~m}^{2} \\
\text { averaged } \\
\text { arithmetically }\end{array}$ & $\begin{array}{c}100 \mathrm{~m}^{2} \\
\text { composited }\end{array}$ & $\begin{array}{c}100 \mathrm{~m}^{2} \\
\text { averaged } \\
\text { arithmetically }\end{array}$ \\
\hline
\end{tabular}

\begin{tabular}{|c|c|c|c|c|c|c|c|}
\hline V363 & 24 & GP20V0363 & 2.71 & 0.30 & 0.81 & 0.05 & 8.24 \\
\hline V371 & 140 & GP20V0371 & 3.02 & 0.30 & & & \\
\hline V373 & 130 & GP20V0373 & 2.82 & 0.30 & & & \\
\hline V377 & 100 & GP20V0377 & 3.16 & 0.30 & 1.05 & 0.05 & 4.81 \\
\hline V379 & 144 & GP20V0379 & 3.03 & 0.30 & & & \\
\hline V380 & 80 & GP20V0380 & 5.35 & 0.30 & & & \\
\hline V382 & 6 & GP20V0382 & 1.78 & 0.30 & & & \\
\hline V386 & 160 & GP20V0386 & 2.13 & 0.30 & & & \\
\hline V387 & 130 & GP20V0387 & 2.10 & 0.30 & 1.51 & 0.08 & 6.11 \\
\hline R416 & 120 & GP20R0416 & 1.93 & 0.30 & 1.24 & 0.05 & 6.87 \\
\hline V430 & 82 & GP20V0430 & 6.95 & 0.40 & 4.05 & 0.27 & 7.56 \\
\hline V436 & 82 & GP20V0436 & 4.05 & 0.30 & 2.57 & 0.11 & 6.73 \\
\hline V443 & 24 & GP20V0443 & 3.83 & 0.30 & 1.59 & 0.08 & 6.04 \\
\hline V451 & 14 & GP1BV0451 & 2.12 & 0.30 & 0.22 & 0.02 & 4.67 \\
\hline V458 & 55 & GP1BV0458 & 3.54 & 0.30 & & & \\
\hline $\mathrm{V} 460$ & 12 & GP1BB0460 & 2.63 & 0.30 & & & \\
\hline V461 & 10 & GP1BB0461 & 2.40 & 0.30 & & & \\
\hline V459 & 20 & GP1BV0459 & 2.02 & 0.30 & 0.81 & 0.05 & 3.64 \\
\hline V480 & 12 & GP1BV0480 & 3.00 & 0.30 & 1.57 & 0.08 & 13.05 \\
\hline V489 & 10 & GP1BV0489 & 3.08 & 0.30 & & & \\
\hline $\mathrm{C} 502$ & 47 & GP2AC0502 & 9.79 & 0.69 & & & \\
\hline RC499 & 82 & GP2ARC499 & 5.22 & 0.40 & 2.97 & 0.27 & 10.99 \\
\hline
\end{tabular}


Table E.1 (continued)

\begin{tabular}{|c|c|c|c|c|c|c|c|c|c||}
\hline \hline \multirow{2}{*}{$\begin{array}{c}\text { Area } \\
\text { ID }\end{array}$} & $\begin{array}{c}\text { Depth, } \\
\text { in. }\end{array}$ & $\begin{array}{c}\text { ORNL/ETS } \\
\text { sample } \\
\text { identifier }\end{array}$ & \multicolumn{2}{|c|}{${ }^{226} \mathrm{Ra}$ concentrations, pCi/g } & \multicolumn{2}{|c|}{${ }^{230} \mathrm{Th}$ concentrations, $\mathrm{pCi} / \mathrm{g}$} & \multicolumn{2}{|c|}{ Tor U concentrations, $\mathrm{pCi} / \mathrm{g}$} \\
\cline { 5 - 8 } & & $\begin{array}{c}100 \mathrm{~m}^{2} \\
\text { composited }\end{array}$ & $+1-$ & $\begin{array}{c}100 \mathrm{~m}^{2} \\
\text { averaged } \\
\text { arithmetically }\end{array}$ & $\begin{array}{c}100 \mathrm{~m}^{2} \\
\text { composited }\end{array}$ & $+1-$ & $\begin{array}{c}100 \mathrm{~m}^{2} \\
\text { averaged } \\
\text { arithmetically }\end{array}$ & $\begin{array}{c}100 \mathrm{~m}^{2} \\
\text { composited }\end{array}$ & $\begin{array}{c}100 \mathrm{~m}^{2} \\
\text { averaged } \\
\text { arithmetically }\end{array}$ \\
\hline
\end{tabular}

\begin{tabular}{|c|c|c|c|c|c|c|c|c|c|c|}
\hline R503A & 47 & GP2AR503A & 3.26 & 0.30 & & 1.11 & 0.05 & & 8.24 & \\
\hline R503E & & GP2AR503E & 2.69 & 0.30 & & 0.76 & 0.05 & & 6.80 & \\
\hline R503F & & GP2AR503F & 4.29 & 0.30 & & 2.32 & 0.08 & & 4.53 & \\
\hline R503G & & GP2AR503G & 3.79 & 0.30 & & 2.48 & 0.08 & & 6.04 & \\
\hline $\mathrm{R} 503 \mathrm{~J}$ & & GP2AR503J & 3.27 & 0.30 & & 1.97 & 0.08 & & 6.11 & \\
\hline C505 & 82 & GP2AC0505 & 34.25 & 2.40 & 4.32 & 19.71 & 0.27 & 2.36 & 14.42 & 3.73 \\
\hline V505B & & GP2AV505B & 4.62 & 0.40 & & 3.24 & 0.27 & & 4.53 & \\
\hline V505D & & GP2AV505D & 5.17 & 0.40 & & 1.84 & 0.08 & & 8.93 & \\
\hline V505E & & GP2AV505E & 5.67 & 0.40 & & 4.59 & 0.27 & & 13.05 & \\
\hline V505G & & GP2AV505G & 3.45 & 0.30 & & 1.54 & 0.08 & & 5.49 & \\
\hline V505J & & GP2AV505J & 2.70 & 0.30 & & 0.59 & 0.05 & & 6.46 & \\
\hline RC506 & 82 & GP2ARC506 & 3.49 & 0.30 & 2.65 & 0.38 & 0.03 & 0.80 & 4.05 & 3.50 \\
\hline R506B & & GP2AR506B & 2.50 & 0.30 & & 0.18 & 0.02 & & 2.06 & \\
\hline R506D & & GP2AR506D & 2.65 & 0.30 & & 0.89 & 0.05 & & 2.40 & \\
\hline R506F & & GP2AR506F & 2.02 & 0.30 & & 0.86 & 0.05 & & 4.26 & \\
\hline R506H & & GP2AR506H & 2.37 & 0.30 & & 0.84 & 0.05 & & 3.78 & \\
\hline R506J & & GP2AR506J & 3.73 & 0.30 & & 1.22 & 0.11 & & 5.01 & $!$ \\
\hline CR510 & 82 & GP2ACR510 & 3.94 & 0.30 & 2.18 & 1.11 & 0.14 & 0.42 & 46.02 & 7.69 \\
\hline R510C & & GP2AR510C & 2.66 & 0.30 & & 0.86 & 0.08 & & 26.79 & \\
\hline R510D & & GP2AR510D & 2.04 & 0.30 & & 0.25 & 0.02 & & 3.64 & \\
\hline R510E & & GP2AR510E & 2.70 & 0.30 & & 0.86 & 0.05 & & 2.61 & \\
\hline R510G & & GP2AR510G & 1.90 & 0.30 & & 0.38 & 0.03 & & 9.62 & \\
\hline
\end{tabular}


Table E.1 (continued)

\begin{tabular}{|c|c|c|c|c|c|c|c|c|c||}
\hline \multirow{2}{*}{$\begin{array}{c}\text { Area } \\
\text { ID }\end{array}$} & $\begin{array}{c}\text { Depth, } \\
\text { in. }\end{array}$ & $\begin{array}{c}\text { ORNL/ETS } \\
\text { sample } \\
\text { identifier }\end{array}$ & \multicolumn{2}{|c|}{${ }^{226} \mathrm{Ra}$ concentrations, $\mathrm{pCi} / \mathrm{g}$} & \multicolumn{2}{|c|}{${ }^{230} \mathrm{Th}$ concentrations, $\mathrm{pCi} / \mathrm{g}$} & \multicolumn{2}{|c|}{ Tot U concentrations, pCi/g } \\
\cline { 5 - 9 } & $\begin{array}{c}100 \mathrm{~m}^{2} \\
\text { composited }\end{array}$ & $+/-$ & $\begin{array}{c}100 \mathrm{~m}^{2} \\
\text { averaged } \\
\text { arithmetically }\end{array}$ & $\begin{array}{c}100 \mathrm{~m}^{2} \\
\text { composited }\end{array}$ & $+/-$ & $\begin{array}{c}100 \mathrm{~m}^{2} \\
\text { averaged } \\
\text { arithmetically }\end{array}$ & $\begin{array}{c}100 \mathrm{~m}^{2} \\
\text { composited }\end{array}$ & $\begin{array}{c}100 \mathrm{~m}^{2} \\
\text { averaged } \\
\text { arithmetically }\end{array}$ \\
\hline
\end{tabular}

\begin{tabular}{|c|c|c|c|c|c|c|c|c|c|c|}
\hline $\mathrm{R} 510 \mathrm{H}$ & & GP2AR510H & 2.03 & 0.30 & & 0.21 & 0.02 & & 5.36 & \\
\hline R510I & & GP2AR510I & 1.83 & 0.30 & & 0.16 & 0.02 & . & 2.61 & \\
\hline R510J & & GP2AR510J & 2.10 & 0.30 & & 0.23 & 0.02 & & 3.23 & \\
\hline CR509 & 54 & GP2ACR509 & 3.78 & 0.30 & 2.01 & 1.51 & 0.08 & 0.27 & 4.88 & 3.27 \\
\hline R509A & & GP2AR509A & 2.48 & 0.30 & & 0.62 & 0.05 & & 4.53 & \\
\hline R509B & & GP2AR509B & 1.83 & 0.30 & & 0.23 & 0.03 & & 2.68 & \\
\hline $\mathrm{R} 509 \mathrm{C}$ & & GP2AR509C & 2.08 & 0.30 & & 0.18 & 0.02 & & 3.37 & \\
\hline R509D & & GP2AR509D & 1.89 & 0.30 & & 0.15 & 0.02 & & 2.13 & \\
\hline R509E & & GP2AR509E & 1.78 & 0.30 & & 0.17 & 0.02 & & 3.64 & \\
\hline $\mathrm{C} 513$ & 10 & GP3AC0513 & 3.47 & 0.30 & 2.30 & 2.16 & 0.11 & 0.69 & 21.29 & 10.56 \\
\hline V513A & & GP3AV513A & 1.85 & 0.30 & & 0.62 & 0.03 & & 16.48 & \\
\hline V513C & & GP3AV513C & 2.22 & 0.30 & & 1 & 0.05 & & 17.17 & \\
\hline V513E & & GP3AV513E & 1.86 & 0.30 & & 0.38 & 0.03 & & 4.67 & \\
\hline V513G & & GP3AV513G & 3.66 & 0.30 & & 1.27 & 0.08 & & 11.68 & \\
\hline V513K & & GP3AV513K & 1.91 & 0.30 & & 0.17 & 0.01 & & 2.82 & \\
\hline V516 & 8 & GP3AV0516 & 2.14 & 0.30 & & 0.35 & 0.03 & & 3.02 & \\
\hline C520 & 48 & $\mathrm{GP} 3 \mathrm{AC} 0520$ & 4.48 & 0.40 & 2.33 & 7.02 & 0.27 & 1.24 & 11.68 & 10.03 \\
\hline V520B & & GP3AV520B & 2.09 & 0.30 & & 0.32 & 0.03 & & 2.06 . & \\
\hline V520D & & GP3AV520D & 2.52 & 0.30 & & 1.7 & 0.08 & & 7.56 & \\
\hline V520F & & GP3AV520F & 2.35 & 0.30 & & 2.67 & 0.08 & & 9.62 & \\
\hline $\mathrm{V} 520 \mathrm{H}$ & & GP3AV520H & 2.46 & 0.30 & & 0.97 & 0.05 & & 11.68 & \\
\hline V520J & & GP3AV520J & 2.22 & 0.30 & & 0.54 & 0.03 & & 0.19 & \\
\hline
\end{tabular}


Table E.1 (continued)

\begin{tabular}{|c|c|c|c|c|c|c|c|c|c|c|}
\hline \multirow{2}{*}{$\begin{array}{l}\text { Area } \\
\text { ID }\end{array}$} & \multirow{2}{*}{$\begin{array}{l}\text { Depth, } \\
\text { in. }\end{array}$} & \multirow{2}{*}{$\begin{array}{l}\text { ORNL/ETS } \\
\text { sample } \\
\text { identifier }\end{array}$} & \multicolumn{3}{|c|}{${ }^{226} \mathrm{Ra}$ concentrations, $\mathrm{pCi} / \mathrm{g}$} & \multicolumn{3}{|c|}{${ }^{230} \mathrm{Th}$ concentrations, $\mathrm{pCi} / \mathrm{g}$} & \multicolumn{2}{|c|}{ 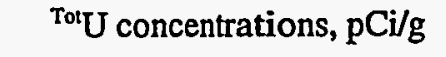 } \\
\hline & & & $\begin{array}{c}100 \mathrm{~m}^{2} \\
\text { composited }\end{array}$ & $+1-$ & $\begin{array}{c}100 \mathrm{~m}^{2} \\
\text { averaged } \\
\text { arithmetically }\end{array}$ & $\begin{array}{c}100 \mathrm{~m}^{2} \\
\text { composited }\end{array}$ & $+1-$ & $\begin{array}{c}100 \mathrm{~m}^{2} \\
\text { averaged } \\
\text { arithmetically }\end{array}$ & $\begin{array}{c}100 \mathrm{~m}^{2} \\
\text { composited }\end{array}$ & $\begin{array}{c}100 \mathrm{~m}^{2} \\
\text { averaged } \\
\text { arithmetically }\end{array}$ \\
\hline
\end{tabular}

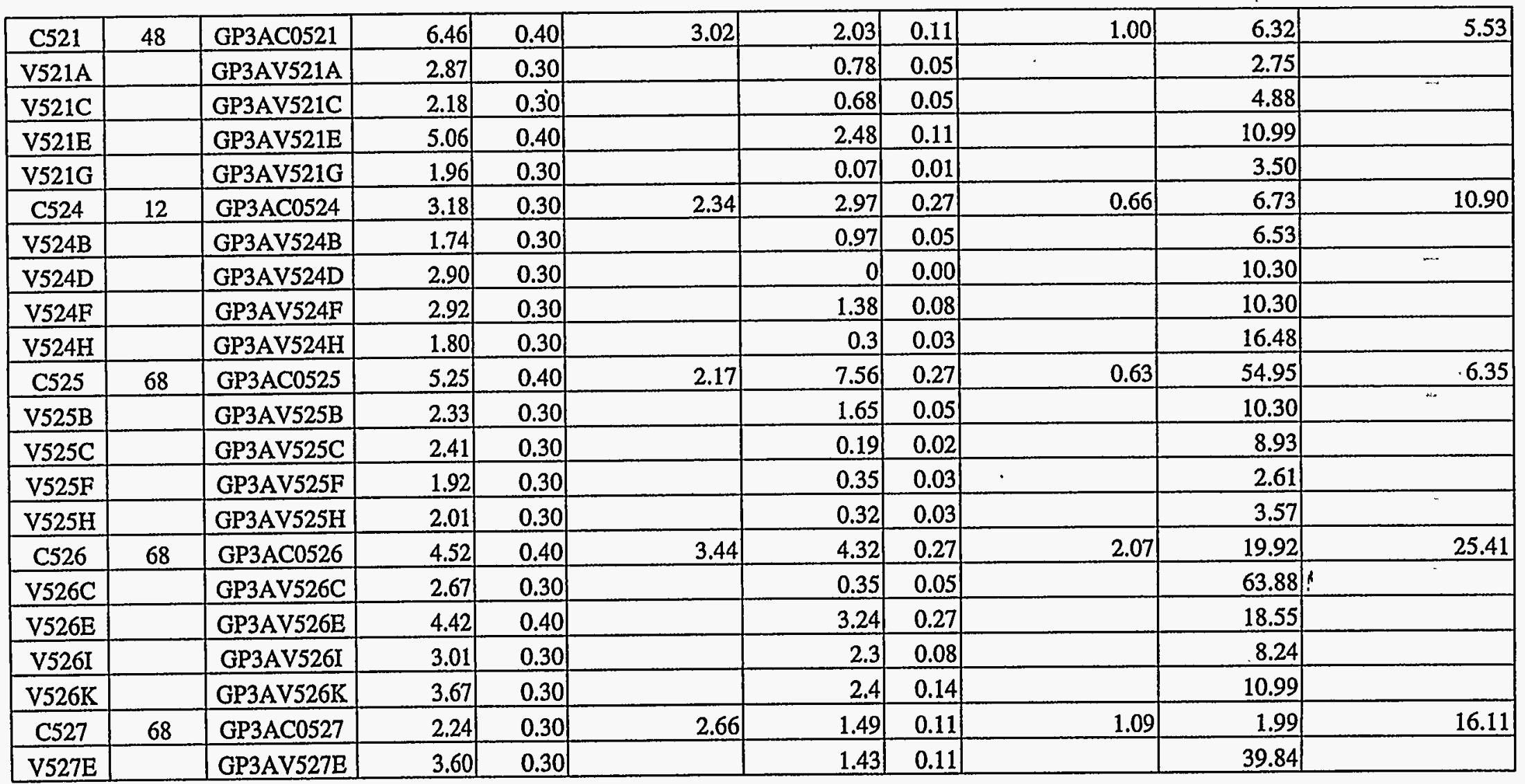


Table E.1 (continued)

\begin{tabular}{||c|c|c|c|c|c|c|c|c|c||}
\hline \multirow{2}{*}{$\begin{array}{c}\text { Area } \\
\text { ID }\end{array}$} & $\begin{array}{c}\text { Depth, } \\
\text { in. }\end{array}$ & $\begin{array}{c}\text { ORNL/ETS } \\
\text { sample } \\
\text { identifier }\end{array}$ & \multicolumn{2}{|c|}{${ }^{226} \mathrm{Ra}$ concentrations, $\mathrm{pCi} / \mathrm{g}$} & \multicolumn{2}{|c|}{${ }^{230} \mathrm{Th}$ concentrations, $\mathrm{pCi} / \mathrm{g}$} & \multicolumn{2}{|c|}{ ToiU concentrations, $\mathrm{pCi} / \mathrm{g}$} \\
\cline { 5 - 9 } & $\begin{array}{c}100 \mathrm{~m}^{2} \\
\text { composited }\end{array}$ & $+/-$ & $\begin{array}{c}100 \mathrm{~m}^{2} \\
\text { averaged } \\
\text { arithmetically }\end{array}$ & $\begin{array}{c}100 \mathrm{~m}^{2} \\
\text { composited }\end{array}$ & $+1 /-$ & $\begin{array}{c}100 \mathrm{~m}^{2} \\
\text { averaged } \\
\text { arithmetically }\end{array}$ & $\begin{array}{c}100 \mathrm{~m}^{2} \\
\text { composited }\end{array}$ & $\begin{array}{c}100 \mathrm{~m}^{2} \\
\text { averaged } \\
\text { arithmetically }\end{array}$ \\
\hline
\end{tabular}

\begin{tabular}{|c|c|c|c|c|c|c|c|c|c|c|}
\hline V527F & & GP3AV527F & 2.40 & 0.30 & & 0.54 & 0.05 & & 7.56 & \\
\hline V527K & & GP3AV527K & 2.27 & 0.30 & & 0.59 & 0.05 & & 15.80 & \\
\hline V527L & & GP3AV527L & 2.37 & 0.30 & & 1.81 & 0.11 & . & 1.24 & \\
\hline C529 & 68 & GP3AC0529 & 2.56 & 0.30 & 2.76 & 2.67 & 0.14 & 3.31 & 0.69 & 6.90 \\
\hline V529A & & GP3AV529A & 2.70 & 0.30 & & 5.13 & 0.27 & & 2.47 & \\
\hline V529E & & GP3AV529E & 1.99 & 0.30 & & 0.86 & 0.08 & & 2.95 & \\
\hline V529G & & GP3AV529G & 2.31 & 0.30 & & 1.03 & 0.05 & & 16.48 & \\
\hline $\mathrm{V} 529 \mathrm{H}$ & & GP3AV529H & 4.04 & 0.30 & & 6.21 & 0.27 & & 5.70 & \\
\hline C530 & 68 & GP3AC0530 & 5.29 & 0.40 & 3.56 & 1.27 & 0.05 & 1.95 & 5.77 & 2.70 \\
\hline $\mathrm{V} 530 \mathrm{~A}$ & & GP3AV530A & 2.29 & 0.30 & & 1.89 & 0.11 & & 2.82 & \\
\hline V530B & & GP3AV530B & 2.00 & 0.30 & & 0.32 & 0.03 & & 1.10 & \\
\hline V530G & & GP3AV530G & 7.66 & 0.54 & & 3.51 & 0.27 & & 4.33 & \\
\hline V530L & & GP3AV530L & 2.28 & 0.30 & & 2.08 & 0.16 & & 2.54 & \\
\hline C531 & 68 & GP3AC0531 & 6.52 & 0.40 & 2.76 & 2.97 & 0.27 & 1.24 & 1.44 & 13.55 \\
\hline V531I & & GP3AV531I & 3.12 & 0.30 & & 1.43 & 0.08 & & 41.90 & \\
\hline $\mathrm{V} 531 \mathrm{~J}$ & & GP3AV531J & 2.03 & 0.30 & & 0.16 & 0.02 & & 3.30 & \\
\hline V531K & & GP3AV531K & 2.86 & 0.30 & & 2.03 & 0.14 & & 6.59 & \\
\hline V531L & & GP3AV531L & 3.05 & 0.30 & & 1.35 & 0.11 & & 2.40 & \\
\hline C552 & 72 & GP1CC0552 & 2.19 & 0.30 & 1.99 & 0.35 & 0.05 & 0.41 & 35.85 & 11.98 \\
\hline V552A & & GP1CV552A & 1.96 & 0.30 & & 0.32 & 0.05 & & 26.51 & \\
\hline V552C & & GP1CV552C & 1.87 & 0.30 & & 0.51 & 0.03 & & 10.51 & \\
\hline V552F & & GP1CV552F & 2.10 & 0.30 & & 0.3 & 0.03 & & 3.08 & \\
\hline
\end{tabular}


Table E.1 (continued)

\begin{tabular}{|c|c|c|c|c|c|c|c|c|c|c|}
\hline \multirow{2}{*}{$\begin{array}{l}\text { Area } \\
\text { ID }\end{array}$} & \multirow{2}{*}{$\begin{array}{l}\text { Depth, } \\
\text { in. }\end{array}$} & \multirow{2}{*}{$\begin{array}{l}\text { ORNL/ETS } \\
\text { sample } \\
\text { identifier }\end{array}$} & \multicolumn{3}{|c|}{${ }^{226} \mathrm{Ra}$ concentrations, $\mathrm{pCi} / \mathrm{g}$} & \multicolumn{3}{|c|}{${ }^{230} \mathrm{Th}$ concentrations, $\mathrm{pCi} / \mathrm{g}$} & \multicolumn{2}{|c|}{${ }^{T o} \mathrm{U}$ concentrations, $\mathrm{p} \mathrm{Ci} / \mathrm{g}$} \\
\hline & & & $\begin{array}{c}100 \mathrm{~m}^{2} \\
\text { composited }\end{array}$ & +1 & $\begin{array}{c}100 \mathrm{~m}^{2} \\
\text { averaged } \\
\text { arithmetically }\end{array}$ & $\begin{array}{c}100 \mathrm{~m}^{2} \\
\text { composited }\end{array}$ & $+1-$ & $\begin{array}{c}100 \mathrm{~m}^{2} \\
\text { averaged } \\
\text { arithmetically }\end{array}$ & $\begin{array}{c}100 \mathrm{~m}^{2} \\
\text { composited }\end{array}$ & $\begin{array}{c}100 \mathrm{~m}^{2} \\
\text { averaged } \\
\text { arithmetically }\end{array}$ \\
\hline
\end{tabular}

\begin{tabular}{|c|c|c|c|c|c|c|c|c|c|c|}
\hline $\mathrm{V} 552 \mathrm{H}$ & & GP1CV552H & 2.02 & 0.30 & & 0.51 & 0.05 & & 7.83 & \\
\hline C590 & 42 & GP40C0590 & 2.38 & 0.30 & 2.76 & 2.46 & 0.08 & 3.65 & 14.42 & 11.35 \\
\hline V590A & & GP40V590A & 3.56 & 0.30 & & 5.67 & 0.27 & & 16.48 & \\
\hline V590D & & GP40V590D & 2.92 & 0.30 & & 3.51 & 0.27 & & 5.56 & \\
\hline $\mathrm{V} 590 \mathrm{H}$ & & GP40V590H & 3.02 & 0.30 & & 4.59 & 0.27 & & 8.24 & \\
\hline V590K & & GP40V590K & 1.52 & 0.30 & & 0.81 & 0.03 & & 15.11 & \\
\hline $\mathrm{C} 592$ & 44 & GP40C0592 & 5.05 & 0.40 & 3.38 & 3.24 & 0.27 & 3.30 & 16.32 & 33.38 \\
\hline V592E & & GP40V592E & 4.92 & 0.40 & . & 4.86 & 0.27 & & 30.91 & \\
\hline V592G & & GP40V592G & 2.84 & 0.30 & & 3.24 & 0.27 & & 41.90 & \\
\hline V592I & & GP40V592I & 2.41 & 0.30 & & 2.38 & 0.08 & & 46.02 & \\
\hline V592J & & GP40V592J & 3.36 & 0.30 & & 2.7 & 0.27 & & 14.42 & \\
\hline C594 & 36 & GP40C0594 & 6.24 & 0.40 & 2.81 & 4.05 & 0.27 & 2.44 & 57.01 & 28.00 \\
\hline V594A & & GP40V594A & 3.31 & 0.30 & & 2.48 & 0.08 & & 17.17 & \\
\hline V594B & & GP40V594B & 3.17 & 0.30 & & 2.97 & 0.27 & & 17.17 & \\
\hline V594D & & GP40V594D & 2.54 & 0.30 & & 1.7 & 0.08 & & 18.55 & \\
\hline V594F & & GP40V594F & 2.21 & 0.30 & & 2.62 & 0.08 & & 24.04 & \\
\hline $\mathrm{C} 613$ & 24 & GP40C 0613 & 4.85 & 0.40 & 1.82 & 7.56 & 0.27 & 2.21 & 82.42 & 9.10 \\
\hline V613B & & GP40V613B & 1.17 & 0.30 & & 0.7 & 0.03 & & 3.43 & \\
\hline V613D & & GP40V613D & 3.71 & 0.30 & & 5.94 & 0.27 & & 15.80 & \\
\hline V613J & & GP40V613J & 1.26 & 0.30 & & 1.7 & 0.08 & & 10.30 & \\
\hline V613L & & GP40V613L & 1.15 & 0.30 & & 0.51 & 0.08 & & 6.87 & \\
\hline C629 & 55 & GP3AC0629 & 12.00 & 0.84 & 1.98 & 35.1 & 2.70 & 7.20 & 14.42 & 9.32 \\
\hline
\end{tabular}


Table E.1 (continued)

\begin{tabular}{||c|c|c|c|c|c|c|c|c|c||}
\hline \multirow{2}{*}{$\begin{array}{c}\text { Area } \\
\text { ID }\end{array}$} & $\begin{array}{c}\text { Depth, } \\
\text { in. }\end{array}$ & $\begin{array}{c}\text { ORNL/ETS } \\
\text { sample } \\
\text { identifier }\end{array}$ & \multicolumn{2}{|c|}{${ }^{226} \mathrm{Ra}$ concentrations, $\mathrm{pCi} / \mathrm{g}$} & \multicolumn{2}{|c|}{${ }^{230} \mathrm{Th}$ concentrations, $\mathrm{pCi} / \mathrm{g}$} & \multicolumn{2}{|c|}{ TotU concentrations, $\mathrm{pCi} / \mathrm{g}$} \\
\cline { 5 - 9 } & & $\begin{array}{c}100 \mathrm{~m}^{2} \\
\text { composited }\end{array}$ & $+1 /$ & $\begin{array}{c}100 \mathrm{~m}^{2} \\
\text { averaged } \\
\text { arithmetically }\end{array}$ & $\begin{array}{c}100 \mathrm{~m}^{2} \\
\text { composited }\end{array}$ & $+1-$ & $\begin{array}{c}100 \mathrm{~m}^{2} \\
\text { averaged } \\
\text { arithmetically }\end{array}$ & $\begin{array}{c}100 \mathrm{~m}^{2} \\
\text { composited }\end{array}$ & $\begin{array}{c}100 \mathrm{~m}^{2} \\
\text { averaged } \\
\text { arithmetically }\end{array}$ \\
\hline
\end{tabular}

\begin{tabular}{|c|c|c|c|c|c|c|c|c|c|c|}
\hline V629A & & GP3AV629A & 1.67 & 0.30 & & 4.86 & 0.27 & & 3.92 & \\
\hline V629D & & GP3AV629D & 2.18 & 0.30 & & 8.64 & 0.27 & & 14.42 & \\
\hline $\mathrm{V} 629 \mathrm{~F}$ & & GP3AV629F & 2.10 & 0.30 & & 8.1 & 0.27 & & 9.62 & \\
\hline $\mathrm{C} 643$ & 55 & GP3AC0643 & 3.28 & 0.30 & 1.58 & 5.67 & 0.27 & 4.77 & 6.66 & 5.74 \\
\hline V643A & & GP3AV643A & 0.92 & 0.30 & & 1.65 & 0.11 & & 7.56 & \\
\hline V643D & & GP3AV643D & 3.38 & 0.30 & & 8.1 & 0.27 & & 8.24 & \\
\hline V643F & & GP3AV643F & 1.20 & 0.30 & & 8.91 & 0.27 & & 4.81 & \\
\hline V643J & & GP3AV643I & 0.83 & 0.30 & & 0.43 & 0.05 & & 2.34 & \\
\hline V656 & 72 & GP1CV0656 & 1.04 & 0.30 & & 0.14 & 0.02 & & 4.67 & \\
\hline V658 & 84 & GP1CV0658 & 0.99 & 0.30 & & 0.07 & 0.02 & & 5.56 & \\
\hline V670 & 64 & GP4AV0670 & 1.09 & 0.30 & & 0.04 & 0.01 & & 13.05 & \\
\hline V671 & 64 & GP4AV0671 & 1.46 & 0.30 & & 0.3 & 0.03 & & 39.84 & \\
\hline V673 & 64 & GP4AV0673 & 2.80 & 0.30 & & 0.49 & 0.05 & & 4.05 & \\
\hline V675A & 18 & GP4AV675A & 1.26 & 0.30 & 1.23 & 0.27 & 0.03 & 0.33 & & \\
\hline V675B & & GP4AV675B & 1.06 & 0.30 & & 0.27 & 0.04 & & & \\
\hline V675C & & GP4AV675C & 0.75 & 0.30 & & 0.15 & 0.03 & & & \\
\hline V675D & & GP4AV675D & 1.48 & 0.30 & & 0.54 & 0.05 & & & $!$ \\
\hline V675E & & GP4AV675E & 1.26 & 0.30 & & 0.35 & 0.05 & & & \\
\hline V675F & & GP4AV675F & 0.97 & 0.30 & & 0.35 & 0.05 & & & \\
\hline V675G & & GP4AV675G & 1.60 & 0.30 & & 0.41 & 0.05 & & & \\
\hline $\mathrm{V} 675 \mathrm{H}$ & & GP4AV675H & 1.46 & 0.30 & & 0.3 & 0.03 & & & \\
\hline V677A & 20 & GP4AV677A & 1.64 & 0.30 & 1.21 & 1.03 & 0.08 & 0.41 & & \\
\hline
\end{tabular}


Table E.1 (continued)

\begin{tabular}{|c|c|c|c|c|c|c|c|c|c|c|}
\hline \multirow{2}{*}{$\begin{array}{c}\text { Area } \\
\text { ID }\end{array}$} & \multirow{2}{*}{$\begin{array}{l}\text { Depth, } \\
\text { in. }\end{array}$} & \multirow{2}{*}{$\begin{array}{l}\text { ORNL/ETS } \\
\text { sample } \\
\text { identifier }\end{array}$} & \multicolumn{3}{|c|}{${ }^{226} \mathrm{Ra}$ concentrations, $\mathrm{pCi} / \mathrm{g}$} & \multicolumn{3}{|c|}{${ }^{230} \mathrm{Th}$ concentrations, $\mathrm{pCi} / \mathrm{g}$} & \multicolumn{2}{|c|}{${ }^{\mathrm{T} t} \mathrm{U}$ concentrations, $\mathrm{pCi} / \mathrm{g}$} \\
\hline & & & $\begin{array}{c}100 \mathrm{~m}^{2} \\
\text { composited }\end{array}$ & $+1-$ & $\begin{array}{c}100 \mathrm{~m}^{2} \\
\text { averaged } \\
\text { arithmetically }\end{array}$ & $\begin{array}{c}100 \mathrm{~m}^{2} \\
\text { composited }\end{array}$ & +1 & $\begin{array}{c}100 \mathrm{~m}^{2} \\
\text { averaged } \\
\text { arithmetically }\end{array}$ & $\begin{array}{c}100 \mathrm{~m}^{2} \\
\text { composited }\end{array}$ & $\begin{array}{c}100 \mathrm{~m}^{2} \\
\text { averaged } \\
\text { arithmetically }\end{array}$ \\
\hline
\end{tabular}

\begin{tabular}{|c|c|c|c|c|c|c|c|c|c|c|c|}
\hline V677B & & GP4AV677B & 1.02 & 0.30 & & 0.43 & 0.05 & & & & \\
\hline V677C & & GP4AV677C & 1.20 & 0.30 & & 0.26 & 0.04 & & & & \\
\hline V677D & & GP4AV677D & 1.05 & 0.30 & & 0.46 & 0.05 & & & & \\
\hline V677E & & GP4AV677E & 1.25 & 0.30 & & 0.41 & 0.05 & & & & \\
\hline V677F & & GP4AV677F & 0.97 & 0.30 & & 0.24 & 0.04 & & & & \\
\hline V677G & & GP4AV677G & 1.04 & 0.30 & & 0.21 & 0.03 & & & & \\
\hline $\mathrm{V} 677 \mathrm{H}$ & & GP4AV677H & 1.10 & 0.30 & & 0.54 & 0.05 & & & & \\
\hline V677I & & GP4AV677I & 1.17 & 0.30 & & 0.19 & 0.03 & & & & \\
\hline V677J & & GP4AV677J & 1.56 & 0.30 & & 0.49 & 0.05 & & & 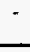 & \\
\hline V677K & & GP4AV677K & 1.28 & 0.30 & & 0.27 & 0.05 & & & & \\
\hline V707A & 24 & GP4AV707A & 1.11 & 0.30 & 1.09 & 0.19 & 0.03 & 0.50 & 1.03 & & 1.28 \\
\hline V707B & & GP4AV707B & 0.88 & 0.30 & & 0.76 & 0.05 & & 1.24 & & \\
\hline V707C & & GP4AV707C & 1.20 & 0.30 & & 0.76 & 0.11 & & 1.17 & & \\
\hline V707D & & GP4AV707D & 1.17 & 0.30 & & 1.19 & 0.11 & & 3.09 & & \\
\hline V707E & & GP4AV707E & 1.06 & 0.30 & & 0.26 & 0.04 & & 1.31 & & \\
\hline V707F & & GP4AV707F & 1.04 & 0.30 & & 0.43 & 0.08 & & 0.96 & & \\
\hline V707G & & GP4AV707G & 1.20 & 0.30 & & 0.25 & 0.03 & & 1.10 & & \\
\hline $\mathrm{V} 707 \mathrm{H}$ & & GP4AV707H & 1.06 & 0.30 & & 0.3 & 0.03 & & 1.03 & & \\
\hline V707I & & GP4AV707I & 1.11 & 0.30 & & 0.35 & 0.05 & & 0.63 & & \\
\hline V714 & 36 & GP4AV714A & 0.80 & 0.30 & 1.04 & 0.23 & 0.03 & 1.12 & 1.31 & & 2.56 \\
\hline V714 & & GP4AV714B & 1.28 & 0.30 & & 1.03 & 0.08 & & 3.71 & & \\
\hline V714 & & GP4AV714C & 0.91 & 0.30 & & 0.26 & 0.04 & & 1.65 & & \\
\hline
\end{tabular}


Table E.1 (continued)

\begin{tabular}{|c|c|c|c|c|c|c|c|c|c|c|}
\hline \multirow{2}{*}{$\begin{array}{l}\text { Area } \\
\text { ID }\end{array}$} & \multirow{2}{*}{$\begin{array}{l}\text { Depth, } \\
\text { in. }\end{array}$} & \multirow{2}{*}{$\begin{array}{l}\text { ORNL/ETS } \\
\text { sample } \\
\text { identifier }\end{array}$} & \multicolumn{3}{|c|}{${ }^{226} \mathrm{Ra}$ concentrations, $\mathrm{pCi} / \mathrm{g}$} & \multicolumn{3}{|c|}{${ }^{230} \mathrm{Th}$ concentrations, $\mathrm{pCi} / \mathrm{g}$} & \multicolumn{2}{|c|}{${ }^{T o 1} \mathrm{U}$ concentrations, $\mathrm{pCi} / \mathrm{g}$} \\
\hline & & & $\begin{array}{c}100 \mathrm{~m}^{2} \\
\text { composited }\end{array}$ & $+1-$ & $\begin{array}{c}100 \mathrm{~m}^{2} \\
\text { averaged } \\
\text { arithmetically }\end{array}$ & $\begin{array}{c}100 \mathrm{~m}^{2} \\
\text { composited }\end{array}$ & $+\%$ & $\begin{array}{c}100 \mathrm{~m}^{2} \\
\text { averaged } \\
\text { arithmetically }\end{array}$ & $\begin{array}{c}100 \mathrm{~m}^{2} \\
\text { composited }\end{array}$ & $\begin{array}{c}100 \mathrm{~m}^{2} \\
\text { averaged } \\
\text { arithmetically }\end{array}$ \\
\hline
\end{tabular}

\begin{tabular}{|c|c|c|c|c|c|c|c|c|c|c|}
\hline V714 & & GP4AV714D & 1.16 & 0.30 & & 2.97 & 0.27 & & 3.57 & \\
\hline V722A & 60 & GP4AV722A & 1.77 & 0.30 & 1.56 & 2.57 & 0.11 & 1.37 & 3.64 & 3.58 \\
\hline V722B & & GP4AV722B & 3.21 & 0.30 & & 1.92 & 0.11 & & 3.02 & \\
\hline V722C & & GP4AV722C & 1.72 & 0.30 & & 1.49 & 0.11 & & 3.16 & \\
\hline V722D & & GP4AV722D & 1.17 & 0.30 & & 0.35 & 0.05 & & 2.20 & \\
\hline V722E & & GP4AV722E & 1.19 & 0.30 & & 0.46 & 0.05 & & 1.37 & \\
\hline $\mathrm{V} 722 \mathrm{~F}$ & & GP4AV722F & 1.29 & 0.30 & & 1 & 0.05 & & 3.23 & \\
\hline V722G & & GP4AV722G & 1.05 & 0.30 & & 2.4 & 0.14 & & 3.43 & \\
\hline $\mathrm{V} 722 \mathrm{H}$ & & GP4AV722H & 1.19 & 0.30 & & 0.73 & 0.03 & & 4.67 & \\
\hline V722I & & GP4AV722I & 1.42 & 0.30 & & 2.03 & 0.11 & & 6.11 & \\
\hline V725 & 60 & GP4AV725A & 1.31 & 0.30 & 1.37 & 3.78 & 0.27 & 3.91 & 4.67 & 4.41 \\
\hline V725 & & GP4AV725B & 1.34 & 0.30 & & 3.51 & 0.27 & & 3.71 & \\
\hline V725 & & GP4AV725C & 1.46 & 0.30 & & 4.86 & 0.27 & & 4.67 & \\
\hline V725 & & GP4AV725D & 1.38 & 0.30 & & 3.51 & 0.27 & & 4.60 & \\
\hline V740 & 24 & GP4AV740A & 0.97 & 0.30 & 1.22 & 0.38 & 0.05 & 0.42 & 1.72 & 2.32 \\
\hline V740 & & GP4AV740B & 1.39 & 0.30 & & 0.43 & 0.05 & & 1.92 & \\
\hline V740 & & GP4AV740C & 0.97 & 0.30 & & 0.51 & 0.05 & & 3.30 & \\
\hline V740 & & GP4AV740D & 1.56 & 0.30 & & 0.35 & 0.05 & & 2.34 & \\
\hline V745A & 42 & GP4AV745A & 1.08 & 0.30 & 1.68 & 0.32 & 0.03 & 2.06 & 6.53 & 4.11 \\
\hline V745B & & GP4AV745B & 1.37 & 0.30 & & 0.86 & 0.05 & & 8.24 & \\
\hline V745C & & GP4AV745C & 3.06 & 0.30 & & 2.4 & 0.08 & & 2.54 & \\
\hline V745D & & GP4AV745D & 1.89 & 0.30 & & 1.78 & 0.08 & & 2.82 & \\
\hline
\end{tabular}


Table E.1 (continued)

\begin{tabular}{|c|c|c|c|c|c|c|c|c|c|c|}
\hline \multirow{2}{*}{$\begin{array}{c}\text { Area } \\
\text { ID }\end{array}$} & \multirow{2}{*}{$\begin{array}{l}\text { Depth, } \\
\text { in. }\end{array}$} & \multirow{2}{*}{$\begin{array}{c}\text { ORNL/ETS } \\
\text { sample } \\
\text { identifier }\end{array}$} & \multicolumn{3}{|c|}{${ }^{226} \mathrm{Ra}$ concentrations, $\mathrm{pCi} / \mathrm{g}$} & \multicolumn{3}{|c|}{${ }^{230} \mathrm{Th}$ concentrations, $\mathrm{pCi} / \mathrm{g}$} & \multicolumn{2}{|c|}{${ }^{T o} \mathrm{U}$ concentrations, $\mathrm{pCi} / \mathrm{g}$} \\
\hline & & & $\begin{array}{c}100 \mathrm{~m}^{2} \\
\text { composited }\end{array}$ & $+1-$ & $\begin{array}{c}100 \mathrm{~m}^{2} \\
\text { averaged } \\
\text { arithmetically }\end{array}$ & $\begin{array}{c}100 \mathrm{~m}^{2} \\
\text { composited }\end{array}$ & $+/$ & $\begin{array}{c}100 \mathrm{~m}^{2} \\
\text { averaged } \\
\text { arithmetically }\end{array}$ & $\begin{array}{c}100 \mathrm{~m}^{2} \\
\text { composited }\end{array}$ & $\begin{array}{c}100 \mathrm{~m}^{2} \\
\text { averaged } \\
\text { arithmetically }\end{array}$ \\
\hline
\end{tabular}

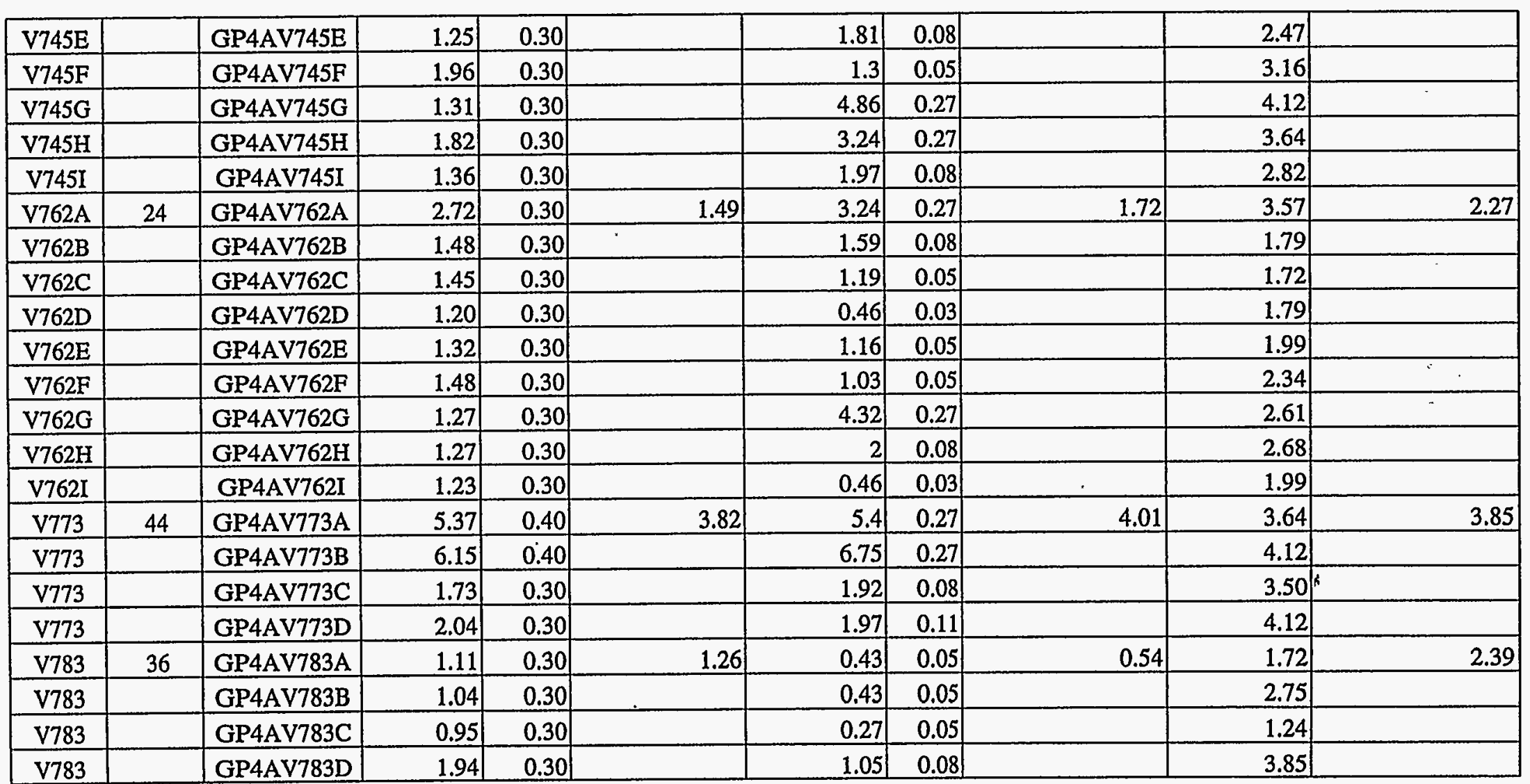


Table E.1 (continued)

\begin{tabular}{|c|c|c|c|c|c|c|c|c|c|c|}
\hline \multirow{2}{*}{$\begin{array}{l}\text { Area } \\
\text { ID }\end{array}$} & \multirow{2}{*}{$\begin{array}{l}\text { Depth, } \\
\text { in. }\end{array}$} & \multirow{2}{*}{$\begin{array}{c}\text { ORNL/ETS } \\
\text { sample } \\
\text { identifier }\end{array}$} & \multicolumn{3}{|c|}{${ }^{226} \mathrm{Ra}$ concentrations, $\mathrm{pCi} / \mathrm{g}$} & \multicolumn{3}{|c|}{${ }^{230} \mathrm{Th}$ concentrations, $\mathrm{pCi} / \mathrm{g}$} & \multicolumn{2}{|c|}{ Tot $\mathrm{U}$ concentrations, $\mathrm{pCi} / \mathrm{g}$} \\
\hline & & & $\begin{array}{c}100 \mathrm{~m}^{2} \\
\text { composited }\end{array}$ & +1 & $\begin{array}{c}100 \mathrm{~m}^{2} \\
\text { averaged } \\
\text { arithmetically }\end{array}$ & $\begin{array}{c}100 \mathrm{~m}^{2} \\
\text { composited }\end{array}$ & $+1-$ & $\begin{array}{c}100 \mathrm{~m}^{2} \\
\text { averaged } \\
\text { arithmetically }\end{array}$ & $\begin{array}{c}100 \mathrm{~m}^{2} \\
\text { composited }\end{array}$ & $\begin{array}{c}100 \mathrm{~m}^{2} \\
\text { averaged } \\
\text { arithmetically }\end{array}$ \\
\hline
\end{tabular}

\begin{tabular}{|c|c|c|c|c|c|c|c|c|c|c|}
\hline V785 & 43 & GP4AV785A & 1.34 & 0.30 & 1.27 & 0.3 & 0.05 & 0.48 & 1.79 & 2.35 \\
\hline V785 & & GP4AV785B & 1.07 & 0.30 & & 0.43 & 0.05 & & 2.54 & \\
\hline V785 & & GP4AV785C & 1.30 & 0.30 & & 0.62 & 0.08 & & 2.06 & \\
\hline V785 & & GP4AV785D & 1.39 & 0.30 & & 0.57 & 0.11 & & 3.02 & \\
\hline V795 & 24 & GP4AV795A & 0.93 & 0.30 & 1.01 & 0.27 & 0.03 & 0.31 & 2.75 & 2.75 \\
\hline V795 & & GP4AV795B & 1.07 & 0.30 & & 0.46 & 0.03 & & & \\
\hline V795 & & GP4AV795C & 1.03 & 0.30 & & 0.22 & 0.02 & & 3.02 & \\
\hline V799 & 18 & GP4AV799A & 0.98 & 0.30 & 1.16 & 0.3 & 0.03 & 0.35 & 4.33 & 3.14 \\
\hline V799 & & GP4AV799B & 1.64 & 0.30 & & 0.46 & 0.05 & & 2.82 & \\
\hline V799 & & GP4AV799C & 1.16 & 0.30 & & 0.32 & 0.03 & & 3.43 & \\
\hline V799 & & GP4AV799D & 0.88 & 0.30 & & 0.32 & 0.03 & & 1.99 & \\
\hline V808 & 18 & GP4AV808A & 0.84 & 0.30 & 0.98 & 0.32 & 0.03 & 0.34 & 2.40 & 3.67 \\
\hline V808 & & GP4AV808B & 0.97 & 0.30 & & 0.27 & 0.03 & & 2.95 & \\
\hline V808 & & GP4AV808D & 0.94 & 0.30 & & 0.43 & 0.03 & & 4.26 & \\
\hline V814 & 9 & GP4AC0814 & & & 0.95 & 0.26 & 0.03 & & 2.27 & \\
\hline V814 & & GP4AV814A & 0.87 & 0.30 & & & & & & \\
\hline V814 & & GP4AV814B & 0.94 & 0.30 & & & & & & \\
\hline V814 & & GP4AV814C & 0.99 & 0.30 & & & & & & \\
\hline V814 & & GP4AV814D & 0.98 & 0.30 & & & & & & \\
\hline V830 & 48 & GP4AC0830 & & & 1.27 & 0.38 & 0.03 & & 2.88 & \\
\hline
\end{tabular}


Table E.1 (continued)

\begin{tabular}{||c|c|c|c|c|c|c|c|c|c||}
\hline \multirow{2}{*}{$\begin{array}{c}\text { Area } \\
\text { ID }\end{array}$} & $\begin{array}{c}\text { Depth, } \\
\text { in. }\end{array}$ & $\begin{array}{c}\text { ORNL/ETS } \\
\text { sample } \\
\text { identifier }\end{array}$ & \multicolumn{2}{|c|}{${ }^{226}$ Ra concentrations, pCi/g } & \multicolumn{2}{|c|}{${ }^{230} \mathrm{Th}$ concentrations, $\mathrm{pCi} / \mathrm{g}$} & \multicolumn{2}{|c|}{ TotU concentrations, pCi/g } \\
\cline { 4 - 8 } & & $\begin{array}{c}100 \mathrm{~m}^{2} \\
\text { composited }\end{array}$ & $+/-$ & $\begin{array}{c}100 \mathrm{~m}^{2} \\
\text { averaged } \\
\text { arithmetically }\end{array}$ & $\begin{array}{c}100 \mathrm{~m}^{2} \\
\text { composited }\end{array}$ & $+/-$ & $\begin{array}{c}100 \mathrm{~m}^{2} \\
\text { averaged } \\
\text { arithmetically }\end{array}$ & $\begin{array}{c}100 \mathrm{~m}^{2} \\
\text { composited }\end{array}$ & $\begin{array}{c}100 \mathrm{~m}^{2} \\
\text { averaged } \\
\text { arithmetically }\end{array}$ \\
\hline
\end{tabular}

\begin{tabular}{|c|c|c|c|c|c|c|c|c|c|c|}
\hline V830 & & \begin{tabular}{|l|} 
GP4AV830A \\
\end{tabular} & 1.04 & 0.30 & & & & & & \\
\hline V830 & & GP4AV830B & 0.98 & 0.30 & & & & & & \\
\hline V830 & & GP4AV830C & 1.78 & 0.30 & & & & & & \\
\hline V830 & & GP4AV830D & 1.29 & 0.30 & & & & & & \\
\hline V840 & 42 & GP4AC0840 & & & 1.06 & 0.35 & 0.03 & & 0.69 & \\
\hline V840 & & GP4AV840A & 0.98 & 0.30 & & & & & & \\
\hline V840 & & GP4AV840B & 0.99 & 0.30 & & & & & & \\
\hline V840 & & GP4AV840C & 1.43 & 0.30 & & & & & & \\
\hline V840 & & GP4AV840D & 0.85 & 0.30 & & & & & & \\
\hline V860 & 42 & GP4AC0860 & & & 1.01 & 0.35 & 0.03 & & 1.79 & \\
\hline V860 & & GP4AV860A & 1.06 & 0.30 & & & & & & $\cdot$ \\
\hline V860 & & GP4AV860B & 0.98 & 0.30 & & & & & & $\because$ \\
\hline V860 & & GP4AV860C & 1.06 & 0.30 & & & & & & \\
\hline V860 & & GP4AV860D & 0.95 & 0.30 & & & & & & \\
\hline V865 & 36 & GP4AC0865 & & & 1.33 & 0.7 & 0.05 & & 3.64 & i \\
\hline V865 & & GP4AV865A & 1.30 & 0.30 & & & & & & . \\
\hline V865 & & GP4AV865B & 1.71 & 0.30 & & & & & & 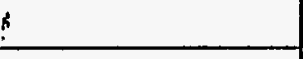 \\
\hline V865 & & GP4AV865C & 1.22 & 0.30 & & & & & & \\
\hline V865 & & GP4AV865D & 1.07 & 0.30 & & & & & & \\
\hline V871 & 54 & GP4AV871A & 1.31 & 0.30 & 1.47 & 0.46 & 0.05 & 1.16 & 6.53 & 4.53 \\
\hline V871 & & GP4AV871B & 0.94 & 0.30 & & 0.35 & 0.03 & & 1.24 & \\
\hline V871 & & GP4AV871C & 1.26 & 0.30 & & 0.32 & 0.03 & & 2.13 & \\
\hline
\end{tabular}


Table E.1 (continued)

\begin{tabular}{|c|c|c|c|c|c|c|c|c|c|c|}
\hline \multirow{2}{*}{$\begin{array}{c}\text { Area } \\
\text { ID }\end{array}$} & \multirow{2}{*}{$\begin{array}{l}\text { Depth, } \\
\text { in. }\end{array}$} & \multirow{2}{*}{$\begin{array}{l}\text { ORNL/ETS } \\
\text { sample } \\
\text { identifier }\end{array}$} & \multicolumn{3}{|c|}{${ }^{226} \mathrm{Ra}$ concentrations, $\mathrm{pCi} / \mathrm{g}$} & \multicolumn{3}{|c|}{${ }^{230} \mathrm{Th}$ concentrations, $\mathrm{pCi} / \mathrm{g}$} & \multicolumn{2}{|c|}{ Tot $\mathrm{U}$ concentrations, $\mathrm{pCi} / \mathrm{g}$} \\
\hline & & & $\begin{array}{c}100 \mathrm{~m}^{2} \\
\text { composited }\end{array}$ & $+1-$ & $\begin{array}{c}100 \mathrm{~m}^{2} \\
\text { averaged } \\
\text { arithmetically }\end{array}$ & $\begin{array}{c}100 \mathrm{~m}^{2} \\
\text { composited }\end{array}$ & $+1-$ & $\begin{array}{c}100 \mathrm{~m}^{2} \\
\text { averaged } \\
\text { arithmetically }\end{array}$ & $\begin{array}{c}100 \mathrm{~m}^{2} \\
\text { composited }\end{array}$ & $\begin{array}{c}100 \mathrm{~m}^{2} \\
\text { averaged } \\
\text { arithmetically }\end{array}$ \\
\hline
\end{tabular}

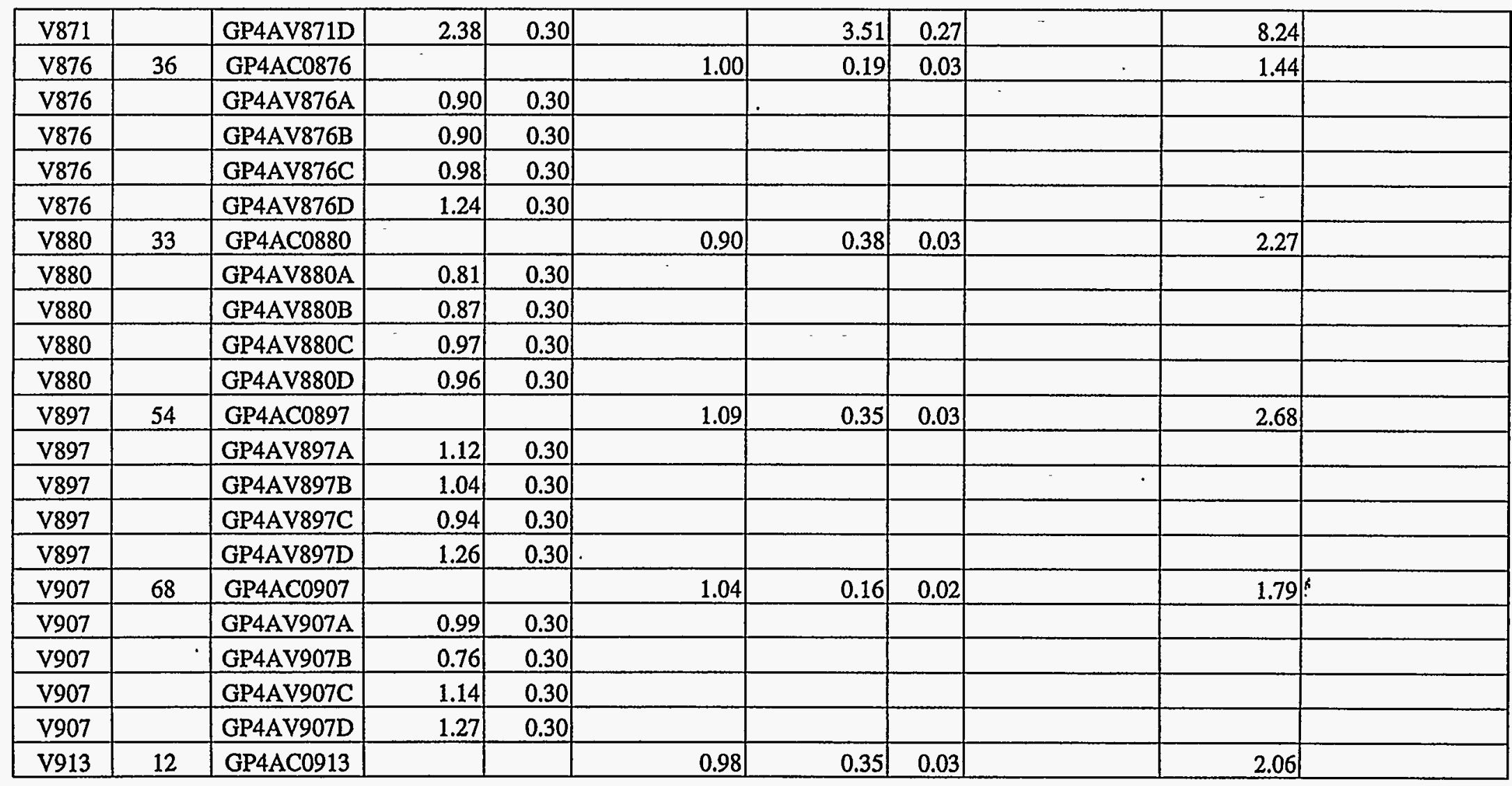


Table E.1 (continued)

\begin{tabular}{|c|c|c|c|c|c|c|c|c|c|c|}
\hline \multirow{2}{*}{$\begin{array}{c}\text { Area } \\
\text { ID }\end{array}$} & \multirow{2}{*}{$\begin{array}{l}\text { Depth, } \\
\text { in. }\end{array}$} & \multirow{2}{*}{$\begin{array}{c}\text { ORNL/ETS } \\
\text { sample } \\
\text { identifier }\end{array}$} & \multicolumn{3}{|c|}{${ }^{226} \mathrm{Ra}$ concentrations, $\mathrm{pCi} / \mathrm{g}$} & \multicolumn{3}{|c|}{${ }^{230} \mathrm{Th}$ concentrations, $\mathrm{pCi} / \mathrm{g}$} & \multicolumn{2}{|c|}{${ }^{\text {Tot }} \mathrm{U}$ concentrations, $\mathrm{pCi} / \mathrm{g}$} \\
\hline & & & $\begin{array}{c}100 \mathrm{~m}^{2} \\
\text { composited }\end{array}$ & $+/-$ & $\begin{array}{c}100 \mathrm{~m}^{2} \\
\text { averaged } \\
\text { arithmetically }\end{array}$ & $\begin{array}{c}100 \mathrm{~m}^{2} \\
\text { composited }\end{array}$ & $+/-$ & $\begin{array}{c}100 \mathrm{~m}^{2} \\
\text { averaged } \\
\text { arithmetically }\end{array}$ & $\begin{array}{c}100 \mathrm{~m}^{2} \\
\text { composited }\end{array}$ & $\begin{array}{c}100 \mathrm{~m}^{2} \\
\text { averaged } \\
\text { arithmetically }\end{array}$ \\
\hline
\end{tabular}

\begin{tabular}{|c|c|c|c|c|c|c|c|c|c|c|}
\hline V913 & & GP4AV913A & 1.07 & 0.30 & & & & & & \\
\hline Y913 & & GP4AV913B & 0.93 & 0.30 & & & & & & \\
\hline V913 & & GP4AV913C & 1.06 & 0.30 & & & & & & \\
\hline V913 & & GP4AV913D & 0.86 & 0.30 & & & & & & \\
\hline V928 & 18 & GP4AC0928 & & & 0.96 & 0.32 & 0.03 & & 1.37 & \\
\hline V928 & & \begin{tabular}{|l|} 
GP4AV928A \\
\end{tabular} & 1.04 & 0.30 & & & & & & \\
\hline V928 & & GP4AV928B & 0.95 & 0.30 & & & & & & \\
\hline V928 & & GP4AV928C & 0.99 & 0.30 & & & & & & \\
\hline V928 & & GP4AV928D & 0.86 & 0.30 & & & & & & \\
\hline V932 & 36 & GP4AC0932 & & & 1.01 & 0.3 & 0.03 & & 1.58 & \\
\hline V932 & & \begin{tabular}{|l|} 
GP4AV932A \\
\end{tabular} & 1.24 & 0.30 & & & & & & \\
\hline V932 & & GP4AV932B & 0.92 & 0.30 & & & & & & \\
\hline V932 & & GP4AV932C & 1.17 & 0.30 & & & & & & \\
\hline V932 & & GP4AV932D & 0.72 & 0.30 & & & & & & \\
\hline V938 & 72 & GP4AC0938 & & & 2.67 & 0.38 & 0.03 & & 1.65 & \\
\hline V938 & & GP4AV938A & 0.99 & 0.30 & & & & & & \\
\hline V938 & & GP4AV938B & 7.63 & 0.53 & & & & & & \\
\hline V938 & - & GP4AV938C & 1.01 & 0.30 & & & & & & \\
\hline V938 & & GP4AV938D & 1.06 & 0.30 & & & & & & \\
\hline V941 & 66 & GP4AC0941 & & & 1.33 & 0.38 & 0.03 & & 2.47 & \\
\hline V941 & & GP4AV941A & 0.91 & 0.30 & & & & & & \\
\hline V941 & & GP4AV941B & 1.94 & 0.30 & & & & & & \\
\hline
\end{tabular}


Table E.1 (continued)

\begin{tabular}{|c|c|c|c|c|c|c|c|c|c||}
\hline \multirow{2}{*}{$\begin{array}{c}\text { Area } \\
\text { ID }\end{array}$} & $\begin{array}{c}\text { Depth, } \\
\text { in. }\end{array}$ & $\begin{array}{c}\text { ORNL/ETS } \\
\text { sample } \\
\text { identifier }\end{array}$ & \multicolumn{2}{|c|}{${ }^{226} \mathrm{Ra}$ concentrations, $\mathrm{pCi} / \mathrm{g}$} & \multicolumn{2}{|c|}{${ }^{230} \mathrm{Th}$ concentrations, pCi/g } & \multicolumn{3}{|c|}{ TolU concentrations, pCi/g } \\
\cline { 5 - 9 } & & $\begin{array}{c}100 \mathrm{~m}^{2} \\
\text { composited }\end{array}$ & $+/-$ & $\begin{array}{c}100 \mathrm{~m}^{2} \\
\text { averaged } \\
\text { arithmetically }\end{array}$ & $\begin{array}{c}100 \mathrm{~m}^{2} \\
\text { composited }\end{array}$ & $+/-$ & $\begin{array}{c}100 \mathrm{~m}^{2} \\
\text { averaged } \\
\text { arithmetically }\end{array}$ & $\begin{array}{c}100 \mathrm{~m}^{2} \\
\text { composited } \\
\cdot\end{array}$ & $\begin{array}{c}100 \mathrm{~m}^{2} \\
\text { averaged } \\
\text { arithmetically }\end{array}$ \\
\hline
\end{tabular}

\begin{tabular}{|c|c|c|c|c|c|c|c|c|c|c|}
\hline V941 & & GP4AV941C & 1.35 & 0.30 & & & & & & \\
\hline V941 & & GP4AV941D & 1.10 & 0.30 & & & & & & \\
\hline V945 & 36 & GP4AV945A & 0.97 & 0.30 & 1.06 & 0.25 & 0.03 & 0.42 & 1.44 & 1.94 \\
\hline V945 & & GP4AV945B & 1.21 & 0.30 & & 0.27 & 0.03 & & 1.03 & \\
\hline V945 & & GP4AV945C & 1.08 & 0.30 & & 0.92 & 0.05 & & 4.67 & \\
\hline V945 & & GP4AV945D & 0.97 & 0.30 & & 0.22 & 0.03 & & 0.63 & \\
\hline V964 & 48 & GP4AC0964 & & & 1.11 & 0.38 & 0.05 & & 3.02 & \\
\hline V964 & & GP4AV964A & 1.34 & 0.30 & & & & & & \\
\hline V964 & & GP4AV964B & 0.99 & 0.30 & & & & & & \\
\hline V964 & & GP4AV964C & 1.01 & 0.30 & & & & & & \\
\hline V964 & - & GP4AV964D & 1.11 & 0.30 & & & & & & \\
\hline V968 & 60 & GP4AC0968 & & & 1.96 & 0.78 & 0.05 & & 8.24 & \\
\hline V968 & & GP4AV968A & 1.78 & 0.30 & & & & & & \\
\hline V968 & & GP4AV968B & 2.42 & 0.30 & & & & & & \\
\hline V968 & & GP4AV968C & 1.81 & 0.30 & & & & & & \\
\hline V968 & & GP4AV968D & 1.82 & 0.30 & & & & & & \\
\hline V974 & 24 & GP4AC0974 & & & 2.59 & 0.81 & 0.05 & & $3.377^{4}$ & \\
\hline V974 & & GP4AV974A & 2.61 & 0.30 & & & & & & \\
\hline V974 & & GP4AV974B & 4.94 & 0.40 & & & & & & \\
\hline V974 & & GP4AV974C & 1.11 & 0.30 & & & & & & \\
\hline V974 & & GP4AV974D & 1.71 & 0.30 & & & & & & \\
\hline V995 & 78 & GP4AV995A & 3.55 & 0.30 & 2.85 & 2.97 & 0.27 & 2.11 & 4.05 & 3.42 \\
\hline
\end{tabular}


Table E.1 (continued)

\begin{tabular}{||c|c|c|c|c|c|c|c|c|c|c||}
\hline \multirow{2}{*}{$\begin{array}{c}\text { Area } \\
\text { ID }\end{array}$} & $\begin{array}{c}\text { Depth, } \\
\text { in. }\end{array}$ & $\begin{array}{c}\text { ORNL/ETS } \\
\text { sample } \\
\text { identifier }\end{array}$ & \multicolumn{2}{|c|}{${ }^{226} \mathrm{Ra}$ concentrations, pCi/g } & \multicolumn{2}{|c|}{${ }^{230}$ Th concentrations, pCi/g } & \multicolumn{2}{c|}{ TotU concentrations, pCi/g } \\
\cline { 5 - 9 } & & $\begin{array}{c}100 \mathrm{~m}^{2} \\
\text { composited }\end{array}$ & $+/-$ & $\begin{array}{c}100 \mathrm{~m}^{2} \\
\text { averaged } \\
\text { arithmetically }\end{array}$ & $\begin{array}{c}100 \mathrm{~m}^{2} \\
\text { composited }\end{array}$ & $+/-$ & $\begin{array}{c}100 \mathrm{~m}^{2} \\
\text { averaged } \\
\text { arithmetically }\end{array}$ & $\begin{array}{c}100 \mathrm{~m}^{2} \\
\text { composited }\end{array}$ & $\begin{array}{c}100 \mathrm{~m}^{2} \\
\text { averaged } \\
\text { arithmetically }\end{array}$ \\
\hline
\end{tabular}

\begin{tabular}{|c|c|c|c|c|c|c|c|c|c|c|}
\hline V995 & & GP4AV995B & 2.09 & 0.30 & & 1 & 0.05 & & 1.85 & \\
\hline V995 & & GP4AV995C & 3.52 & 0.30 & & 2.59 & 0.11 & & 5.63 & \\
\hline V995 & & GP4AV995D & 2.25 & 0.30 & & 1.89 & 0.08 & & 2.13 & \\
\hline V996 & 20 & \begin{tabular}{|l|} 
GP4AV996A \\
\end{tabular} & 1.19 & 0.30 & 1.21 & 0.35 & 0.03 & 0.41 & 2.75 & 2.92 \\
\hline V996 & & \begin{tabular}{|l|} 
GP4AV996B \\
\end{tabular} & 1.17 & 0.30 & & 0.35 & 0.03 & & 2.95 & \\
\hline V996 & & GP4AV996C & 1.44 & 0.30 & & 0.54 & 0.05 & & 3.50 & \\
\hline V996 & & \begin{tabular}{|l|} 
GP4AV996D \\
\end{tabular} & 1.02 & 0.30 & & 0.41 & 0.05 & . & 2.47 & \\
\hline V1003 & 42 & GP4AV1003A & 1.23 & 0.30 & 2.05 & 0.49 & 0.03 & 1.17 & 2.75 & 5.22 \\
\hline V1003 & & GP4AV1003B & 4.34 & 0.40 & & 2.97 & 0.27 & & 9.62 & \\
\hline V1003 & & GP4AV1003C & 1.62 & 0.30 & & 1.05 & 0.05 & & 7.56 & \\
\hline V1003 & & GP4AV1003D & 1.02 & 0.30 & & 0.17 & 0.02 & & 0.96 & \\
\hline V1009 & 63 & GP4AV1009A & 0.92 & 0.30 & 0.97 & 0.26 & 0.03 & 0.47 & 1.31 & 4.52 \\
\hline V1009 & & GP4AV1009B & 1.37 & 0.30 & & 0.7 & 0.05 & & 5.77 & \\
\hline V1009 & & GP4AV1009C & 0.93 & 0.30 & & 0.7 & 0.03 & & 6.32 & \\
\hline V1009 & & GP4AV1009D & 0.67 & 0.30 & & 0.22 & 0.03 & & 4.67 & 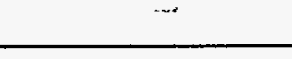 \\
\hline V1072 & 36 & GP4AV1072A & 0.97 & 0.30 & & & & & & \\
\hline V1072 & & GP4AV1072B & 1.36 & 0.30 & & & & & & 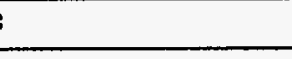 \\
\hline V1072 & & GP4AV1072C & 2.69 & 0.30 & & & & & & \\
\hline V1072 & & GP4AV1072D & 0.94 & 0.30 & & & & & & \\
\hline
\end{tabular}


APPENDIX F

COMPARISON OF RAC AND IVC SPLIT SAMPLE ANALYSES 
Table F.1. ${ }^{226}$ Ra split sample analysis, $\mathrm{pCi} / \mathrm{g}$

\begin{tabular}{|c|c|c|c|c|c|}
\hline \multicolumn{3}{|c|}{ ORNL/ETS analysis of Geotech splits } & \multicolumn{2}{|c|}{ Geotech analysis results } & \multirow[b]{2}{*}{$\begin{array}{l}\text { ORNL minus Geotech } \\
\text { difference }\end{array}$} \\
\hline Area ID & $\begin{array}{c}\text { ORNL/ETS } \\
\text { split sample ID }\end{array}$ & ${ }^{226} \mathrm{Ra}, \mathrm{pCi} / \mathrm{g}$ & $\begin{array}{c}\text { Geotech } \\
\text { soil ticket number }\end{array}$ & ${ }^{226} \mathrm{Ra}, \mathrm{pCi} / \mathrm{g}$ & \\
\hline V3 & GP1AX0003 & 4.15 & MJO-431 & 1.35 & 2.80000 \\
\hline V16 & GP1AX0016 & 1.63 & MCJ-862 & 1.80 & -0.17000 \\
\hline V19 & GP1AX0019 & 1.27 & MCJ-865 & 1.19 & 0.08000 \\
\hline V27 & GP1AX0027 & 4.15 & MCJ-873 & 1.40 & 2.75000 \\
\hline V36 & GP1AX0036 & 2.49 & MKQ-983 & 2.58 & -0.09000 \\
\hline $\mathrm{V} 40$ & GP1AX0040 & 4.12 & MKQ-987 & 4.54 & -0.42000 \\
\hline V49 & GP1AX0049 & 2.16 & MKQ-996 & 2.58 & -0.42000 \\
\hline V52 & GP1AX0052 & 1.12 & MKQ-999 & 1.73 & -0.61000 \\
\hline V54 & GP1AX0054 & 4.03 & MHH-777 & 1.87 & $2.16000^{\circ}$ \\
\hline V64 & GP1AX0064 & 1.35 & MHH-789 & 1.48 & -0.13000 \\
\hline V85 & GP.1AX0085 & 1.30 & MHH-821 & 1.12 & 0.18000 \\
\hline V91 & GP1AX0091 & 3.95 & MIP-927 & 1.16 & 2.79000 \\
\hline V97 & GP1AX0097 & 1.35 & MIP-936 & 2.10 & -0.75000 \\
\hline V104 & GP1AX0104 & 3.42 & MIP-943 & 2.57 & 0.85000 \\
\hline V105 & GP1AX0105 & 3.59 & MIP-944 & 3.01 & 0.58000 \\
\hline V106 & GP1AX0106 & 2.47 & MIP-945 & 2.49 & -0.2000 \\
\hline V129 & GP1AX0129 & 2.60 & MIP-968 & 2.51 & 0.09000 \\
\hline V159 & GP1AX0159 & 7.69 & MKQ-940 & 7.94 & -0.25000 \\
\hline V161 & GP1AX0161 & 1.39 & MKQ-942 & 1.34 & 0.05000 \\
\hline V163 & GP1AX0163 & 1.89 & MKQ-944 & 1.86 & 0.03000 \\
\hline
\end{tabular}


Table F.1. (continued)

\begin{tabular}{|c|c|c|c|c|c|}
\hline \multicolumn{3}{|c|}{ ORNL/ETS analysis of Geotech splits } & \multicolumn{2}{|c|}{ Geotech analysis results } & \multirow{2}{*}{ ORNL minus Geotech } \\
\hline Area ID & $\begin{array}{l}\text { ORNL/ETS } \\
\text { split sample ID }\end{array}$ & ${ }^{226} \mathrm{Ra}, \mathrm{pCi} / \mathrm{g}$ & $\begin{array}{l}\text { Geotech } \\
\text { soil ticket number }\end{array}$ & ${ }^{226} \mathrm{Ra}, \mathrm{pCi} / \mathrm{g}$ & \\
\hline V165 & GP1AX0165 & 1.20 & MKQ-946 & 1.34 & -0.14000 \\
\hline $\mathrm{V} 180$ & GP1AX0180 & 1.42 & $\mathrm{MDH}-614$ & 1.72 & -0.30000 \\
\hline V181 & GP1AX0181 & 1.41 & MDH-615 & 1.54 & -0.13000 \\
\hline V236 & GP1AX0236 & 1.72 & MGD-049 & 1.91 & -0.19000 \\
\hline V237 & GP1AX0237 & 1.84 & MGD-050 & 1.98 & -0.14000 \\
\hline V239 & GP1AX0239 & 1.80 & MIP-584 & 1.84 & -0.04000 \\
\hline V268 & GP1AX0268 & 4.01 & MIP-814 & 4.16 & -0.15000 \\
\hline V286 & GP1AX0286 & 2.68 & MLT-009 & 3.44 & -0.76000 \\
\hline V289 & GP1AX0289 & 3.63 & MLT-012 & 3.88 & -0.25000 \\
\hline V293 & GP1AX0293 & 1.54 & MLT-014 & 1.39 & 0.15000 \\
\hline V301 & GP1AX0301 & 3.85 & MLT-022 & 3.91 & -0.06000 \\
\hline V307 & GP1AXX0307 & 2.76 & MLT-028 & 2.96 & -0.20000 \\
\hline V319 & GP1AX0319 & 1.21 & MDH-597 & 1.41 & -0.20000 \\
\hline V321 & GP1AX0321 & 1.28 & MDH-599 & 1.50 & -0.22000 \\
\hline V326 & GP1AX0326 & 1.17 & MLT-180 & 1.30 & -0.13000 \\
\hline V332 & GP1AX0332 & 0.85 & MLT-186 & 1.50 & -0.65000 \\
\hline V370 & GP20X0370 & 1.96 & NAL-080 & 1.80 & 0.16000 \\
\hline V379 & GP20X0379 & 2.25 & NAL-088 & 2.30 & -0.05000 \\
\hline V408 & GP20X0408 & 10.40 & NAF-100 & 9.60 & 0.80000 \\
\hline V418 & GP20X0418 & 4.18 & NAE-196 & 4.50 & -0.32000 \\
\hline
\end{tabular}


Table F.1. (continued)

\begin{tabular}{|c|c|c|c|c|c|}
\hline \multicolumn{3}{|c|}{ ORNL/ETS analysis of Geotech splits } & \multicolumn{2}{|c|}{ Geotech analysis results } & \multirow[b]{2}{*}{$\begin{array}{l}\text { ORNL minus Geotech } \\
\text { difference }\end{array}$} \\
\hline Area ID & $\begin{array}{l}\text { ORNL/ETS } \\
\text { split sample ID }\end{array}$ & ${ }^{226} \mathrm{Ra}, \mathrm{pCi} / \mathrm{g}$ & $\begin{array}{c}\text { Geotech } \\
\text { soil ticket number }\end{array}$ & ${ }^{226} \mathrm{Ra}, \mathrm{pCi} / \mathrm{g}$ & \\
\hline V445 & GP20X0445 & 2.12 & NAH-410 & 3.10 & -0.98000 \\
\hline V450 & GP1BX0450 & 4.66 & NAB-996 & 5.70 & -1.04000 \\
\hline V459 & GP1BX0459 & 2.95 & NAF-123 & 4.40 & -1.45000 \\
\hline V471 & GP1BX0471 & 1.55 & NAF-287 & 1.70 & -0.15000 \\
\hline V500 & GP2AX0500 & 1.40 & NAO-785 & 1.70 & -0.30000 \\
\hline V504 & GP2AX0504 & 3.25 & NAO-792 & 3.80 & -0.55000 \\
\hline C505 & GP2AX0505 & 1.95 & NAO-797 & 2.20 & -0.25000 \\
\hline V747 & GP4AX0747 & 1.59 & NCE-346 & 2.01 & -0.42000 \\
\hline V793 & GP4AX0793 & 1.22 & NCA-622 & 1.35 & -0.13000 \\
\hline V803 & GP4AX0803 & 2.00 & NCA-632 & 2.18 & -0.18000 \\
\hline V813 & GP4AX0813 & 0.90 & NCA-643 & 1.35 & -0.45500 \\
\hline V823 & GP4AX0823 & 1.06 & NAY-118 & 1.55 & -0.49000 \\
\hline V837 & GP4AX0837 & 0.87 & NAY-132 & 1.71 & -0.84000 \\
\hline V847 & GP4AX0847 & 1.10 & NAY-813 & 2.06 & -0.96000 \\
\hline V852 & GP4AX0852 & 1.09 & NAY-792 & 2.01 & -0.92000 \\
\hline V869 & GP4AX0869 & 1.06 & NAY-803 & 1.91 & -0.85000 \\
\hline V875 & GP4AX0875 & 1.03 & NAY-828 & 1.02 & 0.01000 \\
\hline V885 & GP4AX0885 & 0.86 & NAY-838 & 1.03 & -0.16700 \\
\hline V895 & GP4AX0895 & 0.97 & NCB-410 & 1.18 & -0.21200 \\
\hline V905 & GP4AX0905 & 1.05 & $\mathrm{NCB}-420$ & 1.25 & -0.20000 \\
\hline
\end{tabular}


Table F.1. (continued)

\begin{tabular}{|c|c|c|c|c|c|}
\hline \multicolumn{3}{|c|}{ ORNL/ETS analysis of Geotech splits } & \multicolumn{2}{|c|}{ Geotech analysis results } & \multirow[b]{2}{*}{$\begin{array}{l}\text { ORNL minus Geotech } \\
\text { difference }\end{array}$} \\
\hline Area ID & $\begin{array}{l}\text { ORNL/ETS } \\
\text { split sample ID }\end{array}$ & ${ }^{226} \mathrm{Ra}, \mathrm{pCi} / \mathrm{g}$ & $\begin{array}{c}\text { Geotech } \\
\text { soil ticket number }\end{array}$ & ${ }^{226} \mathrm{Ra}, \mathrm{pCi} / \mathrm{g}$ & \\
\hline V915 & GP4AX0915 & 0.94 & NCB-505 & 1.10 & -0.16500 \\
\hline V925 & GP4AX0925 & 1.11 & NCB-515 & 1.46 & -0.35000 \\
\hline V935 & GP4AX0935 & 3.11 & NCB-525 & 3.58 & -0.47000 \\
\hline V947 & GP4AX0947 & 1.02 & NAZ-483 & 1.09 & -0.07000 \\
\hline V949 & GP4AX0949 & 1.18 & NAZ-485 & 2.53 & -1.35000 \\
\hline V969 & GP4AX0969 & 1.15 & NCF-014 & 3.43 & -2.28000 \\
\hline V979 & GP4AX0979 & 1.65 & NCF-024 & 3.75 & -2.10000 \\
\hline V1023 & GP4AX1023 & 1.16 & NCF-130 & 2.25 & -1.09000 \\
\hline V1033 & GP4AX1033 & 1.33 & NCF-141 & 3.20 & -1.87000 \\
\hline V1043 & GP4AX1043 & 1.41 & NCF-305 & 3.19 & -1.78000 \\
\hline V1053 & GP4AX1053 & 0.81 & NCF-107 & 3.36 & -2.54800 \\
\hline V1063 & GP4AX1063 & 1.21 & NCF-117 & 5.31 & -4.10000 \\
\hline
\end{tabular}


Table F.2. Tot $\mathrm{U}$ split sample analysis, $\mathrm{pCi} / \mathrm{g}$

\begin{tabular}{||c|c|c|c|c|c||}
\hline \multicolumn{2}{|c|}{ ORNL/ETS analysis of Geotech splits } & \multicolumn{2}{c|}{ Geotech analysis results } & \multirow{2}{*}{ ORNL minus } \\
\cline { 1 - 4 } Area ID & $\begin{array}{c}\text { ORNL/ETS } \\
\text { split sample ID }\end{array}$ & TotU, pCi/g & $\begin{array}{c}\text { Geotech } \\
\text { soil ticket number }\end{array}$ & TolU, pCi/g & Geotech difference \\
\hline V332 & GP1AX0332 & 2.82 & MLT-186 & 4.12 & -1.310505 \\
\hline V871A & GP4AX871A & 2.58 & NAY-821 & 4.05 & -1.47673 \\
\hline V871B & GP4AX871B & 0.77 & NAY-822 & 1.79 & -1.01501 \\
\hline V871D & GP4AX871D & 2.08 & NAY-824 & 3.43 & -1.34995 \\
\hline V941A & GP4AX941A & 1.63 & NAZ-471 & 4.40 & -2.76517 \\
\hline V941C & GP4AX941C & 2.13 & NAZ-473 & 3.71 & -1.58150 \\
\hline V945C & GP4AX945C & 4.65 & NAZ-480 & 6.18 & -1.52703 \\
\hline V996D & GP4AX996D & 5.46 & NCF-047 & 3.92 & 1.54154 \\
\hline V1009A & GP4AX1009A & 1.70 & NCF-062 & 6.46 & -4.75288 \\
\hline V1009B & GP4AX1009B & 2.45 & NCF-063 & 6.87 & -4.41710 \\
\hline V1072 & GP4AX1072 & 3.61 & NCE-811 & 4.46 & -0.85475 \\
\hline V1074 & GP4AX1074 & 2.55 & NCE-813 & 4.12 & -1.56702 \\
\hline
\end{tabular}


Table F.3. ${ }^{230} \mathrm{Th}$ split sample analysis, pCi/g

\begin{tabular}{|c|c|c|c|c|c|}
\hline \multicolumn{3}{|c|}{ ORNL/ETS analysis of Geotech splits } & \multicolumn{2}{|c|}{ Geotech analysis results } & \multirow[b]{2}{*}{$\begin{array}{l}\text { ORNL minus Geotech } \\
\text { difference }\end{array}$} \\
\hline Area ID & $\begin{array}{l}\text { ORNL/ETS } \\
\text { split sample ID }\end{array}$ & ${ }^{230} \mathrm{Th}, \mathrm{pCi} / \mathrm{g}$ & $\begin{array}{c}\text { Geotech } \\
\text { soil ticket number }\end{array}$ & ${ }^{230} \mathrm{Th}, \mathrm{pCi} / \mathrm{g}$ & \\
\hline V319 & GP1AX0319 & 0.12 & MDH-597 & 2.10 & -1.9812 \\
\hline V332 & GP1AX0332 & 0.27 & MLT-186 & 14.00 & -13.7300 \\
\hline V702 & GP4AX0702 & 4.05 & NCE-303 & 6.30 & -2.2500 \\
\hline V710 & GP4AX0710 & 1.27 & NCE-309 & 2.20 & -0.9310 \\
\hline V734 & GP4AX0734 & 4.59 & NCE-333 & 6.20 & -1.6100 \\
\hline V740 & GP4AX0740 & 0.43 & NCE-339 & 0.82 & -0.3880 \\
\hline V746 & GP4AX0746 & 1.38 & NCE-345 & 2.70 & -1.3230 \\
\hline V1072 & GP4AX1072 & 0.43 & NCE-811 & 1.70 & -1.2680 \\
\hline
\end{tabular}


APPENDIX G

REVIEW OF RAC's JUSTIFICATION FOR CERTIFICATION OF LAV AREAS 


\section{APPENDIX G}

\section{REVIEW OF RAC'S JUSTIFICATION FOR CERTIFICATION OF THE LAV AREAS}

\section{G.1 Review of Regression Results for LAV Data}

The fifty-two $L A V^{226} \mathrm{Ra}$ and ${ }^{230} \mathrm{Th}$ pairs were entered into Minitab. A linear regression of the ${ }^{230} \mathrm{Th}$ values versus the ${ }^{226} \mathrm{Ra}$ values was run. The ORNL-calculated regression values are listed below with the Geotech reported regression values. The correlation coefficient, slope, intercept, and standard error about $Y$ are all in excellent agreement.

\begin{tabular}{|l|c|c|}
\hline \multirow{2}{*}{} & \multicolumn{2}{|c|}{ Regression results for LAV data in Table B-1* } \\
\cline { 2 - 3 } & Geotech's Table 2 results & ORNL results \\
\hline Sample size & 52 & 52 \\
\hline Correlation coefficient & 0.82 & 0.82 \\
\hline Slope & 2.17 & 2.17 \\
\hline Intercept & 0.51 & 0.51 \\
\hline Standard error about $Y$ & 2.97 & 2.97 \\
\hline
\end{tabular}

*Rust 1994. Justification for Certifying 47 Large-Area Verification Areas at the Grand Junction Projects Office. GJ-GJPR-94-1. Rust Geotech, Grand Junction, Colorado.

The ${ }^{226} \mathrm{Ra}$ value for which the confidence level is $95 \%$ that residual concentrations of ${ }^{230} \mathrm{Th}$ in LAV areas are less than $17 \mathrm{pCi} / \mathrm{g}$ is given in the report as $4.88 \mathrm{pCi} / \mathrm{g}$. The value ORNL calculated using a Minitab macro was $4.80 \mathrm{pCi} / \mathrm{g}$. The difference of $0.08 \mathrm{pCi} / \mathrm{g}$ should be of no practical concern and is probably due to either different calculation methods or rounding effects.

\section{G.2 Apparent Problem with Table 3}

The number and percent of LAV samples with ${ }^{226} \mathrm{Ra}$ values exceeding the $95 \%$ confidence level is given in Table 3 as two samples (3.8\%) (Rust 1994). While doing this review observations were made that five of the 52 samples exceed the $4.88 \mathrm{pCi} / \mathrm{g} 95 \%$ confidence level. Since Geotech only reports two samples exceeding the $4.88 \mathrm{pCi} / \mathrm{g}$ level, Rich Engelder of Geotech was contacted to see if a mistake had been made. He explained that 